Igor dos Santos Silva

\title{
DESENVOLVIMENTO DE UM VEÍCULO AQUÁTICO NÃO TRIPULADO EMPREGADO COMO PLATAFORMA DE TESTES DE SISTEMAS DE NAVEGAÇÃO
}


Igor dos Santos Silva

\section{DESENVOLVIMENTO DE UM VEÍCULO AQUÁTICO NÃO TRIPULADO EMPREGADO COMO PLATAFORMA DE TESTES DE SISTEMAS DE NAVEGAÇÃO}

Dissertação apresentada à Escola Politécnica da Universidade de São Paulo para obtenção do Título de Mestre em Ciências

Área de Concentração: Engenharia de Controle e Automação Mecânica

Orientador: Prof. Dr. Ettore Apolonio de Barros

São Paulo

2019 
Autorizo a reprodução e divulgação total ou parcial deste trabalho, por qualquer meio convencional ou eletrônico, para fins de estudo e pesquisa, desde que citada a fonte.

Este exemplar foi revisado e corrigido em relação à versão original, sob responsabilidade única do autor e com a anuência de seu orientador.

São Paulo, de de

Assinatura do autor:

Assinatura do orientador:

\section{Catalogação-na-publicação}

Silva, Igor dos Santos

Desenvolvimento de um veículo aquático não tripulado empregado como plataforma de testes de sistemas de navegação / I. S. Silva -- versão corr. -- São Paulo, 2019.

$88 \mathrm{p}$.

Dissertação (Mestrado) - Escola Politécnica da Universidade de São Paulo. Departamento de Engenharia Mecânica.

1.Veículo aquático não tripulado 2.Arquitetura naval 3.Arquitetura de Controle I.Universidade de São Paulo. Escola Politécnica. Departamento de Engenharia Mecânica II.t. 


\section{Agradecimentos}

Ao professor Doutor Ettore Apolonio de Barros pela oportunidade de trabalhar no LVNT desde a minha iniciação científica durante a graduação até o desenvolvimento deste trabalho no mestrado.

Aos meus amigos e colegas de laboratório: Alexander Alvarez, Aléxis Uenojo, Fábio Campopiano, Gabriel Lopes, Humberto Silva (ordenados alfabeticamente), pela ajuda durante as atividades diárias e, principalmente, nos testes em campo.

Aos meus pais Luiz Fernando dos Santos Silva Junior e Priscila Marcia Cunha dos Santos Silva que sempre me apoiaram com relação aos estudos durante todos esses anos.

Ao meus avô José Francisco Cunha cuja trajetória de vida serve de inspiração e à minha avó Maura Colin Cunha que me assistiu desde o ensino fundamental com muita paciência e carinho.

À minha namorada Giulia de Freitas Lopes Pinto por estar ao meu lado durante os momentos mais difíceis. 


\section{Resumo}

A atual exploração do ambiente aquático é praticamente inexpressivo frente ao tamanho dos oceanos e sua importância para os seres humanos. O campo de robótica marinha pode auxiliar na pesquisa desses ambientes com o desenvolvimento de UUVs, USVs e ROVs, veículos que podem realizar diversas tarefas sem colocar em risco vidas humanas. No entanto, esses veículos estão em constante desenvolvimento tecnológico e são objetos de pesquisa em diversas áreas de conhecimento, e uma delas é a navegação. Uma das áreas do campo de navegação de veículos autônomos é a estimativa da posição do veículo. Em AUVs, essa estimativa é essencial para diversas missões que requerem grande precisão e baixíssimas incertezas.

O desenvolvimento de sistemas de navegação para AUVs é uma tarefa complexa pois além da implementação no sistema embarcado, são necessários diversos testes de validação que exigem árduas operações logísticas. Por isso, projetar um veículo de superfície aquático como plataforma de testes é fundamental para diminuir o tempo de desenvolvimento de algoritmos de navegação para AUVs. Além disso, esse veículo permite também a realização de testes da arquitetura de controle com menos riscos aos sensores embarcados.

Neste trabalho, foca-se em contribuir para uma metodologia de projeto de um USV, analisando práticas usadas em embarcações tripuladas comuns e verificando sua validade para o caso de uma embarcação de menores dimensões não tripulada.

Palavras-chave: Veículo aquático não tripulado, Arquitetura naval, Arquitetura de controle. 


\section{Abstract}

The majority of the Earth's surface is covered by oceans, although the human knowledge about it is still extremely inexpressive. The marine robotics field can aid in the research of these environments with the development of UUVs, USVs and ROVs, vehicles that can perform various tasks without risking human lives. However, these vehicles are in constant technological development and are objects of research in several areas of knowledge, and one of them is navigation. One of the areas of the field of navigation of autonomous vehicles is the estimation of the position of the vehicle. In AUVs, this estimate is essential for several missions that require great precision and very low uncertainties.

The development of navigation systems for AUVs is a complex task because, besides the implementation in the embedded system, several validation tests are required that require arduous logistical operations. Therefore, designing an aquatic surface vehicle as a testing platform is critical to reducing the development time of navigation algorithms for AUVs. In addition, this vehicle also allows testing of the control architecture with less risk to embedded sensors.

In this paper, focus on contributing to a USV design methodology by analyzing practices used on common manned vessels and verifying their validity for a smaller unmanned vessel.

Key-words: Unmanned surface vehicle, Naval architecture, Control architecture 


\section{Sumário}

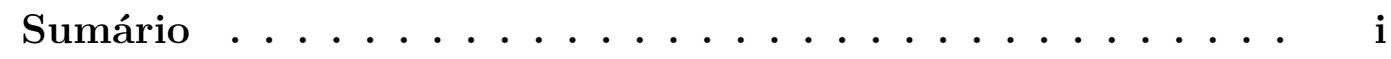

Lista de ilustrações $\ldots \ldots \ldots \ldots \ldots \ldots \ldots$ iv

Lista de tabelas $\ldots \ldots \ldots \ldots \ldots \ldots$ vi

Lista de gráficos $\ldots \ldots \ldots \ldots \ldots \ldots \ldots$ vii

1 INTRODUÇÃO $\ldots \ldots \ldots \ldots \ldots \ldots \ldots$

1.1 Contextualização $\ldots \ldots \ldots \ldots \ldots \ldots$

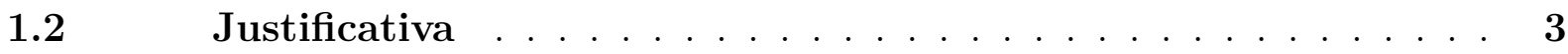

1.3 Objetivos do trabalho $\ldots \ldots \ldots \ldots \ldots \ldots$

$1.4 \quad$ Estrutura do texto $\ldots \ldots \ldots \ldots \ldots \ldots$

$2 \quad$ ESTADO DA ARTE $\ldots \ldots \ldots \ldots \ldots \ldots \ldots \ldots$

2.1 Projetos de veículos de superfície não tripulados de instituições

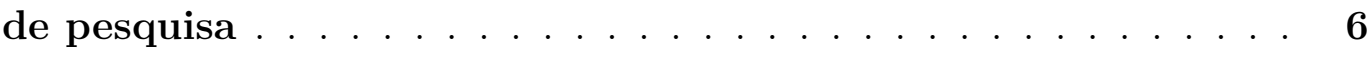

$\begin{array}{lll}\text { 2.1.1 Veículos projetados no Massachusetts Institute of Technology (MIT) } & 6\end{array}$

$\begin{array}{lllll}2.1 .2 & \text { Veículo projetado na University of Rhode Island (URI) } \ldots \ldots & \ldots\end{array}$

2.1.3 Veículo projetado no Istituto di Studi sui Sistemi Intelligenti per

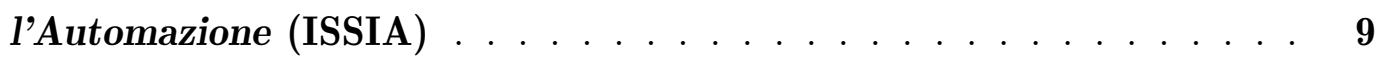

2.1.4 Veículos projetados no Instituto Superior Tecnológico (IST) $\ldots \ldots 11$

2.1.5 Veículos projetados no Instituto Superior de Engenharia do Porto

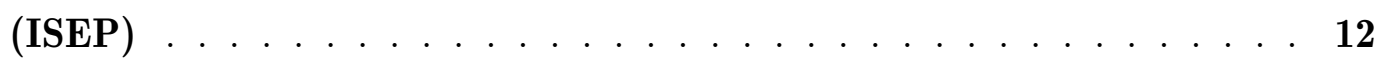

$\underline{2.1 .6}$ Veículo projetado no projeto MESSIN $\ldots \ldots \ldots \ldots \ldots$

2.1.7 Veículo projetado na China $\ldots \ldots \ldots \ldots 14$

2.1.8 Veículo projetado na Escola de Engenharia de São Carlos (EESC) da

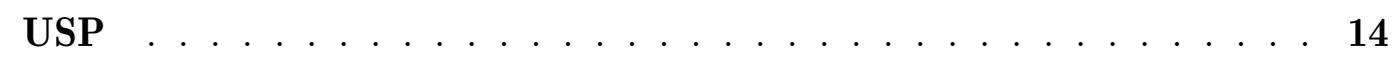

$\underline{2.2}$ Veículos de superfície não tripulados comerciais $\ldots \ldots \ldots 16$

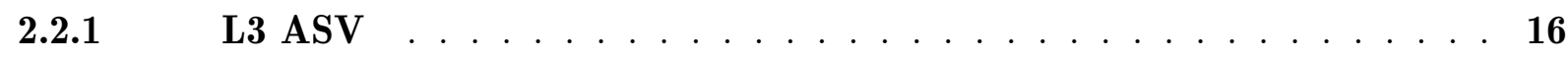

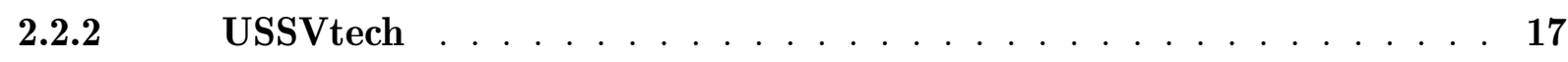

$\underline{2.3}$ Características comuns $\ldots \ldots \ldots \ldots$

3 ANÁLISE DO PROJETO DE UM USV $\ldots \ldots \ldots \ldots 21$

$3.1 \quad$ Requisitos do projeto considerado $\ldots \ldots \ldots 21$

$3.2 \quad$ Metodologia de projeto naval $\ldots \ldots \ldots \ldots 21$

$\underline{3.2 .1 \quad \text { Metodologia de projeto deste trabalho } \ldots \ldots \ldots \ldots 23}$ 


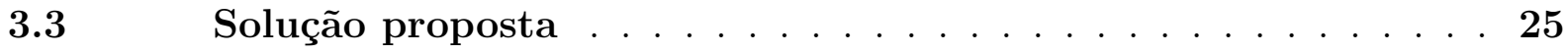

3.3.1 Caracterização da arquitetura naval - Escolha do Trimarã $\ldots \ldots 26$

3.3.2 Caracterização da interface humano-máquina $\ldots \ldots \ldots 28$

3.3.3 Caracterização da eletrônica embarcada $\ldots \ldots \ldots \ldots 28$

3.3.4 Caracterização do sistema de propulsão e de manobra $\ldots \ldots \ldots 29$

3.3.5 Caracterização do sistema de energia $\ldots \ldots \ldots \ldots \ldots$

3.3.6 Caracterização do sistema de navegação $\ldots \ldots \ldots \ldots$

4 PROJETO NAVAL DO USV PROPOSTO $\ldots \ldots \ldots \ldots .34$

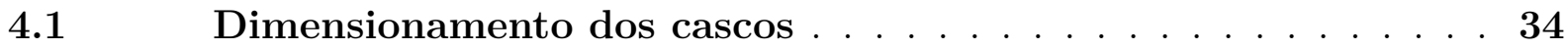

$\underline{4.2 \quad \text { Análise de estabilidade } \ldots \ldots \ldots \ldots \ldots \ldots \ldots \ldots}$

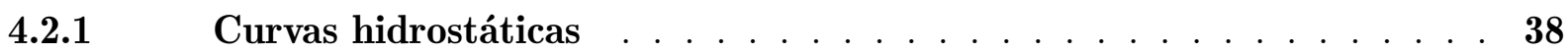

4.2.2 Análise das curvas hidrostáticas $\ldots \ldots \ldots \ldots \ldots \ldots$

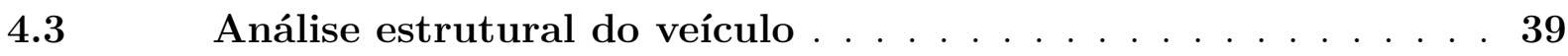

4.3.1 Critério para disposição das anteparas $\ldots \ldots \ldots \ldots$

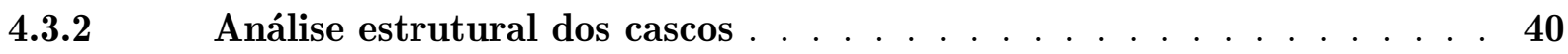

4.3.2.1 Carregamentos $\ldots \ldots \ldots \ldots \ldots \ldots \ldots \ldots$

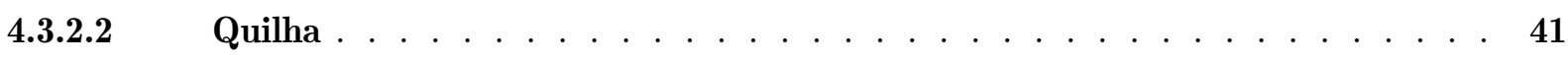

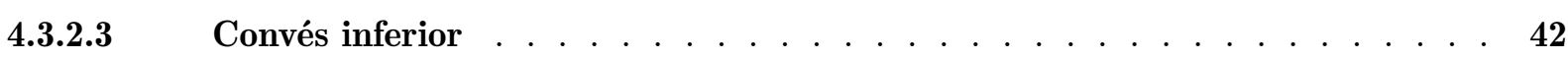

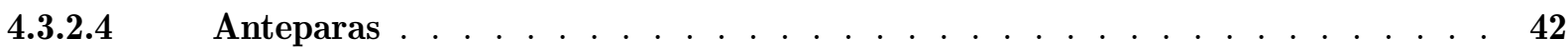

4.3.2.5 Resultados da análise estrutural dos cascos . . . . . . . . . . . 43

4.3.3 Análise estrutural do convés principal $\ldots \ldots \ldots \ldots$

$4.4 \quad$ Cálculo da resistência ao avanço $\ldots \ldots \ldots \ldots 4$

$\underline{4.5}$ Integração casco-hélice-motor $\ldots \ldots \ldots \ldots$

$4.5 .1 \quad$ Projeto do hélice $\ldots \ldots \ldots \ldots \ldots \ldots$

4.5.1.1 Obtenção da geometria do hélice $\ldots \ldots \ldots \ldots \ldots \ldots$

4.5.1.2 Análise de cavitação $\ldots \ldots \ldots \ldots \ldots \ldots \ldots$

4.5.2 Seleção do motor de propulsão $\ldots \ldots \ldots \ldots \ldots \ldots$

4.6 Projeto do sistema de manobra $\ldots \ldots \ldots \ldots$

4.6.1 Projeto do leme $\ldots \ldots \ldots \ldots \ldots \ldots \ldots$

4.6.1.1 Forģas e momentos exercidos no veículo $\ldots \ldots \ldots \ldots \ldots$

4.6.1.2 Raio de giro $\ldots \ldots \ldots \ldots \ldots \ldots \ldots \ldots \ldots$

4.6.1.3 Estimativas das derivadas hidrodinâmicas dos cascos da força e do momento em função das velocidades $\ldots \ldots \ldots \ldots \ldots \ldots$

4.6.1.4 Estimativas das derivadas do leme em função da sua deflexão $\ldots \ldots \ldots$

4.6.1.5 Dimensionamento do leme $\ldots \ldots \ldots \ldots \ldots$

$\underline{4.6 .2}$ Seleção do motor de manobra $\ldots \ldots \ldots \ldots \ldots \ldots$

$4.7 \quad$ Configurações do trimarã $\ldots \ldots \ldots \ldots 1$

5 SISTEMA EMBARCADO $\ldots \ldots \ldots \ldots \ldots \ldots \ldots$ 
$5.1 \quad$ Arquitetura de controle $\ldots \ldots \ldots \ldots 6$

5.1.1 Arquitetura de hardware $\ldots \ldots \ldots \ldots \ldots$

5.1.1.1 Estrutura dos módulos $\ldots \ldots \ldots \ldots \ldots \ldots$

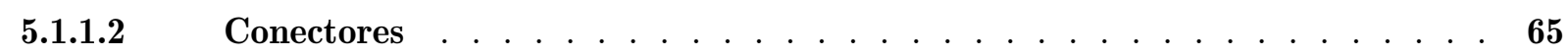

$\mathbf{5 . 1 . 2}$ Arquitetura de software $\ldots \ldots \ldots \ldots \ldots \ldots$

5.1.2.1 Distribuição das funcionalidades do veículo $\ldots \ldots \ldots \ldots 6$

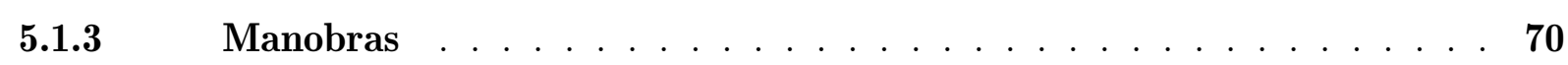

$\underline{5.1 .4 \quad \text { Robustez do sistema } \ldots \ldots \ldots \ldots \ldots}$

6 CONSIDERAÇÕES FINAIS $\ldots \ldots \ldots \ldots \ldots \ldots \ldots$

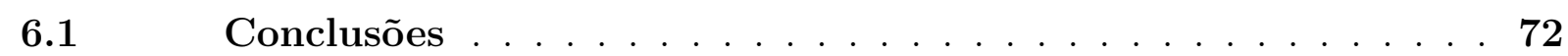

6.1.1 Metodologia de Projeto $\ldots \ldots \ldots \ldots \ldots \ldots$

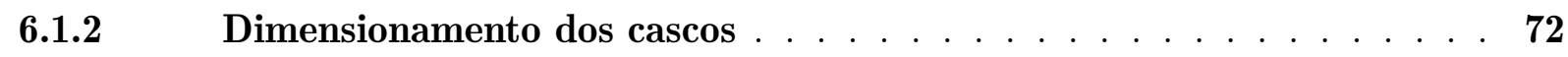

6.1.3 Sistema de Propulsão $\ldots \ldots \ldots \ldots \ldots$

$\underline{6.1 .4 \quad \text { Cálculo hidrodinâmico } \ldots \ldots \ldots \ldots}$

6.1.5 Análise Estrutural $\ldots \ldots \ldots \ldots \ldots \ldots \ldots$

6.1.6 Sistema de energia $\ldots \ldots \ldots \ldots \ldots \ldots \ldots$

$\underline{6.2}$ Trabalhos futuros $\ldots \ldots \ldots \ldots \ldots \ldots$

REFERENCIAS $\ldots \ldots \ldots \ldots \ldots \ldots \ldots$

A GRÁFICOS DAS PROPRIEDADES HIDROSTÁTICAS DA

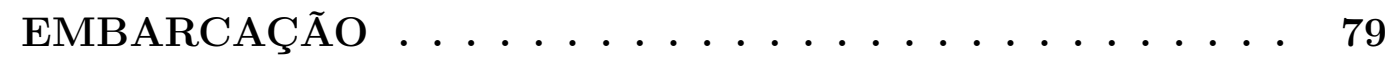

B CARREGAMENTOS, CORTANTE E MOMENTO FLETOR NOS CASCOS $\ldots \ldots \ldots \ldots \ldots \ldots$ 


\section{Lista de ilustrações}

Figura 1.1 - ASV AutoCat desenvolvido no MIT. Fonte: [MANLEY, 2008] . . . . . 2

Figura 1.2 - AUV Pirajuba desenvolvido pelo LVNT da EPUSP. Fonte: autor . . 2

Figura 1.3 - ROVs de vários tamanhos. Fonte: [CHRIST; WERNLI, 2007] $\ldots . . .3$

Figura 2.4-ASV SCOUT. Fonte: [CURCIO; LEONARD; PATRIKALAKIS, 2005] 8

Figura 2.5 - USV SCOAP da URI. Fonte: [CODIGA, 2015] . . . . . . . . . . . 9

Figura 2.6-Propulsores fixos do SCOAP. Fonte: [CODIGA, 2015] . . . . . . . . . . 9

Figura 2.7 - ASV Charlie durante o projeto SESAMO. Fonte: [CACCIA et al., 2003] 10

Figura 2.8 - ASV Delfim. Fonte: [ALVES et al., 2006] . . . . . . . . . . . . . . . 11

Figura 2.9 - ASV Caravela. Fonte: [VILLAS BOAS, 2006] . . . . . . . . . . . . . 12

Figura 2.10-Veículos projetados no ISEP . . . . . . . . . . . . . . . 13

Figura 2.11-ASV Dolphin, do projeto MESSIN. Fonte: [MAJOHR; BUCH, 2006] • 14

Figura 2.12-ASV desenvolvido em um projeto da Chinese Academy Sciences. Fonte: [PENG; HAN, 2009] . . . . . . . . . . . . . . . 15

Figura 2.13-Veículo aquático autônomo desenvolvido na EESC da USP. Fonte: [AL-

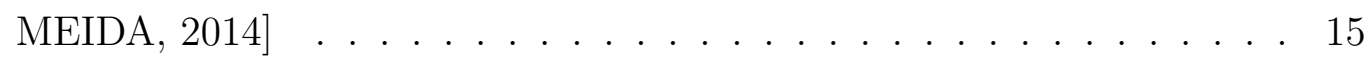

Figura 2.14-ASV C-Cat 3 da empresa L3 ASV. Fonte: [L3 ASV, 2019] . . . . . . . 16

Figura 2.15-ASV C-Enduro da empresa L3 ASV. Fonte: [L3 ASV, 2019] . . . . . . 17

Figura 2.16-USV Tucunaré da empresa USSVtech. Fonte: [USSVTECH, 2019] . . . 18

Figura 2.17-USV C-400 da empresa USSVtech. Fonte: [USSVTECH, 2019] . . . . . 18

Figura 3.18-Espiral de Projeto proposta por Evans. Fonte: [EVANS, 1959] … . . 22

Figura 3.19-Espiral de Projeto adaptada para o caso de um USV. Fonte: adaptado de $[$ EVANS, 1959] . . . . . . . . . . . . . . . . . . 24

Figura 3.20-Unidade de medição inercial modelo KVH CG-5100. Fonte: [KVH, 2017] 31

Figura 3.21-Bússola modelo KVH C100. Fonte: [KVH, 2010] . . . . . . . . . . . . . 31

Figura 3.22-DVL do modelo NavQuest 600 Micro. Fonte: [NAVQUEST MODELS,

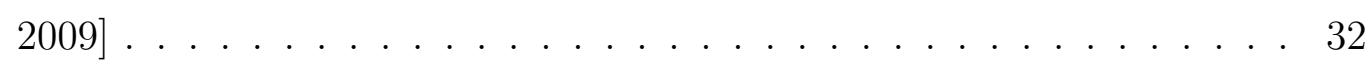

Figura 3.23-Sensor de pressão MLH050PGB01B. Fonte: [HONEYWELL, 2016] . 32

Figura 3.24-Sistema de posicionamento global (GPS) Garmin 15xH. Fonte: [GAR-

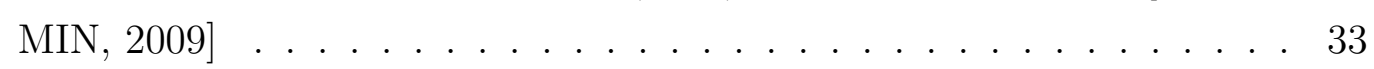

Figura 4.25-Plano de balizas da série sistemática NPL do modelo 100A. Fonte:

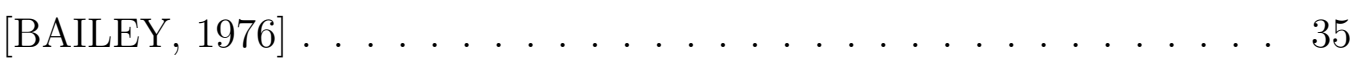

Figura 4.26-Casco central do trimarã $\ldots \ldots$. . . . . . . . . . . . 37

Figura 4.27-Casco central e cascos laterais fabricados em fibra de vidro. Fonte: autor 37

Figura 4.28-Esquemático do convés. Fonte: autor . . . . . . . . . . . . . . . 43

Figura 4.29-Configuração do convés com $\bar{a}=0,21$ a esquerda e com $\bar{a}=0,4$ a direita. Fonte: autor . . . . . . . . . . . . . . . 44 
Figura 4.30-Dimensões da viga sanduíche e corte AA à direita. Fonte: [ALMEIDA,

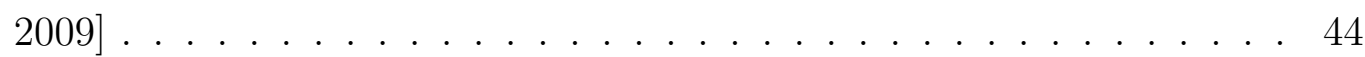

Figura 4.31-Sistema de coordenads e forças externas no trimarã. Fonte: adaptado de $[$ ZHANG, 1997] . . . . . . . . . . . . . . . . . . . . 55

Figura 5.32-Organização dos módulos. Fonte: [SILVA et al., 2018] . . . . . . . . . 68

Figura 5.33-Sinais de entrada do módulo sensores. Fonte: autor . . . . . . . . . . . 69

Figura 5.34-Integração da IMU. Fonte: autor . . . . . . . . . . . . . . . . . . . 69

Figura 5.35-Integração da IMU. Fonte: autor $\ldots . . . . . . . .70$ 


\section{Lista de tabelas}

Tabela 1 - Especificações do ASV ARTEMIS . . . . . . . . . . . . . 6

Tabela 2 - Especificações do ASV ACES $\ldots \ldots \ldots \ldots \ldots 7$

Tabela 3 - Especificações do ASV Charlie $\ldots \ldots \ldots \ldots . \ldots \ldots$

Tabela 4 - Especificações do ASV Delfim $\ldots \ldots \ldots \ldots \ldots \ldots \ldots$

Tabela 5 - Especificações do ASV Caravela $\ldots \ldots \ldots \ldots . \ldots \ldots 12$

Tabela 6 - Especificações técnicas do ROAZ e do ROAZ II . . . . . . . . . . 13

Tabela 7 - Especificações do ASV Dolphin do projeto MESSIN . . . . . . . . . . 14

Tabela 8 - Especificações do ASV C-Cat 3 da empresa L3 ASV $\ldots \ldots \ldots 17$

Tabela 9 - Especificações do ASV C-Enduro da empresa L3 ASV … . . . 17

Tabela 10 - Especificações do USV Tucunaré da empresa USSVtech . . . . . . . . . 18

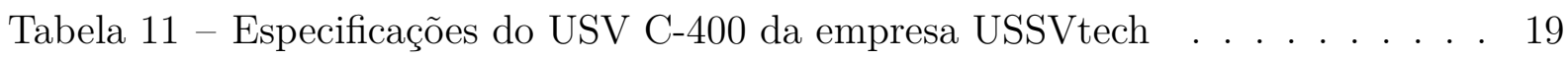

Tabela 12 - Raio de giro sobre o comprimento do veículo para diferentes soluções

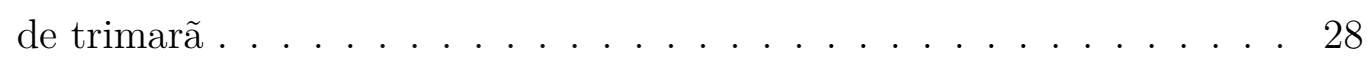

Tabela 13 - Adimensionais de forma do modelo 100A . . . . . . . . . . . . 35

Tabela 14 - Soluções de divisão do deslocamento total entre os cascos analisadas $\quad 36$

Tabela 15 - Dimensões principais dos cascos $\ldots \ldots \ldots \ldots \ldots \ldots$

Tabela 16 - Distância relativa entre os cascos . . . . . . . . . . . . . . 37

Tabela 17 - Cálculos das propriedades mecânicas de [LLOYDS, 2008]. Fonte: adaptado de [LLOYDS, 2008] . . . . . . . . . . . . . . . . 40

Tabela 18 - Cálculos das propriedades mecânicas de [RINA, 1994]. Fonte: adap-

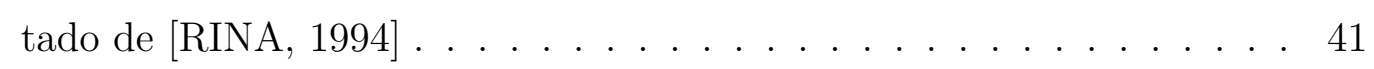

Tabela 19 - Valores para calcular a resistência residual . . . . . . . . . . 47

Tabela 20 - Valores para calcular a resistência friccional $\ldots \ldots \ldots \ldots$

Tabela 21 - Resistência total do veículo . . . . . . . . . . . . . . . . . . 49

Tabela 22 - Valores para realização da integração casco-hélice $\ldots . . \ldots .51$

Tabela 23 - Características geométricas do hélice com maior eficiência … . . . 51

Tabela 24 - Condição de operação do hélice . . . . . . . . . . . . . . . . . . 52

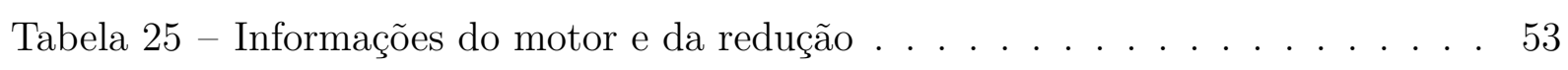

Tabela 26 - Parâmetros geométricos do leme … . . . . . . . . 60

Tabela 27 - Informações do motor e da redução selecionada $\ldots \ldots . \ldots .60$

Tabela 28 - Comparação do raio de giro entre as possíveis configurações do trimarã. 62

Tabela 29 - Quantidades e tipos de conexões da placa universal . . . . . . . . 65 


\section{Lista de gráficos}

Gráfico $1-G M_{T}$ em função do calado do catamarã e trimarã. Fonte: autor . . . . 26

Gráfico 2 - Comparação da resistência total em função da velocidade. Fonte: autor 27

Gráfico 3 - Resistência residual. Fonte: [BAILEY, 1976] . . . . . . . . . . . . 46

Gráfico 4 - Área Molhada. Fonte: adaptado de [BAILEY, 1976] . . . . . . . . . . 48

Gráfico 5 - Integração casco-hélice. Fonte: autor . . . . . . . . . . . . . . 51

Gráfico 6 - Faixa de operação do motor selecionado para o hélice. Fonte: adaptado de [MAXON MOTOR, 2017b] .................. 53

Gráfico 7 - R/L em função do ângulo de deflexão do leme para diferentes áreas e razão de aspecto 1. Fonte: autor . . . . . . . . . . . . . . . . . 59

Gráfico $8-\mathrm{R} / \mathrm{L}$ em função do ângulo de deflexão do leme para diferentes áreas e razão de aspecto 2. Fonte: autor . . . . . . . . . . . . . . . 59

Gráfico 9 - Resultados numéricos e esperimentais dos coeficientes adimensionais do leme. Fonte:[DANTAS; BARROS, 2013] . . . . . . . . . . . . . . . 60

Gráfico 10 - R/L em função do ângulo de deflexão do leme disponível no LVNT.

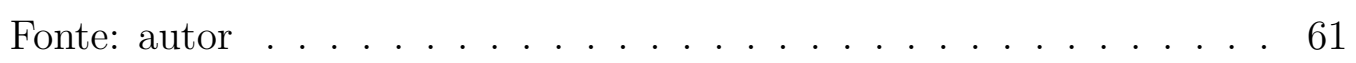

Gráfico 11 - Faixa de operação do motor selecionado para o leme. Fonte: adaptado de [MAXON MOTOR, 2017a] . . . . . . . . . . . . 6 61

Gráfico 12 - Comparação da resistência ao avanço entre as possíveis configurações do trimarã. Fonte: autor . . . . . . . . . . . . . . . 62

Gráfico 13 - Área do plano de linha d'água em função do calado. Fonte: autor . . . 79

Gráfico 14 - Posição do centro de flutuação longitudinal em função do calado.

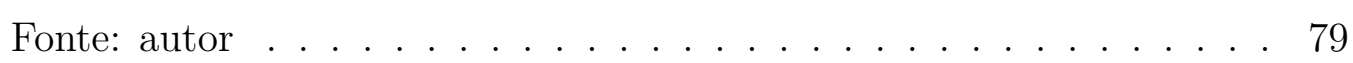

Gráfico 15 - Altura do centro de carena em função do calado. Fonte: autor . . . . . 80

Gráfico 16 - Raio metacêntrico transversal em função do calado. Fonte: autor .. 80

Gráfico 17 - Raio metacêntrico longitudinal em função do calado. Fonte: autor . 80

Gráfico 18 - Deslocamento em função do calado. Fonte: autor . . . . . . . . . . . . 81

Gráfico 19 - Posição longitudinal do centro de carena. Fonte: autor . . . . . . . . . 81

Gráfico 20 - Área molhada de toda a embarcação em função do calado. Fonte: autor 81

Gráfico 21 - Área molhada do casco central em função do calado. Fonte: autor . . 82

Gráfico 22 - Área molhada do casco lateral em função do calado. Fonte: autor . . . 82

Gráfico 23 - Altura metacêntrica trasversal em função do calado. Fonte: autor . . 82

Gráfico 24 - Altura metacêntrica longitudinal em função do calado. Fonte: autor $\quad 83$

Gráfico 25 - Carregamentos das configurações 1 e 2 para o caso A. Fonte: autor . . 84

Gráfico 26 - Diagrama da cortante e do momento fletor das configurações 1 e 2 para o caso A. Fonte: autor . . . . . . . . . . . . . . 84

Gráfico 27 - Carregamentos das configurações 1 e 2 para o caso B. Fonte: autor · . 85 
Gráfico 28 - Diagrama da cortante e do momento fletor das configurações 1 e 2 para o caso B. Fonte: autor . . . . . . . . . . . . . . . . . . 85

Gráfico 29 - Carregamentos das configurações 1 para o caso A. Fonte: autor .. . 85

Gráfico 30 - Diagrama da cortante e do momento fletor das configurações 1 para o caso A. Fonte: autor . . . . . . . . . . . . . . . . . . . . 85

Gráfico 31 - Carregamentos das configurações 1 para o caso B. Fonte: autor . . . . 86

Gráfico 32 - Diagrama da cortante e do momento fletor das configurações 1 para o caso B. Fonte: autor . . . . . . . . . . . . . . . 86

Gráfico 33 - Carregamentos das configurações 2 para o caso A. Fonte: autor . . . . 86

Gráfico 34 - Diagrama da cortante e do momento fletor das configurações 2 para o caso A. Fonte: autor . . . . . . . . . . . . . . . 86

Gráfico 35 - Carregamentos das configurações 2 para o caso B. Fonte: autor . . . 87

Gráfico 36 - Diagrama da cortante e do momento fletor das configurações 2 para o caso B. Fonte: autor . . . . . . . . . . . . . . . . . . . . . . . . 87 


\section{Lista de abreviaturas e siglas}

\begin{tabular}{|c|c|}
\hline $\mathrm{ADCP}$ & Acoustic Doppler Current Profiler \\
\hline AHRS & Attitude and Heading Reference System \\
\hline $\mathrm{ASC}$ & Autonomus Surface Craft \\
\hline ASV & Autonomous Surface Vehicle \\
\hline AUV & Autonomous Underwater Vehicle \\
\hline BMS & Battery Management System \\
\hline CAD & Computer-Aided Design \\
\hline CAE & Computer-Aided Engineering \\
\hline CAN & Controller Area Network \\
\hline DVL & Doppler Velocity Log \\
\hline DMA & Direct Memory Access \\
\hline EESC & Escola de Engenharia de São Carlos \\
\hline EPUSP & Escola Politécnica da Universidade de São Paulo \\
\hline FPU & Floating Point Unit \\
\hline GPS & Global Positionig System \\
\hline IMU & Inertial Measurement Unit \\
\hline INS & Inertial Navigation System \\
\hline ISEP & Instituto Superior de Engenharia do Porto \\
\hline ISSIA & Istituto di Studi sui Sistemi Intelligenti per l'Automazione \\
\hline IST & Instituto Superior Técnico \\
\hline LVNT & Laboratório de Veículos Não Tripulados \\
\hline MIT & Massachusetts Institute of Technology \\
\hline SCOAP & Surveying Coastal Ocean Autonomous Profiler \\
\hline SDIO & Security Digital Input Output \\
\hline
\end{tabular}


SWATH Small Waterplane Area Twin Hull

RTC Real-Time Clock

ROV Remotely Operated Vehicles

URI University of Rhode Island

USP Universidade de São Paulo

USV Unmanned Surface Vehicle

UUV Unmanned Underwater Vehicle

WGS84 World Geodetic System 1984 


\section{Lista de símbolos}

\begin{tabular}{|c|c|}
\hline$\overline{K B}$ & Altura do centro de carena \\
\hline$A_{W P}$ & Área do plano de linha d'água \\
\hline$B$ & Boca \\
\hline$T$ & Calado \\
\hline$C_{B}$ & Coeficiente de bloco \\
\hline $\mathrm{w}$ & Coeficiente de esteira \\
\hline$L$ & Comprimento \\
\hline$\rho$ & Densidade \\
\hline$\Delta$ & Deslocamento em massa \\
\hline$D_{H E L I C E}$ & Diâmetro do hélice \\
\hline $\mathrm{t}$ & Fator de redução da resistência \\
\hline (M) & Razão entre comprimento e deslocamento \\
\hline$F_{\nabla}$ & Número de Froude volumétrico \\
\hline $\mathrm{Z}$ & Número de pás do hélice \\
\hline$R_{N}$ & Número de Reynolds \\
\hline$D$ & Pontal \\
\hline$\overline{B M}_{L}$ & Raio metacêntrico longitudinal \\
\hline$\overline{B M}_{T}$ & Raio metacêntrico transversal \\
\hline$G_{c}$ & Razão da massa de reforçadores sobre a massa total do laminado \\
\hline$f_{c}$ & Razão da massa de reforçadores sobre a massa total do laminado \\
\hline$A_{E} / A_{0}$ & Razão de área expandida \\
\hline $\mathrm{P} / \mathrm{D}$ & Razão passo sobre diâmetro do hélice \\
\hline$R_{F}$ & Resistência friccional \\
\hline$R_{R}$ & Resistência residual \\
\hline
\end{tabular}


$R_{T} \quad$ Resistência total

$V_{S} \quad$ Velocidade de serviço 


\section{Introdução}

\subsection{Contextualização}

Os oceanos representam cerca de dois terços da superfície terrestre e afetam diretamente a existência humana, entretanto, por serem ambientes extremamente complexos, foram pouco explorados [YUH; MARANI; BLIDBERG, 2011]. O campo de robótica marinha pode auxiliar na pesquisa desses ambientes com o desenvolvimento de veículos aquáticos não tripulados, uma vez que esses podem realizar missões sem colocar em risco vidas humanas. A robótica marinha apresenta diversos desafios que não estão presentes nos campos de robótica terrestre e aérea, e muitas vezes isso impossibilita a transferência de soluções entre áreas [ZHANG et al., 2015].

Esses veículos aquáticos não tripulados permitem diversas aplicações, incluindo missões militares, ambientais, científicas e industriais. Esses veículos não só apresentam uma área de pesquisa ativa, como também uma promissora área industrial, com o objetivo de suprir a crescente demanda por veículos mais desenvolvidos para variadas funções.

Houve, nas últimas décadas, um progresso significativo em uma série de tecnologias críticas de sistemas desses veículos. Apesar desses avanços, pesquisas em áreas como autonomia, navegação, manipulação robótica subaquática e comunicação permanecem sendo realizadas [YUH; MARANI; BLIDBERG, 2011].

Os veículos aquáticos não tripulados podem ser nomeados de acordo com sua condição de operação:

- Veículos de Superfície Não Tripulados (USVs), também chamados de Veículos de Superfície Autônomos (ASVs ou ASCs);

- Veículos Subaquáticos Não Tripulados (UUVs), conhecido também como Veículos Subaquáticos Autônomos (AUVs);

- Veículos remotamente operados (ROVs).

Os USVs realizam missões na superfície da água sem tripulação embarcada e, embora o termo autônomo seja constantemente utilizado na literatura, ele não se refere restritamente à sua definição uma vez que esses veículos são, muitas vezes, remotamente controlados. Dentre as diversas aplicações desses veículos, pode-se citar mapeamento batimétrico, monitoramento de poluição, vigilância, estudos oceanográficos. O veículo AutoCat (Figura 1.1) é um exemplo de ASV que foi desenvolvido no MIT para realização de experimento batimétricos [YAAKOB et al., 2012]; [MANLEY, 2008]; [FERREIRA; NETO; MONTEIRO, 2016]. 


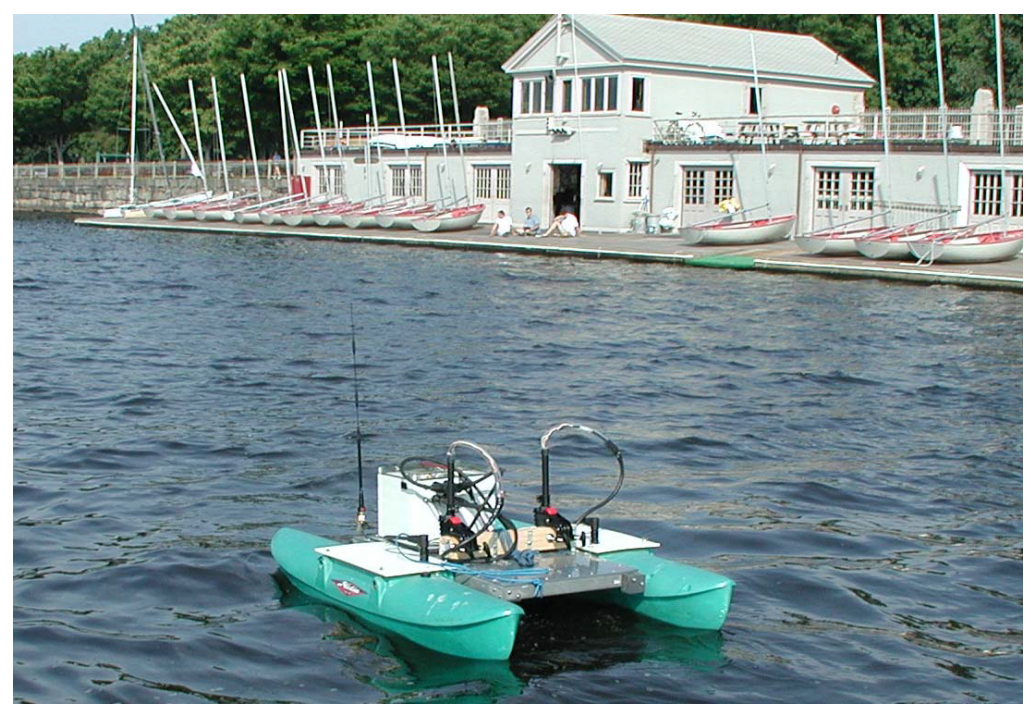

Figura 1.1 - ASV AutoCat desenvolvido no MIT. Fonte: [MANLEY, 2008]

Os UUVs executam tarefas, de forma autônoma, submersos na água e o seu desenvolvimento começou, de fato, na década de 1970. Desde então, avanços na eficiência, tamanho e capacidade de memória dos computadores possibilitaram a completa automação de tarefas que eram originalmente realizadas por veículos tripulados. Atualmente, AUVs são usados em diversas funções, tais como em estudos oceanográficos, desminagem e coleta de dados batimétricos e um sistema de navegação preciso é essencial para garantir a validade dos dados obtidos [PAULL et al., 2014]. Como exemplo, pode-se citar o AUV Pirajuba (Figura 1.2) que é um projeto do LVNT da EPUSP que teve início em 2008 e já foi utilizado como plataforma de estudos de hidrodinâmica, de arquitetura de controle e de navegação.

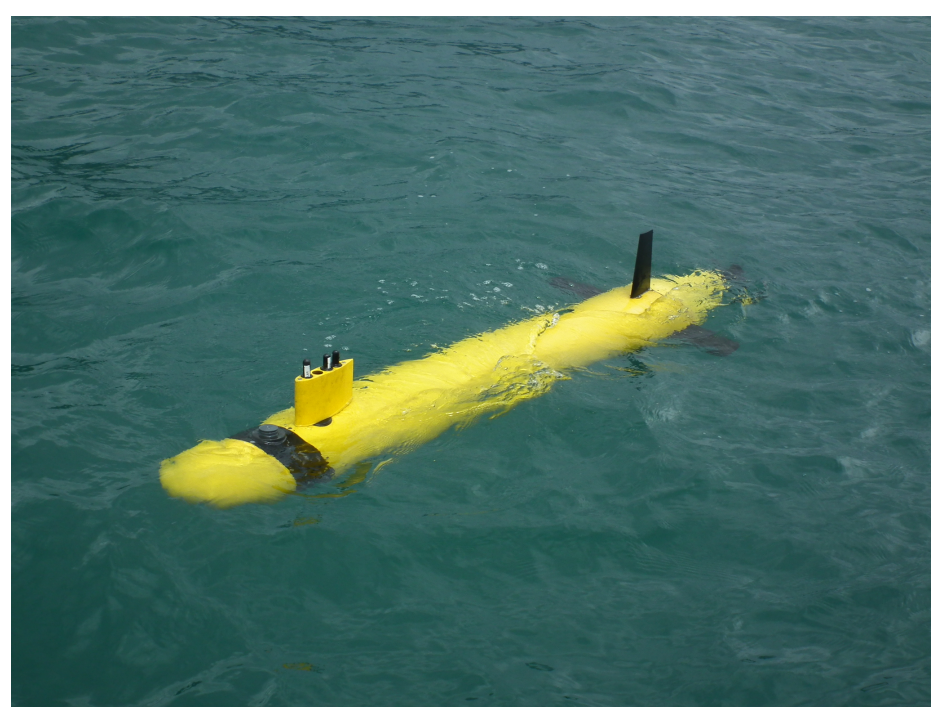

Figura 1.2 - AUV Pirajuba desenvolvido pelo LVNT da EPUSP. Fonte: autor

Os ROVs são veículos subaquáticos que estão conectados via cabo umbilical com uma estação base, desta forma, é possível receber e transmitir dados em tempo real. Além dos 
sistemas de propulsão, esses veículos podem ser equipados com manipuladores mecânicos e sensores de acordo com os tipos de missões para os quais foram projetados. A Figura 1.3 apresenta ROVs de vários tamanhos [CHRIST; WERNLI, 2007].

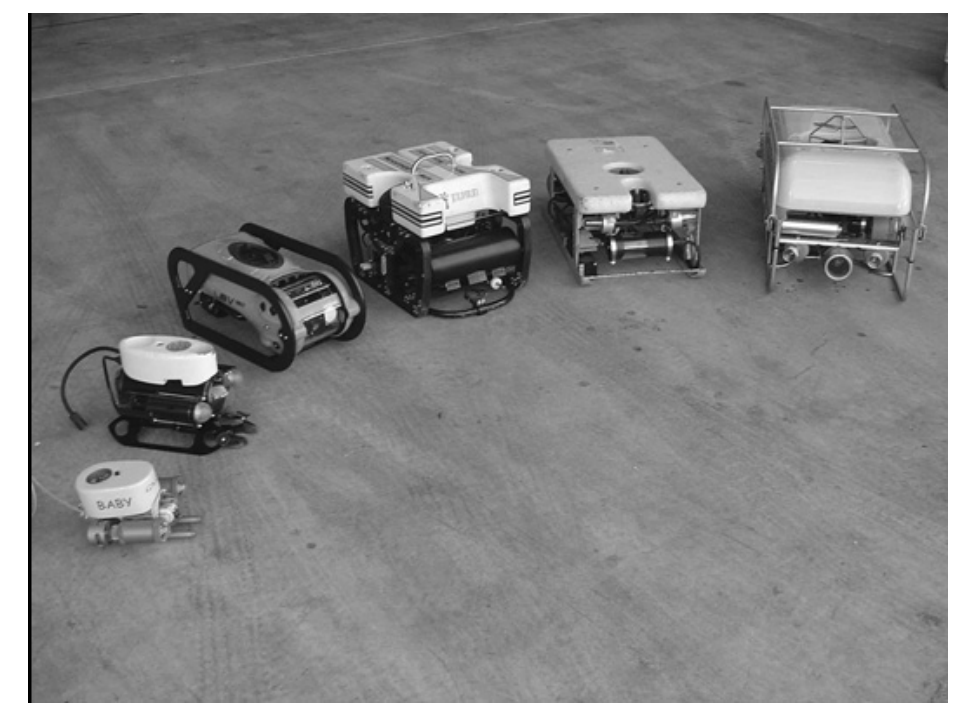

Figura 1.3 - ROVs de vários tamanhos. Fonte: [CHRIST; WERNLI, 2007]

\subsection{Justificativa}

Nas aplicações de veículos aquáticos não tripulados, principalmente AUVs, é de essencial importância um sistema de navegação preciso que assegure a associação das informações colhidas com a sua localização. A navegação de AUVs é um sistema complexo devido principalmente à rápida atenuação de sinais de alta frequência na água, que impossibilita o uso do GPS quando o veículo esta submerso, e a natureza estocástica do ambiente marinho, que dificulta a modelagem do sistema. Na superfície da água, a maioria dos sistemas autônomos depende de comunicação via rádio e sistema de posicionamento global (GPS). No entanto, embaixo da água esses sinais não estão disponíveis. Logo, sistemas de navegação com GPS para veículos subaquáticos são limitados a operações de águas rasas com a necessidade de emersão para a atualização da posição de tempos em tempos para limitar o erro de predição [PAULL et al., 2014] [LEE et al., 2007].

Durante o desenvolvimento de um sistema de navegação de um AUV, a fase de validação pode ser feita de diferentes formas:

- Teste em campo com o próprio veículo na superfície;

- Simulação numética do veículo;

- Teste em campo com sistemas de aquisição de dados próximos aos usados no veículo. 
Na fase de teste e validação do sistema de navegação de um AUVs, costuma-se realizar testes na superfície para adquirir dados do GPS instalado no veículo que serão usados como base de comparação com os obtidos a partir do algoritmo de navegação. A antena de recepção do sinal do GPS é marinizada (deve ser estanque e resistir as pressões hidrostáticas) e fica bem próxima da superfície da água atrapalhando a aquisição de dados dos satélites, o que torna a posição do GPS não muito precisa. Além disso, a complexidade mecânica e eletrônica de um AUV, e toda sua logística de operação dificultam o desenvolvimento e verificação do sistema de navegação no ambiente de operação.

A simulação numérica de manobras é outra opção para validar o sistema de navegação. Nela, leituras dos sensores e seus respectivos erros são gerados de acordo com os modelos considerados e com a manobra simulada. Em seguida, verifica-se a qualidade dos resultados fornecidos pelo sistema de navegação. Uma desvantagem desse procedimento é que só são computados os erros modelados dos sensores. Dentro da categoria de simulação numérica, há também aquelas realizadas em tempo real em que, além de se buscar a qualidade dos dados obtidos, pretende-se avaliar se esses dados estão sendo gerados dentro das restrições de tempo do sistema.

A implementação do sistema de navegação em outro tipo de veículo também é uma forma de verificação. Em [ZANONI, 2012] , além da simulação numérica, o sistema de navegação projetado para um AUV foi testado usando um veículo automotivo (carro). Neste teste, foram realizadas algumas adaptações dos sensores: o sistema acústico de posicionamento foi substituído pelo GPS e o DVL (sensor acústico de velocidade) pelo velocímetro. A desvantagem de utilizar um veículo não aquático é a necessidade de adaptar sensores, logo, os erros não são os mesmos do sistema projetado. Assim, a utilização de um ASV é uma boa opção para validar o sistema de navegação para um AUV, já que sistemas acústicos (como o DVL) e sensores de pressão podem ser instalados no casco, fazendo com que o sistema de navegação trate dos sinais dos sensores que serão instalados posteriormente no AUV. Além disso, fatores como a maior facilidade de operação e a utilização de antenas de GPS com melhor recepção de sinal corroboram a aplicação de ASVs.

\subsection{Objetivos do trabalho}

Este trabalho busca alcançar os seguintes objetivos:

- Contribuir para uma metodologia de projeto de um USV, adaptando procedimentos empregados para embarcações de passageiros e analisando as diferenças entre tais aplicações;

- Analisar a aplicação de veículos multicascos no projeto de USVs; 
- Analisar o desempenho de um USV trimarã do ponto de vista de resistência ao avanço e manobrabilidade;

- Apresentar uma arquitetura de controle, originalmente usada no AUV Pirajuba, modificada para atender os requisitos de um USV.

Com relação ao desenvolvimento de hardware e projeto do gerenciamento de energia, essas tarefas foram realizadas por outros alunos do Laboratório de Veículos Não Tripulados.

\subsection{Estrutura do texto}

No Capítulo 2 são apresentados diversos projetos de veículos de superfície não tripulados desenvolvidos por outras instituições de pesquisa. Faz-se também uma breve análise das características comuns presentes nesses veículos.

No Capítulo 3 são exibidos os requisitos básicos definidos para a embarcação em questão neste trabalho e a caracterização do veículo para atender tais requisitos. Além disso, realiza-se a explicação da representação conhecida como Espiral de Projeto e que foi usada neste trabalho.

O detalhamento do projeto da arquitetura naval da embarcação é mostrado no Capí$\underline{\text { tulo 4, }}$ baseado na representação de projeto descrita anteriormente.

No Capítulo 5 é apresentada a arquitetura de controle do veículo que foi desenvolvida com base na experiência adquirida com o AUV Pirajuba.

E no ?? são expostas as conclusões preliminares e o cronograma dos trabalhos futuros. 


\section{Estado da arte}

\subsection{Projetos de veículos de superfície não tripulados de ins- tituições de pesquisa}

No passado, os veículos de superfície não tripulados foram utilizados como modelos em escala de embarcações reais com o objetivo de validar métodos numéricos e analíticos sobre a hidrodinâmica e a manobrabilidade dos navios reais. Recentemente, com a evolução tecnológica dos sistemas eletrônicos embarcados, ao invés de servirem apenas como plataformas para testes, os ASVs se tornaram sistemas mecatrônicos capazes de realizar missões [VILLAS BOAS, 2006].

O projeto e especificações de um ASV tem grande dependência com o tipo de instituição que o desenvolveu, sendo as principais de cunho comercial, acadêmico e militar. A seguir são apresentados alguns projetos de ASVs de pequeno porte que já foram desenvolvidos e suas características marcantes.

\subsubsection{Veículos projetados no Massachusetts Institute of Technology (MIT)}

O primeiro ASV produzido no MIT Sea Grant College Program foi chamado de ARTEMIS. A embarcação, cujas especificações estão apresentadas na Tabela 1, era um modelo em escala de 1:17 de um navio pesqueiro que foi equipado com um motor elétrico e um leme servo atuado. Para a realização das funções de navegação e controle requeridas pelo ASV, foi instalado um microprocessador, uma bússola eletrônica e um GPS Diferencial. Além disso, para investigar o uso de ASV para coleta de dados, foi adicionada ao veículo uma sonda de profundidade para realizar missões de batimetria.

Tabela 1 - Especificações do ASV ARTEMIS

\begin{tabular}{|c|c|}
\hline Comprimento & $1,37 \mathrm{~m}$ \\
\hline Boca & $0,38 \mathrm{~m}$ \\
\hline Calado & $0,20 \mathrm{~m}$ \\
\hline Deslocamento & $29,5 \mathrm{~kg}$ \\
\hline Autonomia & $4 \mathrm{~h}$ \\
\hline Velocidade de cruzeiro & 2 nós \\
\hline Velocidade máxima & 2,25 nós \\
\hline
\end{tabular}

Uma das principais deficiências do ASV ARTEMIS era o seu tamanho reduzido que limitava a autonomia e o seakeeping do veículo. Isso motivou a análise de um casco de kayak que foi convertido em em ASV com um comprimento de 3 metros. O projeto 
resultante era suficientemente robusto para condições severas de mar, no entanto, não apresentava estabilidade em roll suficiente para coleta de dados de batimetria.

Para continuar com as missões de batimetria iniciadas com o ASV ARTEMIS, um novo ASV chamado de ACES (Autonomous Coastal Exploration System) foi desenvolvido. Para esse novo projeto, buscou-se aumentar a carga embarcada, a autonomia, a velocidade e melhorar a estabilidade em roll. Para isso, um casco do tipo catamarã foi selecionado como melhor opção para o novo ASV. Os cascos utilizados foram selecionados dentre os cascos disponíveis comercialmente e foram unidos com uma estrutura de aço. A Tabela 2 apresenta as especificações do ASV ACES.

Tabela 2 - Especificações do ASV ACES

\begin{tabular}{|c|c|}
\hline Comprimento total & $1,90 \mathrm{~m}$ \\
\hline Boca total & $1,30 \mathrm{~m}$ \\
\hline Calado & $0,46 \mathrm{~m}$ \\
\hline Deslocamento & $158,8 \mathrm{~kg}$ \\
\hline Autonomia & $12-18 \mathrm{~h}$ \\
\hline Velocidade de cruzeiro & 5 nós \\
\hline Velocidade máxima & 10 nós \\
\hline
\end{tabular}

Uma versão modificada do veículo, caracterizado por uma estrutura modular de fibra de vidro, foi testada em 1999. As principais alterações foram no sistema de alimentação e de propulsão. A nova plataforma foi renomeada de AutoCat (Figura 1.1) e apresentava um sistema de controle baseado em lógica fuzzy tendo como sensores um GPS Diferencial, um sistema de navegação inercial (do inglês, INS) e uma bússola eletrônica.

Para realizar missões relacionadas à arqueologia náutica o veículo foi equipado com transdutores de alta frequência capazes de traçar o perfil do terreno logo abaixo da superfície. Além disso, a embarcação executava atividades de caráter ambiental adquirindo dados marinhos.

As características do veículo são bem semelhantes à do ASV ACES tendo com principais mudanças a velocidade de cruzeiro para 7 nós e a diminuição do peso da estrutura devido à alteração do material.

Além desses veículos, no Departamento de Engenharia Oceânica do MIT foram projetados e fabricados quatro ASCs SCOUT (Surface Craft for Oceanographic and Undersea Testing) que tinham como principal objetivo servir como plataforma de desenvolvimento de softwares de controle e operação de múltiplos AUVs. O veículo apresenta um casco de kayak de polietileno de alta densidade (Figura 2.4), modificado para permitir propulsão e controle autônomo através de um computador embarcado.

Durante as fases iniciais de desenvolvimento, fora decidido que o veículo serviria como base de desenvolvimento de algoritmos e teria flexibilidade para instalação de cargas pagas com diferentes funcionalidades. Esse conceito evoluiu de forma que o veículo fosse 


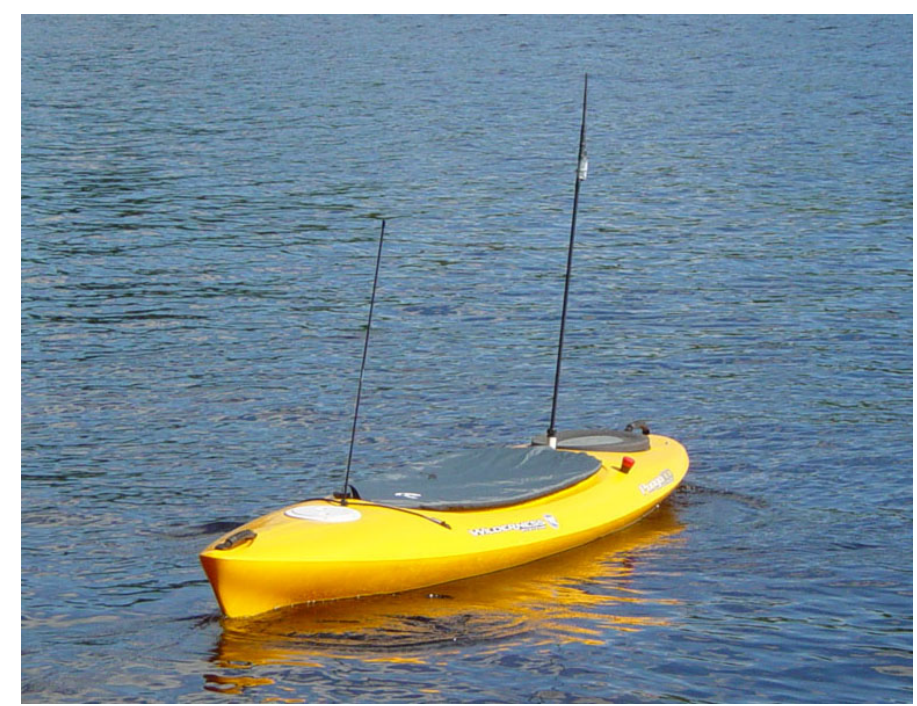

Figura 2.4 - ASV SCOUT. Fonte: [CURCIO; LEONARD; PATRIKALAKIS, 2005]

configurado com um sistema principal "fechado". Assim, os softwares desenvolvidos necessitariam apenas de uma interface com o sistema principal [MANLEY, 1997]; [MANLEY et al., 2000]; [CURCIO; LEONARD; PATRIKALAKIS, 2005]; [CACCIA, 2006].

\subsubsection{Veículo projetado na University of Rhode Island (URI)}

A partir de 2012 iniciou-se o desenvolvimento do SCOAP, um veículo autônomo de superfície com o objetivo de efetuar missões de cunho oceanográfico, principalmente a de coleta de amostras para serem usadas na estimativa do transporte de material residual em áreas costeiras. Essas amostras eram coletadas durante 10 minutos em cada uma das 10 estações, com $2 \mathrm{~km}$ de distância entre elas, 4 vezes ao dia com uma velocidade média entre estações de $2,5 \mathrm{~m} / \mathrm{s}$.

A solução adotada foi de um catamarã (Figura 2.5) com 11 metros de comprimento e 5 metros de boca total cujo projeto e manufatura foi realizado pela SeaRobotics com auxílio da URI. Um dos requisitos do veículo era de providenciar a potência para os sensores oceanográficos, incluindo um ADCP (Acoustic Doppler Current Profiler) instalado no próprio casco, e para um guincho capaz de recuperar sensores em geral.

O sistema de potência do SCOAP apresenta 4 células de bateria AGM 12 V, mantidas por geradores, e 2 tanques de diesel com capacidade total de aproximadamente $1440 \mathrm{~L}$. No projeto foi considerada a utilização de painéis solares que poderiam ser instalados posteriormente. Entretanto, como solução única de geração de energia chegou-se a conclusão que os painéis eram insuficientes para satisfazer as missões de longa duração.

Com relação ao sistema de navegação e controle, o veículo apresenta duas CPUs com sistema operacional baseado em Linux, em que a principal CPU realiza tarefas predeterminadas da missão enquanto que a outra CPU pode executar sistemas autônomos em missões mais sofisticadas. Entre os equipamentos embarcados há um GPS de alta 

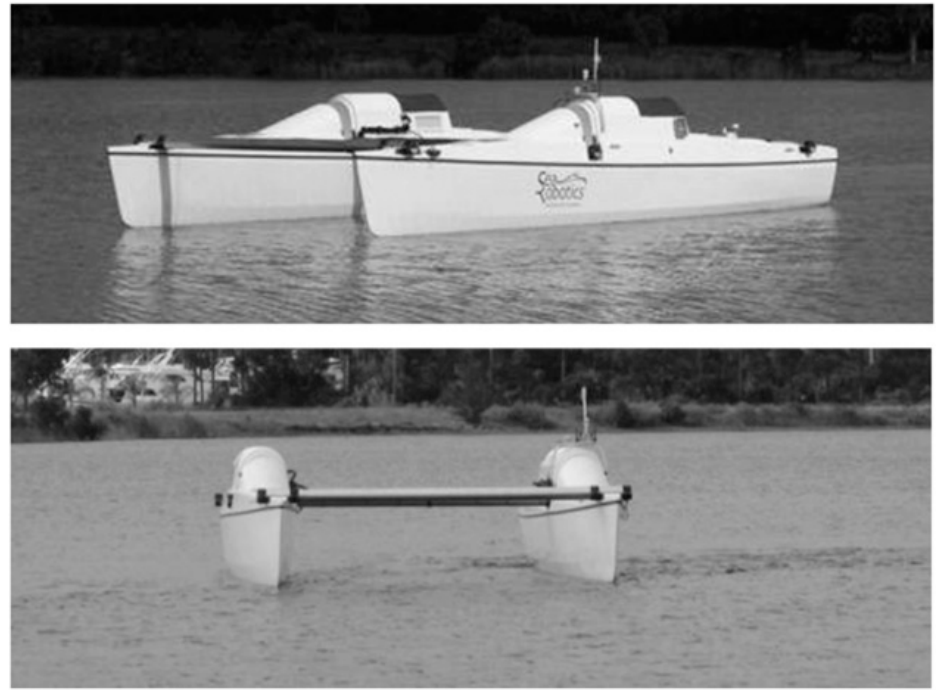

Figura 2.5 - USV SCOAP da URI. Fonte: [CODIGA, 2015]

qualidade, um sensor de rumo e atitude, e um sensor de som para medir a profundidade.

Na Figura 2.6 é mostrado um dos hélices do SCOAP. Cada casco apresenta um propulsor que, além do movimento longitudinal, realiza o controle de rumo do veículo pela rotação diferencial dos hélices.

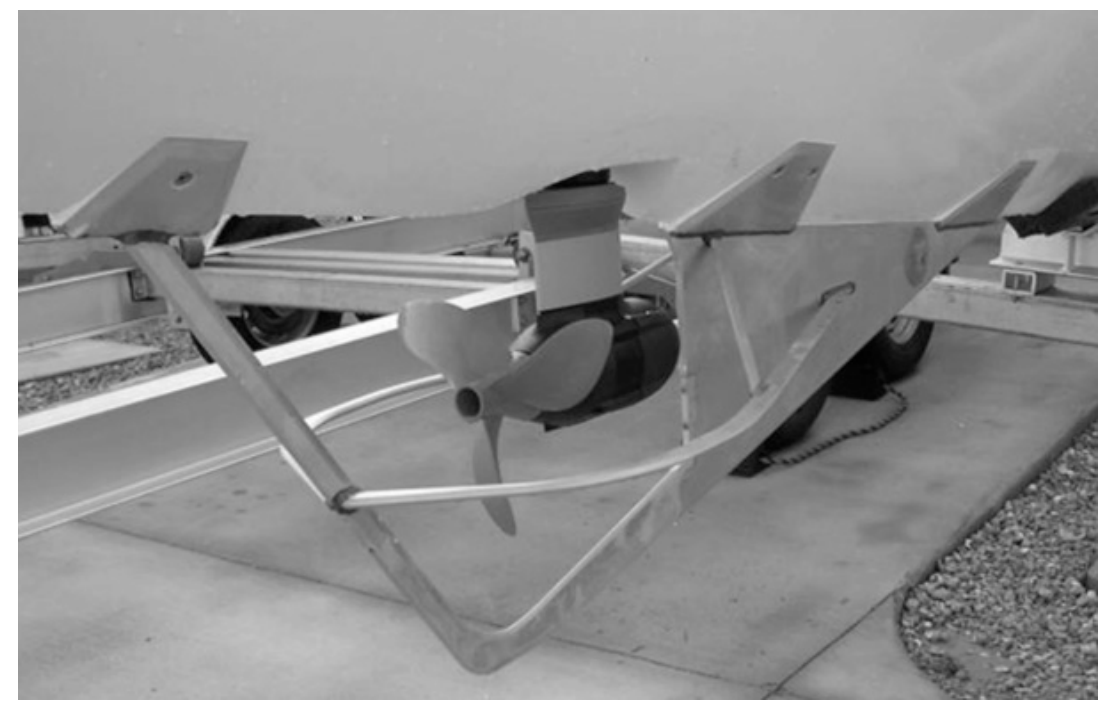

Figura 2.6 - Propulsores fixos do SCOAP. Fonte: [CODIGA, 2015]

\subsubsection{Veículo projetado no Istituto di Studi sui Sistemi Intelligenti per l'Automazione (ISSIA)}

O primeiro ASV desenvolvido no ISSIA de Genova foi proveniente de uma parceria com o Instituto per la dinamica dei processi ambientali de Veneza no projeto SESAMO (Sea Surface Autonomous Modular unit) e foi posteriormente chamado de Charlie. O objetivo do projeto foi desenvolver e testar uma plataforma autônoma modular para 
coletar amostras de finas camadas da superfície do oceano (interface entre o ar e a água) ao longo de trajetórias predefinidas. Para a realização da missão, o veículo apresentava um coletor de amostras capaz de diferenciá-las entre orgânicas e inorgânicas, armazenando-as em reservatórios separados.

O principal requisito científico da missão era evitar qualquer alteração da qualidade das amostras. Esse requisito impôs restrições na escolha do material para construção do coletor de amostras, dos reservatórios e do casco. Além disso, para evitar "poluir" o local de amostragem, o navio suporte deve permanecer a, no mínimo, $1 \mathrm{~km}$ de distância. Desta forma, o veículo devia apresentar dois regimes de operação: se mover com velocidade de cruzeiro relativamente alta durante o translado até a área de operação e se mover com velocidade baixa durante a coleta das amostras.

Foi selecionado um casco do tipo catamarã (Figura 2.7) por oferecer melhor estabilidade em roll. Na Tabela 3 são apresentadas as especificações do ASV Charlie.

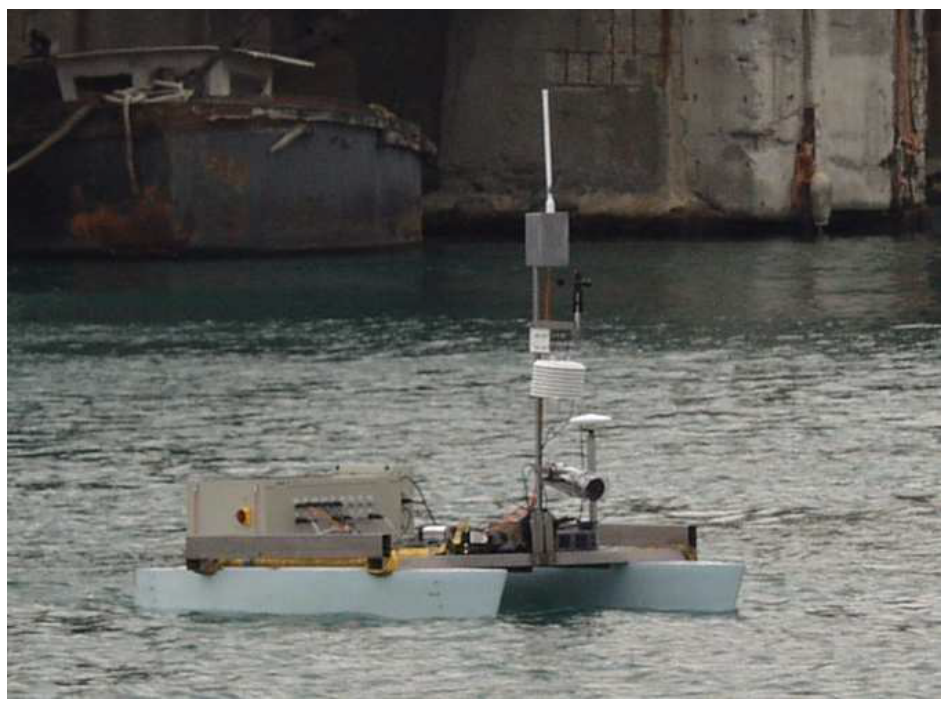

Figura 2.7 - ASV Charlie durante o projeto SESAMO. Fonte: [CACCIA et al., 2003]

Tabela 3 - Especificações do ASV Charlie

\begin{tabular}{|c|c|}
\hline Comprimento & $2,4 \mathrm{~m}$ \\
\hline Boca total & $1,8 \mathrm{~m}$ \\
\hline Pontal & $0,6 \mathrm{~m}$ \\
\hline Separação entre os cascos & $0,6 \mathrm{~m}$ \\
\hline Deslocamento máximo & $400 \mathrm{~kg}$ \\
\hline
\end{tabular}

O sistema de propulsão e manobra da embarcação foi inicialmente composto apenas por dois hélices. Desta forma, para alterar o rumo era necessário aplicar uma diferença de rotação entre os propulsores. Em missões de caça de minas, adicionou-se ao veículo dois lemes rigidamente conectados, posicionados atrás dos hélices. 
O sistema de navegação do veículo era formado pela integração dos dados de um GPS e uma bússola eletrônica capaz de computar o norte verdadeiro a partir da medida do norte magnético e das coordenadas geográficas proveniente do GPS [CACCIA et al., 2003]; [BRUZZONE et al., 2011].

\subsubsection{Veículos projetados no Instituto Superior Tecnológico (IST)}

O projeto de pesquisa e desenvolvimento ASIMOV (Advanced System Integration for Managing the coordinated operation of robotic Ocean Vehicles) foi iniciado em 1998 com o objetivo de implementar o conceito de operação conjunta de AUVs e ASVs para aquisição e transmissão de dados marinhos. Com esta finalidade, no IST foi projetado e fabricado o ASV Delfim (Figura 2.8), um catamarã com as especificações apresentadas na Tabela 4.

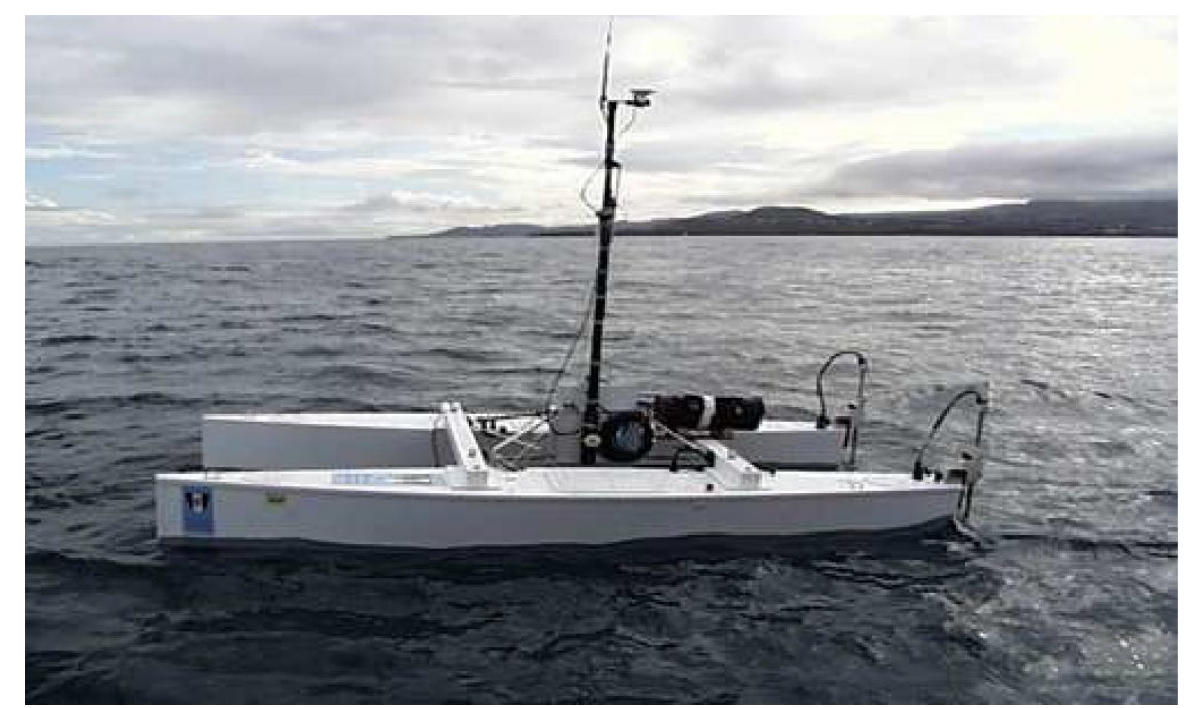

Figura 2.8 - ASV Delfim. Fonte: [ALVES et al., 2006]

Tabela 4 - Especificações do ASV Delfim

\begin{tabular}{|c|c|}
\hline Comprimento & $3,50 \mathrm{~m}$ \\
\hline Boca & $2,00 \mathrm{~m}$ \\
\hline Calado & $0,18 \mathrm{~m}$ \\
\hline Deslocamento & $400 \mathrm{~kg}$ \\
\hline Velocidade máxima & 5 nós \\
\hline
\end{tabular}

Além dos dois cascos e do convés que realiza a conexão entre eles, o ASV Delfim possui um corpo central submerso suportado por uma estrutura com perfil de asa. É nesse corpo central que são instalados os transdutores acústicos para comunicação ou para missões de batimetria.

A navegação, guiamento, controle e gerenciamento da missão são realizados por um sistema embarcado que recebe dados de rumo, velocidade linear e posição de um GPS Diferencial. 
Além do ASV Delfim, o IST participou de um consórcio entre instituições de pesquisa e indústrias parceiras que desenvolveu um ASV de longo alcance chamado Caravela (Figura 2.9), um monocasco com as especificações apresentadas na Tabela 5. O veículo foi projetado para ser completamente autônomo, mas também é capaz de responder comandos via rádio ou satélite.

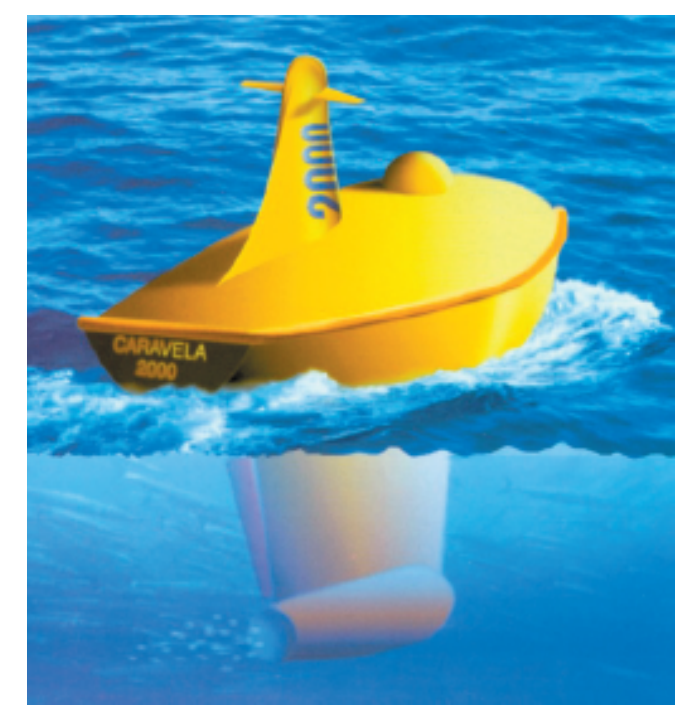

Figura 2.9 - ASV Caravela. Fonte: [VILLAS BOAS, 2006]

Tabela 5 - Especificações do ASV Caravela

\begin{tabular}{|c|c|}
\hline Comprimento & $10,0 \mathrm{~m}$ \\
\hline Boca & $2,0 \mathrm{~m}$ \\
\hline Calado & $2,3 \mathrm{~m}$ \\
\hline
\end{tabular}

O sistema de propulsão do veículo consiste de hélices acionados por motores dieselelétrico. Os transdutores acústicos são alojados em um corpo cilíndrico, com forma de torpedo, fixo a uma quilha que se estende abaixo do casco [PASCOAL; SILVESTRE; OLIVEIRA, 2006]; [ALVES et al., 2006]; [VILLAS BOAS, 2006]; [CACCIA, 2006].

\subsubsection{Veículos projetados no Instituto Superior de Engenharia do Porto (ISEP)}

No ISEP, foram projetados e fabricados dois veículos de superfície, chamados de ROAZ e ROAZ II, cujas principais aplicações eram em missões de batimetria e comunicação acústica com AUVs. Os dois veículos apresentam cascos do tipo catamarã e as especificações de cada um são mostradas na Tabela 6.

Além dos sensores batimétricos, o ASV ROAZ (Figura 2.10a) pode carregar sonares sidescan, CTDs (sensores de condutividade, temperatura e profundidade), além de coletores de amostras de água. O propulsor utilizado foi desenvolvido especificamente para 
Tabela 6 - Especificações técnicas do ROAZ e do ROAZ II

\begin{tabular}{|c|c|c|}
\cline { 2 - 3 } \multicolumn{1}{c|}{} & ROAZ & ROAZ II \\
\hline Comprimento & $1,50 \mathrm{~m}$ & $4,50 \mathrm{~m}$ \\
\hline Boca & $1,00 \mathrm{~m}$ & $2,20 \mathrm{~m}$ \\
\hline Pontal & $0,52 \mathrm{~m}$ & $0,50 \mathrm{~m}$ \\
\hline
\end{tabular}

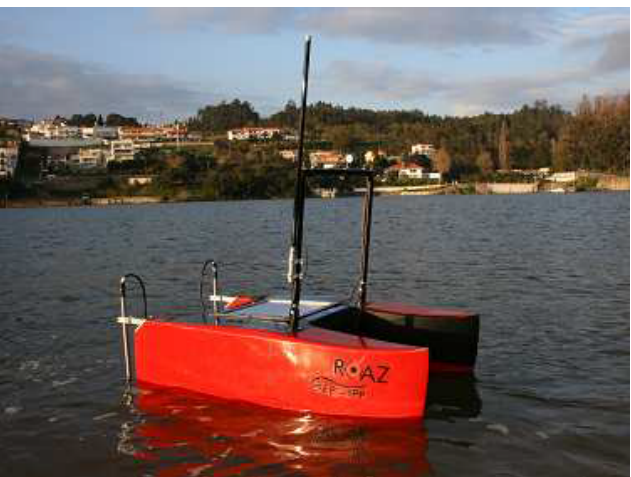

(a) ASV ROAZ. Fonte: [FERREIRA et al., 2006]

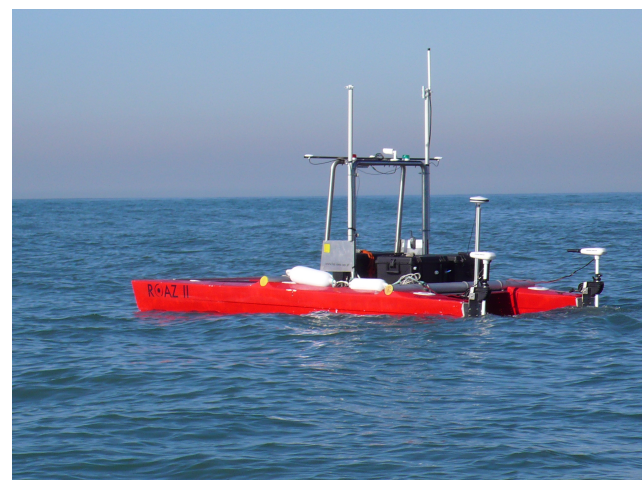

(b) ASV ROAZ II. Fonte: [FERREIRA et al., 2009]

Figura 2.10 - Veículos projetados no ISEP

o veículo. Já para o ASV ROAZ II (Figura 2.10b), foram utilizados motores elétricos padrões de barcos pois desta forma, o empuxo fornecido era mais significativo.

Com relação ao sistema de navegação, os dois veículos usam GPS para posicionamento absoluto, mas também estão equipados com uma unidade de medição inercial (inertial measurement unit em inglês), que fornece velocidade angular e aceleração linear, e um magnetômetro. Um algoritmo de fusão sensorial estima as variáveis de estado do veículo necessárias para o controle e para as aplicações específicas de cada missão [FERREIRA et al., 2006]; [MARTINS et al., 2007]; [FERREIRA et al., 2009].

\subsubsection{Veículo projetado no projeto MESSIN}

Entre 1998 e 2000, o ministério federal alemão da educação, pesquisa e tecnologia financiou o projeto MESSIN para desenvolver e testar o ASV Dolphin (Figura 2.11) para posicionamento de alta precisão e transporte de equipamentos de medição em águas rasas. No projeto do veículo foi dada atenção especial ao tipo do casco. Foi usado um casco de catamarã com o princípio de SWATH para atender os requisitos de mínima movimentação em mar revolto, otimizar a capacidade de carga e evitar danos as equipamentos embarcados.

Na Tabela 7 são expostas as especificações técnicas do veículo. O sistema de energia foi construído de forma modular, sendo que a energia podia ser fornecida por baterias de chumbo ácido ou por geradores a combustão interna. O sistema de navegação era composto por um GPS Diferencial e uma bússola [MAJOHR; BUCH, 2006]; [MAJOHR; 


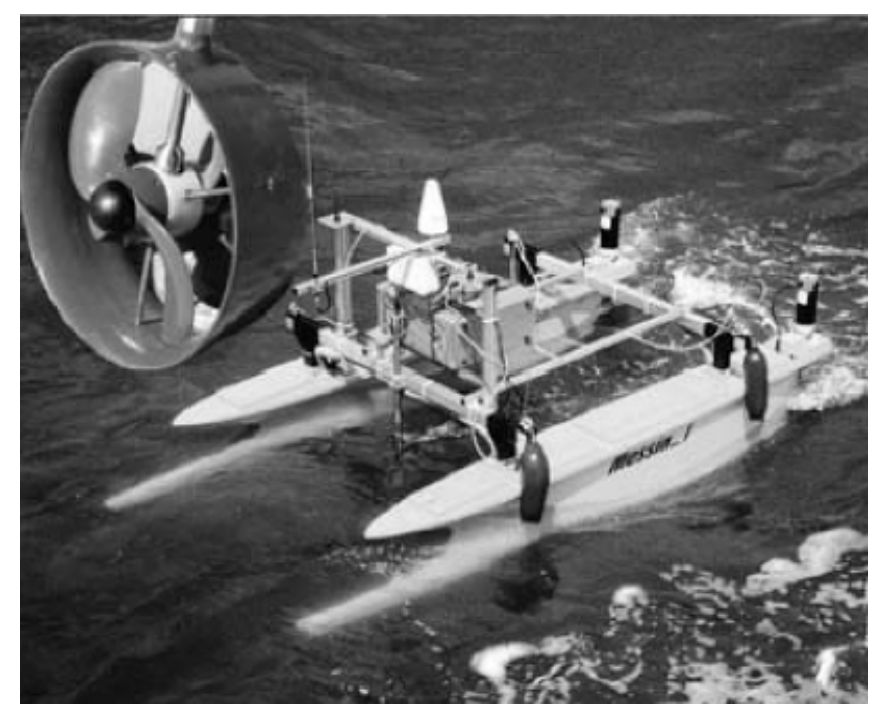

Figura 2.11 - ASV Dolphin, do projeto MESSIN. Fonte: [MAJOHR; BUCH, 2006] BUCH; KORTE, 2000]; [CACCIA, 2006].

Tabela 7 - Especificações do ASV Dolphin do projeto MESSIN

\begin{tabular}{|c|c|}
\hline Comprimento & $3,3 \mathrm{~m}$ \\
\hline Boca & $1,8 \mathrm{~m}$ \\
\hline Pontal & $1,5 \mathrm{~m}$ \\
\hline Calado & $0,4 \mathrm{~m}$ \\
\hline Deslocamento & $250 \mathrm{~kg}$ \\
\hline Velocidade máxima & $2 \mathrm{~m} / \mathrm{s}$ \\
\hline Autonomia (baterias) & $3 \mathrm{~h}$ \\
\hline Autonomia (sistema híbrido) & $10 \mathrm{~h}$ \\
\hline
\end{tabular}

\subsubsection{Veículo projetado na China}

Esse projeto foi desenvolvido pelo Robotics Laboratory da Chinese Academy Sciences e tem como objetivos projetar e implementar um ASV para servir como plataforma de testes do sistema de controle do veículo. Além disso, foi desenvolvido um modelo dinâmico com 6 graus de liberdade para auxiliar a estrutura de controle concebida.

O casco é do tipo trimarã (Figura 2.12) com $4 \mathrm{~m}$ de comprimento e apresenta três motores elétricos, um principal e dois auxiliares [PENG; HAN, 2009].

\subsubsection{Veículo projetado na Escola de Engenharia de São Carlos (EESC) da USP}

Na EESC da USP foi desenvolvido um veículo aquático autônomo com os cascos do tipo trimarã (Figura 2.13). 


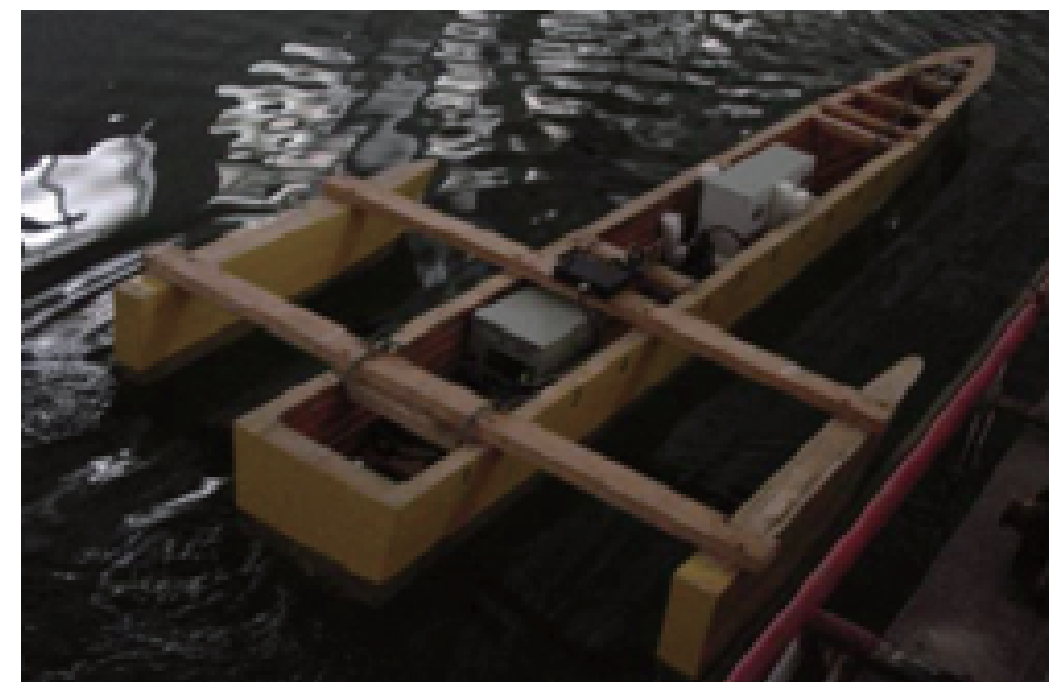

Figura 2.12 - ASV desenvolvido em um projeto da Chinese Academy Sciences. Fonte: [PENG; HAN, 2009]

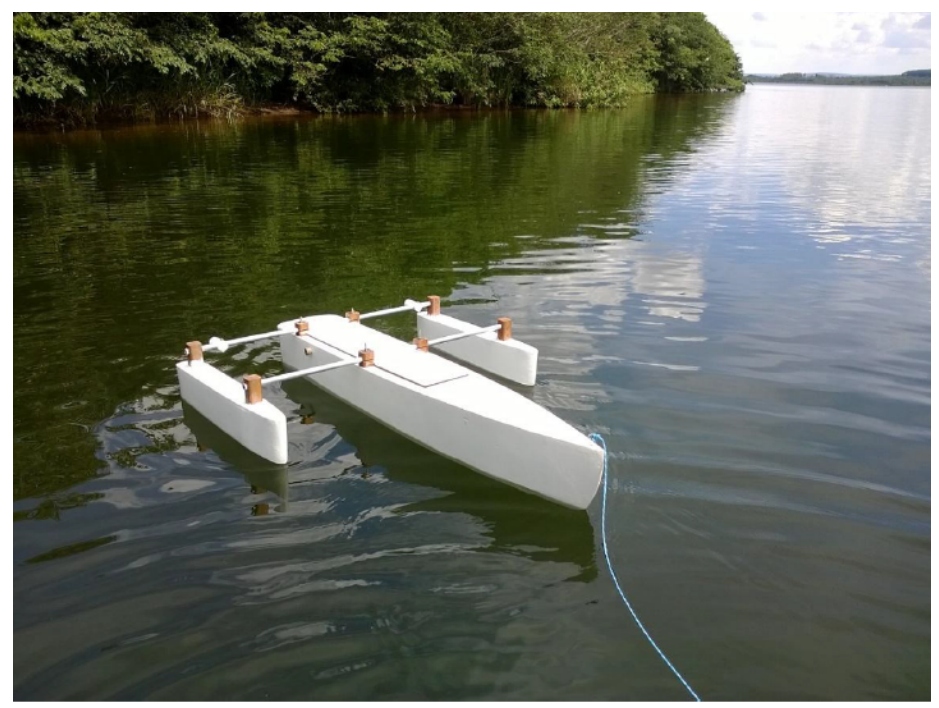

Figura 2.13 - Veículo aquático autônomo desenvolvido na EESC da USP. Fonte: [ALMEIDA, 2014]

O veículo é equipado com dois motores, em cada casco lateral, para realização das manobras. A comunicação com esses motores é realizada através de um sistema de interface com um microcontrolador da família ARM Cortex-M3. Esse microcontrolador também é responsável pelas tarefas para execução das missões da embarcação.

Além disso, o veículo conta com um conjunto de sensores inerciais e um receptor de GPS para o sistema de navegação que permite a obtenção da posição com a precisão necessária paras as missões do veículo [ALMEIDA, 2014]. 


\subsection{Veículos de superfície não tripulados comerciais}

Diferentemente dos veículos projetados em instituições acadêmicas cujas informações de projeto, especificações e aplicações são apresentadas em congressos e artigos científicos, os veículos comerciais são mais restritos com relação aos dados de projeto e expõem apenas algumas especificações físicas e de operação.

\subsubsection{L3 ASV}

A L3 ASV é uma empresa com escritórios nos Estados Unidos, Reino Unido e Brasil. Tem 8 anos de operações com mais de 100 sistemas entregues, para mais de 40 diferentes clientes em 10 países. Atuam nas áreas de engenharia naval, mecânica, elétrica e de software, além de operar ASVs. A empresa apresenta uma vasta gama de produtos, desde ASVs de tamanhos variados até sistema de controle [L3 ASV, 2019].

O C-Cat 3 (Figura 2.14) é um dos ASVs desenvolvidos pela empresa cujo propósito é realizar missões de inspeção e suporte em locais em que embarcações menores são mais adaptadas. Além disso, o veículo conta com uma grande capacidade para carga paga. Na Tabela 8 são apresentadas algumas características do veículo.

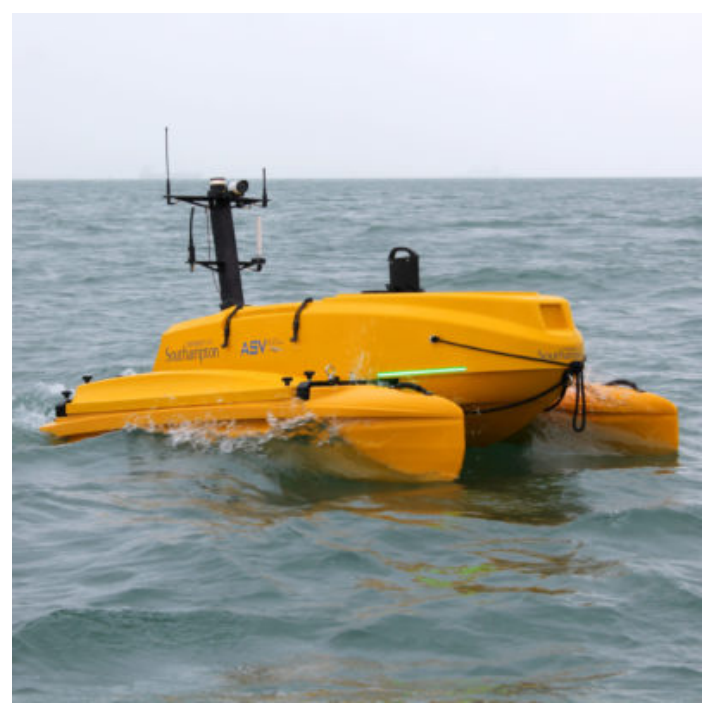

Figura 2.14 - ASV C-Cat 3 da empresa L3 ASV. Fonte: [L3 ASV, 2019]

Outro produto da L3 ASV é o C-Enduro (Figura 2.15), veículo utilizado para missões de coleta de dados marinhos de longa duração. Fabricado para operar em todos os ambiente marinhos, a embarcação usa uma combinação de geradores solares, a diesel e a vento, sendo capaz de operar por mais de 30 dias, dependendo da configuração de potência. O veículo diminui drasticamente os custos de missões de coleta de dados pois remove a necessidade de embarcações tradicionais.

O veículo apresenta painéis solares capazes de gerar até $1,1 \mathrm{~kW}$, que em conjunto com o motor a diesel de $4 \mathrm{~kW}$ e a turbina de vento de $0,5 \mathrm{~kW}$ formam o sistema de potência 
Tabela 8 - Especificações do ASV C-Cat 3 da empresa L3 ASV

\begin{tabular}{|c|c|}
\hline Comprimento & $3,02 \mathrm{~m}$ \\
\hline Boca & $1,55 \mathrm{~m}$ \\
\hline Pontal & $1,4 \mathrm{~m}$ \\
\hline Calado mínimo & $0,39 \mathrm{~m}$ \\
\hline Calado máximo & $0,7 \mathrm{~m}$ (totalmente carregado) \\
\hline Deslocamento Operacional & $270 \mathrm{~kg}$ \\
\hline Carga Paga & $70 \mathrm{~kg}$ \\
\hline Velocidade máxima & $8 \mathrm{nós}$ \\
\hline
\end{tabular}

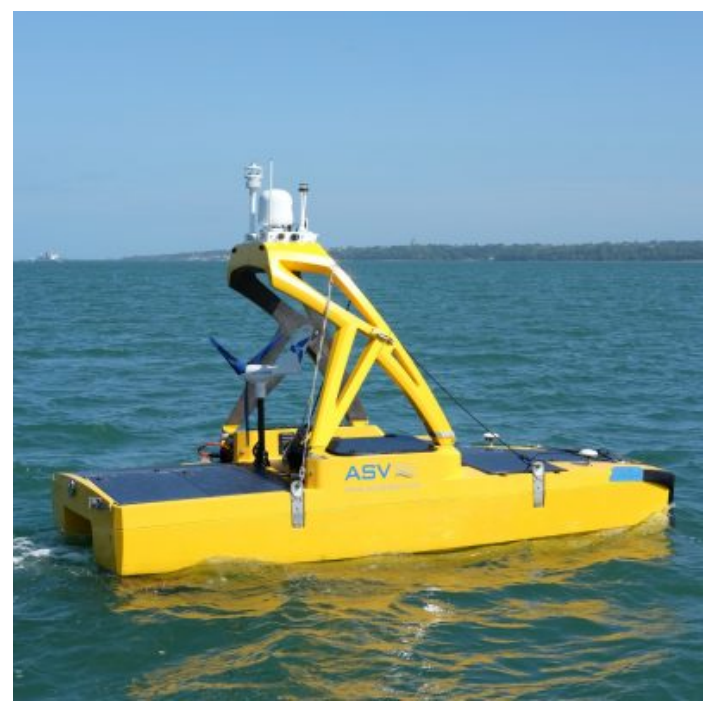

Figura 2.15 - ASV C-Enduro da empresa L3 ASV. Fonte: [L3 ASV, 2019]

do veículo. Além disso, o C-Enduro pode usar um planejador de missões e pontos de referência para obter dados mais acurados. Na Tabela 9 são mostradas as especificações do veículo.

Tabela 9 - Especificações do ASV C-Enduro da empresa L3 ASV

\begin{tabular}{|c|c|}
\hline Comprimento & $4,75 \mathrm{~m}$ \\
\hline Boca & $2,22 \mathrm{~m}$ \\
\hline Pontal & $3,43 \mathrm{~m}$ \\
\hline Calado & $0,52 \mathrm{~m}$ \\
\hline Deslocamento & $910 \mathrm{~kg}$ \\
\hline Carga Paga & $0,4 \mathrm{~m}^{3}$ \\
\hline Velocidade máxima & 6,5 nós \\
\hline
\end{tabular}

\subsubsection{USSVtech}

Empresa brasileira dedicada ao desenvolvimento, fabricação e comercialização de embarcações marítimas autônomas. Nesta empresa, busca-se soluções modulares, com sis- 
tema tolerantes a falhas e com cascos otimizados para cada missão [USSVTECH, 2019].

Um dos produtos da empresa é o USV Tucunaré (Figura 2.16), veículo com casco do tipo trimarã com um convés fixo que conecta todos os cascos, cujas informações são apresentadas na Tabela 10.

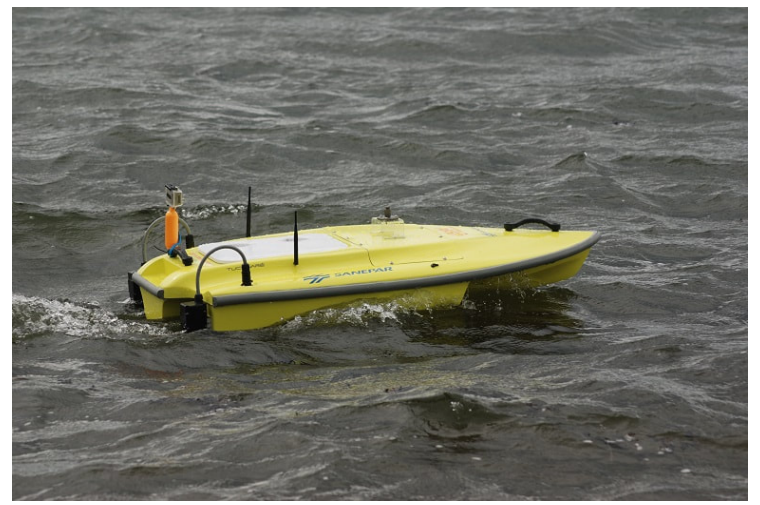

Figura 2.16 - USV Tucunaré da empresa USSVtech. Fonte: [USSVTECH, 2019]

Tabela 10 - Especificações do USV Tucunaré da empresa USSVtech

\begin{tabular}{|c|c|}
\hline Comprimento & $1,52 \mathrm{~m}$ \\
\hline Boca & $0,74 \mathrm{~m}$ \\
\hline Pontal & $0,27 \mathrm{~m}$ \\
\hline Calado & $0,2 \mathrm{~m}$ \\
\hline Deslocamento Operacional & $15 \mathrm{~kg}$ \\
\hline Carga Paga & $10 \mathrm{~kg}$ \\
\hline Velocidade máxima & $7 \mathrm{nós}$ \\
\hline Autonomia & 4 h a 3 nós \\
\hline
\end{tabular}

Outro produto da empresa é o C-400 (Figura 2.17), um USV com casco tipo catamarã cujas características são mostradas na Tabela 11. A navegação do veículo é realizada por GPS e ele apresenta uma interface capaz de realizar o planejamento da missão, controle e monitoramento dos sensores embarcados.

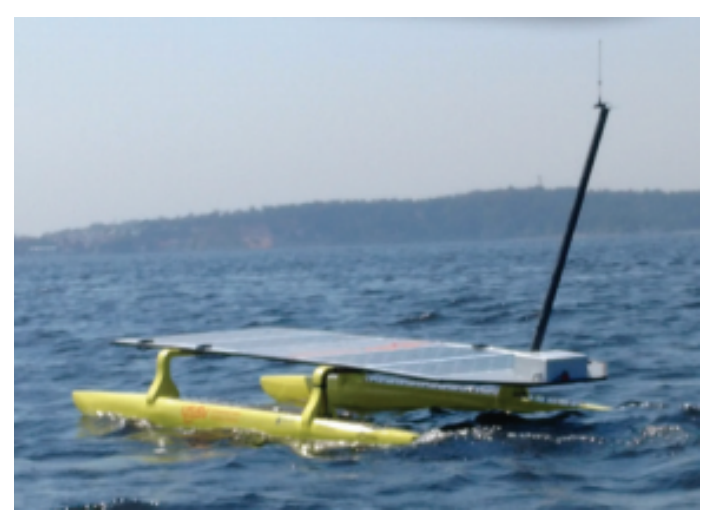

Figura 2.17 - USV C-400 da empresa USSVtech. Fonte: [USSVTECH, 2019] 
Tabela 11 - Especificações do USV C-400 da empresa USSVtech

\begin{tabular}{|c|c|}
\hline Comprimento & $4,35 \mathrm{~m}$ \\
\hline Boca & $1,60 \mathrm{~m}$ \\
\hline Pontal & $0,80 \mathrm{~m}$ \\
\hline Calado & $0,45 \mathrm{~m}$ \\
\hline Deslocamento Operacional & $80 \mathrm{~kg}$ \\
\hline Carga Paga & $20 \mathrm{~kg}$ \\
\hline Velocidade máxima & 4,5 nós \\
\hline Autonomia & 12 h a 3,5 nós \\
\hline
\end{tabular}

\subsection{Características comuns}

Dos veículos de superfície apresentados, todos possuíam vínculos com instituições de pesquisa. Durante o projeto da maioria destes veículos, além de focar nos requisitos técnicos da função principal, eram levados em consideração possíveis aplicações futuras. Desta forma, a substituição e instalação de novos equipamentos poderiam ser facilmente realizadas.

Grande parte desses veículos desempenhavam missões de batimetria que requerem boa estabilidade em roll, por este motivo a opção por multicascos (principalmente catamarãs) era preferível. Além disso, multicascos apresentam maior área de convés que permite a instalação de mais equipamentos ou até de placas de geração de energia solar.

Apenas dois dos veículos apresentados eram do tipo trimarã, e eles não se aproveitaram da maior área de convés que poderia ser utilizada entre os cascos. No veículo deste trabalho, para aumentar a autonomia da embarcação, serão instalados painéis fotovoltáicos sobre as estruturas de conexão dos cascos. Além disso, em nenhum dos projetos de trimarãs são apresentadas uma metodologia de projeto da arquitetura naval detalhada e do sistema embarcado. Assim, não são encontradas informações sobre o desempenho dessas embarcações.

Dos USVs mostrados, não há grande detalhamento, em nenhum deles, do projeto naval do casco. Em boa parte dos casos, os desempenhos dos veículos desenvolvidos (com relação a velocidade, manobrabilidade, autonomia, entre outros) não foram previamente estimados, fazendo com que os projetos fossem mais conservadores. Chega-se a tal conclusão pela observação de como são obtidos os cascos de alguns desses projetos analisados: parceria de projeto com empresas terceiras ou utilização de cascos já existentes disponíveis pela instituição.

A partir da observação da aplicação e especificação destes veículos expostos anteriormente, chega-se à conclusão que, por motivos de estabilidade e área de instalação de equipamentos, os multicascos são maioria, em especial, o catamarã. Entretanto, para o caso deste trabalho, cuja motivação é embarcar sensores de navegação com partes submersas, o catamarã não seria o mais adequado. Caso o equipamento submerso fosse instalado 
em um dos cascos laterais, haveria uma assimetria prejudicial para a manobrabilidade do veículo. Outra possível solução seria instalar o equipamento no centro transversal do catamarã, porém, seriam necessárias complexas estruturas físicas para possibilitar a operação normal do equipamento.

Desta forma, a solução do trimarã ainda apresenta as vantagens do catamarã, e atende a necessidade de instalação do equipamento submerso sem assimetrias ou estruturas complexas ao colocá-lo no casco central. 


\section{Análise do projeto de um USV}

\subsection{Requisitos do projeto considerado}

A definição dos requisitos básicos é de essencial importância para iniciar um projeto de engenharia. No projeto de navios, nos requisitos básicos costuma-se estabelecer a velocidade de operação, o peso (deslocamento) de payload (carga paga) e a autonomia desejada. Além disso, para USVs, também são requisitos básicos condições de operação do veículo bem como sua logística de transporte e operação.

Para o veículo em questão deste trabalho, os requisitos básicos considerados foram:

- Velocidade de operação entre 1 e 4 nós (0,5 e 2,0 m/s aproximadamente);

- Autonomia do sistema de baterias e células fotovoltaicas de 3 horas com velocidade de $2 \mathrm{~m} / \mathrm{s}$ (aproximadamente 4 nós);

- Capacidade de embarque de $30 \mathrm{~kg}$ de carga paga;

- Área de convés para instalação de placas solares;

- Interface gráfica amigável para controle e monitoramento do veículo, para ser utilizada em um notebook, com a possibilidade de integração com controle do veículo manual;

- Veículo com dimensões e estruturas que facilitem o transporte, assim como operações de trimagem (ajuste de pesos e centros), lançamento e recuperação;

- Capacidade de realizar missões em mar calmo sem comprometer a segurança da eletrônica embarcada nem dos sensores de navegação;

- Capacidade de realizar manobras pré-programadas como giro, zigue zague e controle de rumo, cinematicamente compatíveis com as manobras executados por AUVs;

- Interface para manobra de guiamento capaz de receber como entrada pontos referenciados ao WGS84 (sistema de referência usado pelo GPS);

- Módulo de navegação propício à fácil implementação de diferentes algoritmos para testes em campo.

\subsection{Metodologia de projeto naval}

Em 1959, foi proposto pelo arquiteto naval John Harvey Evans uma representação do processo iterativo do projeto de navios em forma de uma espiral que futuramente ficou 
conhecida como Espiral de Projeto. A Figura 3.18 é uma tentativa de representar esse procedimento no caso geral de um navio de superfície.

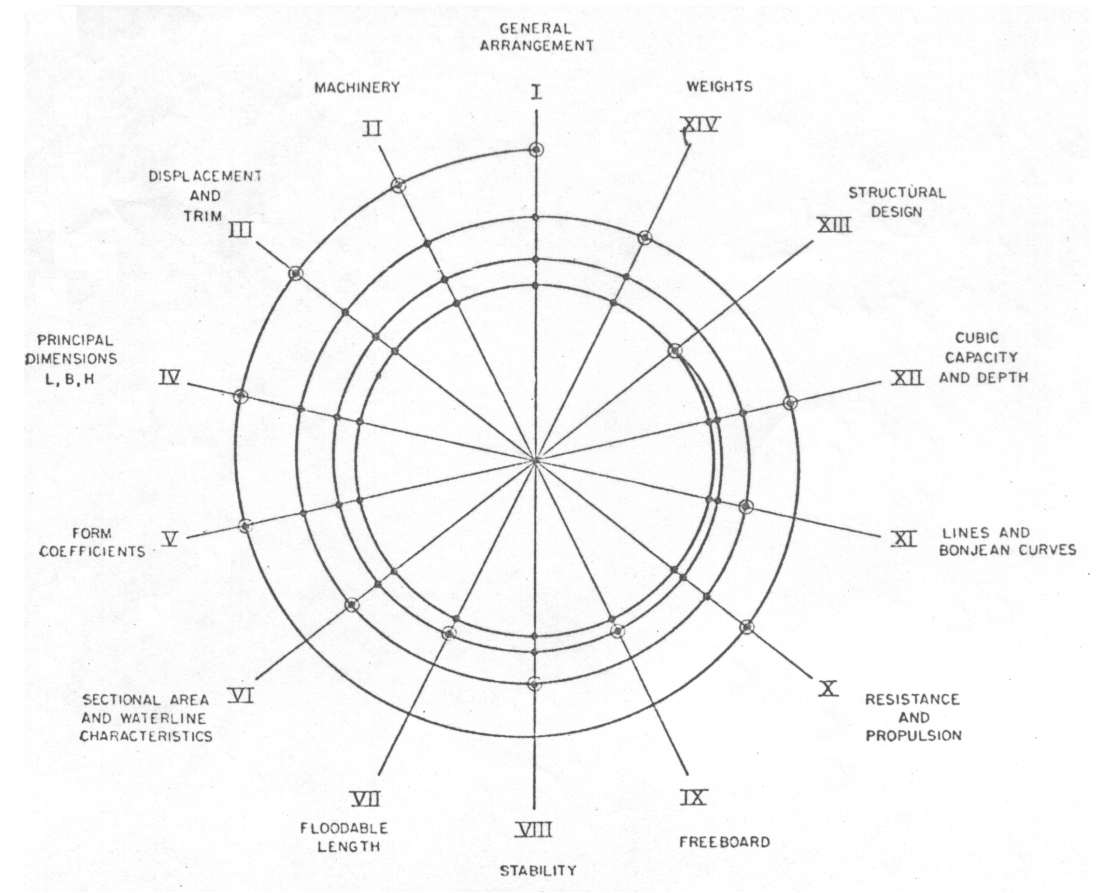

Figura 3.18 - Espiral de Projeto proposta por Evans. Fonte: [EVANS, 1959]

Esse processo consiste em definir as características do projeto a cada volta da espiral. No caso de informações que não podem ser determinadas, estas devem ser estimadas da melhor forma, com base em embarcações semelhantes e conhecimento do projetista. Assim, é possível prosseguir com o projeto até que essas informações desconhecidas sejam determinadas.

Com esse procedimento, a evolução do projeto ocorre de forma iterativa, aumentando o detalhamento geral a cada volta da espiral. Idealmente esse processo converge para a solução que será adotada.

A Espiral de Projeto é baseada na divisão do processo de projeto em etapas. Uma das subdivisões comumente utilizada é em quatro partes: projeto de concepção, projeto preliminar, projeto de contrato e projeto de detalhamento [SANTOS, 2016].

Tradicionalmente, o projeto de concepção era realizado por tentativa e erro ou baseado em técnicas como a do navio semelhante, que buscava embarcações com características parecidas para estimar as características iniciais. Entretanto, com o desenvolvimento progressivo dos computadores e de sua capacidade de cálculos e armazenamento de dados, foi possível a elaboração de novas técnicas de projeto baseadas em análise estatísticas.

Posteriormente, o processo de otimização do projeto do navio foi realizado pela procura de possíveis soluções com a alteração sistemática de variáveis de projeto.Inicialmente essa otimizaão era realizada com apenas uma função objetivo mas, com as novas técnias de otimzação, problemas multi-objetivo já podiam ser resolvidos com metodologias de 
programação não linear [NOWACKI, 2009].

\subsubsection{Metodologia de projeto deste trabalho}

Conforme proposto na seção 1.1, o objetivo principal deste trabalho reside na contribuição para uma metodologia de projeto de USVs que atenda aos requisitos da aplicação.Neste trabalho, tal aplicação diz respeito não só a pesquisa em navegação de AUVs, mas também a possibilidade de adaptação a campanhas oceanográficas. Apesar de apresentar algumas restrições de deslocamento e velocidade de operação, a otimização energética do veículo não é prioritária, face à garantia de um valor mínimo de autonomia e outros fatores relacionados à facilidade de fabricação do USV, conforme explicado a seguir. Desta forma, neste trabalho fez-se uso da técnica de navios semelhantes para realizar as estimativas iniciais das dimensões do veículo. Para algumas características do casco foram realizadas parametrização para facilitar os cálculos quando pretendia-se fazer uma comparação entre diferentes dimensionamentos.

Apesar da existência de outras metodologias de projeto de navios mais eficientes e modernas, com uso de métodos de otimização, neste trabalho optou-se pela seleção de algumas possíveis soluções que seriam analisadas etapa por etapa. Fez-se essa escolha pois, no ambiente acadêmico, muitas vezes o projeto apresenta restrições difíceis de serem modeladas como, por exemplo, verba insuficiente para compra dos melhores equipamentos e componentes, utilização dos sensores disponíveis no laboratório e manufatura dos cascos quase artesanal, lidando com algumas limitações de fabricação de algumas peças e estruturas. Além disso, o processo de manufatura dos cascos foi realizado de forma quase artesanal, sendo necessárias algumas alterações para possibilitar a produção dos cascos.

Outros fatores que tiveram peso significativo durante o projeto do veículo foram a logística de transporte, manuseio e manutenção do veículo em terra, e sua facilidade de operação durante missões de campo. Esses aspectos se mostraram de importante relevância a partir das experiências obtidas em campo com a operação do AUV Pirajuba. Nestes testes ficou comprovada as restrições de tempo relacionadas à disponibilidade de barcos e equipe de apoio, por isso, quanto menos tempo era gasto em manutenções pontuais e preparo para próximas missões, maior era o aproveitamento do ensaio.

Assim, o projeto foi realizado comparando algumas diferentes soluções viáveis seguindo as seguintes etapas de forma iterativa baseada na representação da Espiral de Projeto. A $\underline{\text { Figura } 3.19}$ apresenta uma adaptação da representação do processo de projeto da Espiral de Evans para o caso de um USV.

Com essa divisão de etapas, o detalhamento do projeto foi dividido nas seguintes etapas da Espiral de Projeto:

- Requisitos básicos: adequação dos dados do projeto de forma a cumprir os requisitos básicos previamente definidos; 


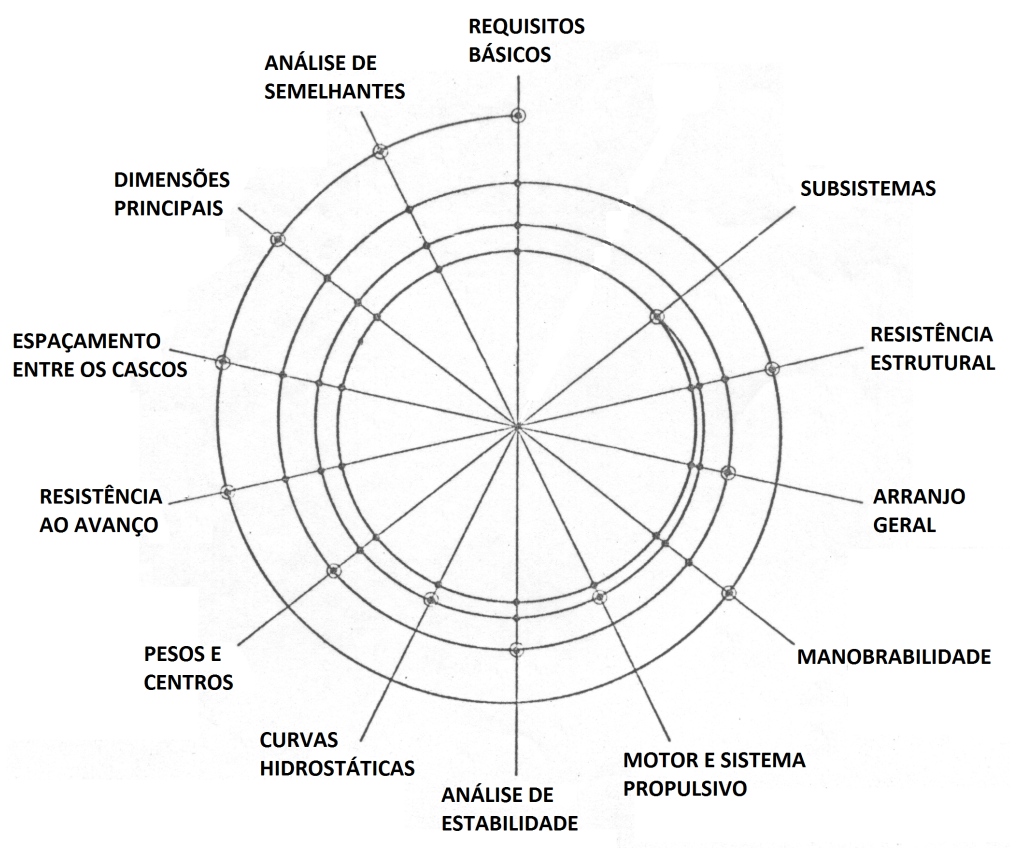

Figura 3.19 - Espiral de Projeto adaptada para o caso de um USV. Fonte: adaptado de [EVANS, 1959]

- Análise de semelhantes: o projeto de um navio é complexo e, por isso, é comum realizar um estudo com embarcações semelhantes para obter informações sobre características similares;

- Dimensões principais: com os dados de veículos semelhantes e com o objetivo de atender os requisitos básicos, faz-se a determinação das dimensões principais. Inicialmente, almeja-se estimar as dimensões de boca, comprimento, pontal, coeficiente de forma e, por se tratar de um veículo multi casco, a distribuição do deslocamento total entre os cascos. Posteriormente, são obtidos resultados refinados conforme o nível de detalhamento do projeto evolui;

- Espaçamento entre os cascos: o veículo projetado neste trabalho apresenta um casco do tipo trimarã (como será apresentado o motivo na subseção 3.3.1), por esta razão, a definição da distância transversal e longitudinal entre os cascos é muito importante. Essas distâncias influenciam na resistência ao avanço, na estabilidade, na manobrabilidade e na resistência estrutural;

- Resistência ao avanço: uma das formas de estimar o valor da resistência ao avanço de uma embarcação é a partir de simulações e métodos numéricos. Neste trabalho, essa estimativa foi realizada usando formulações empíricas. Nessas formulações, a resistência ao avanço é dividida em resistência friccional e residual e seus valores são calculados baseados em testes experimentais com modelos; 
- Pesos e centros: nesta etapa são estimados os pesos e centros com base nas informações das dimensões do projeto. Posteriormente, com as informações do arranjo geral essa estimativa é aperfeiçoada.

- Curvas hidrostáticas: nesta etapa são realizadas as análises hidrostáticas da embarcação em função do calado;

- Análise da estabilidade: Em conjunto com as curvas hidrostáticas, é possível realizar o posicionamento dos equipamentos, sensores e outros sistemas embarcados de forma a garantir a estabilidade tranversal e longitudinal do veículo;

- Motor e sistema propulsivo: com base na estimativa de resistência ao avanço em função da velocidade é possível realizar a integração casco-hélice-motor para a condição de operação estabelecida nos requisitos básicos permitindo a seleção da máquina elétrica;

- Manobrabilidade: o veículo deverá realizar manobras pré-programadas como controle de rumo, giro e zigue zague. Para isso, deve-se projetar as dimensões da superfície de controle (leme). Com as informações já adquiridas, é possível estimar parâmetros, como raio de giro, e usá-los como referência do resultado do sistema de manobra;

- Arranjo geral: etapa na qual ocorre a definição da posição dos sensores e da eletrônica embarcada no veículo. Além disso, para o caso de um USV, leva-se em consideração também a segurança dos equipamentos. Estes devem ficar protegidos por caixas estanques (não permitem a entrada de água), mas que ao mesmo tempo possibilitem a troca de calor com o meio e a interconexão elétrica entre módulos;

- Resistência estrutural: estimativa dos esforços solicitantes considerando os piores casos de operação e manuseio do veículo. Com esses valores é possível dimensionar os compartimentos e as estruturas entre os cascos;

- Subsistemas: Para um USV, diversos subsistemas, como de navegação e comunicação, são de extrema importância para o que o veículo funcione de acordo com os requisitos básicos estabelecidos. Por sua vez, o desenvolvimento desses subsistemas está indiretamente conectado com a Espiral de Projeto do veículo. Assim, as considerações realizadas aos subsistemas durante o projeto do veículo foram do posicionamento, do volume e do peso próprio.

\subsection{Solução proposta}

A representação apresentada na seção 3.2 é usada como ferramenta de auxílio do projeto do USV proposto. Para satisfazer os requisitos básicos considerados na seção 3.1 
o veículo deve possuir as características que são apresentadas a seguir.

\subsubsection{Caracterização da arquitetura naval - Escolha do Trimarã}

Durante as fases iniciais de projeto, fez-se comparações da estabilidade, da resistência ao avanço e da manobrabilidade entre possíveis soluções de monocascos, catamarãs e trimarãs. Foram considerados os cascos da série sistemática NPL [BAILEY, 1976] com o mesmo deslocamento e, para os multicascos, com a mesma boca total.

O monocasco não apresentava estabilidade transversal suficiente, com valores negativos para a altura transversal metacêntrica $\left(G M_{T}\right)$ quando totalmente carregado. No Gráfico 1 pode-se observar a comparação entre o $G M_{T}$ do trimarã e do catamarã. As linhas pontilhadas representam o calado de projeto de cada caso.

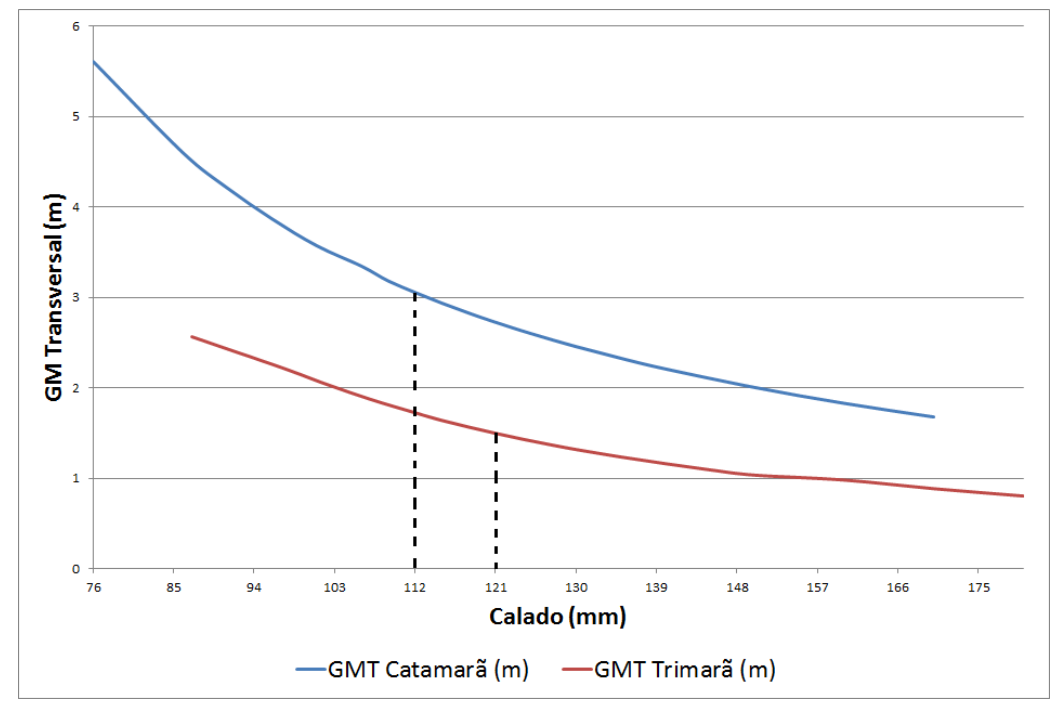

Gráfico $1-G M_{T}$ em função do calado do catamarã e trimarã. Fonte: autor

No Gráfico 2 faz-se a comparação da resistência total de 6 diferentes soluções, incluindo 4 trimarãs com variações na distância longitudinal entre os cascos laterais e o casco central $(\bar{a})$. A resistência friccional foi estimada a partir dos dados da série sistemática NPL [BAILEY, 1976] que usa o modelo de placa plana da ITTC 1957 para calcular o $C_{F}$ (Equação 4.19), e a resistência de ondas e interação entre os cascos, foi adotada as formulações apresentadas em [DUBROVSKY; LYAKHOVITSKY, 2001].

Nessa comparação já é possível notar que um aumento na distância longitudinal entre os cascos $(\bar{a})$ causa uma diminuição na resistência total. Além disso, apesar de que a solução de monocasco apresentava a menor resistência total, ela não tinha estabilidade transversal pois o posicionamento dos painés solares sobre o convés superior aumentava consideravelmente o valor do KG dessa solução. Ademais, quando comparadas com a solução monocasco, as soluções multicascos tem maior área de convés e melhor manobrabilidade em baixa velocidade.

Desta forma, fez-se a escolha de um veículo do tipo trimarã pelos seguintes motivos: 


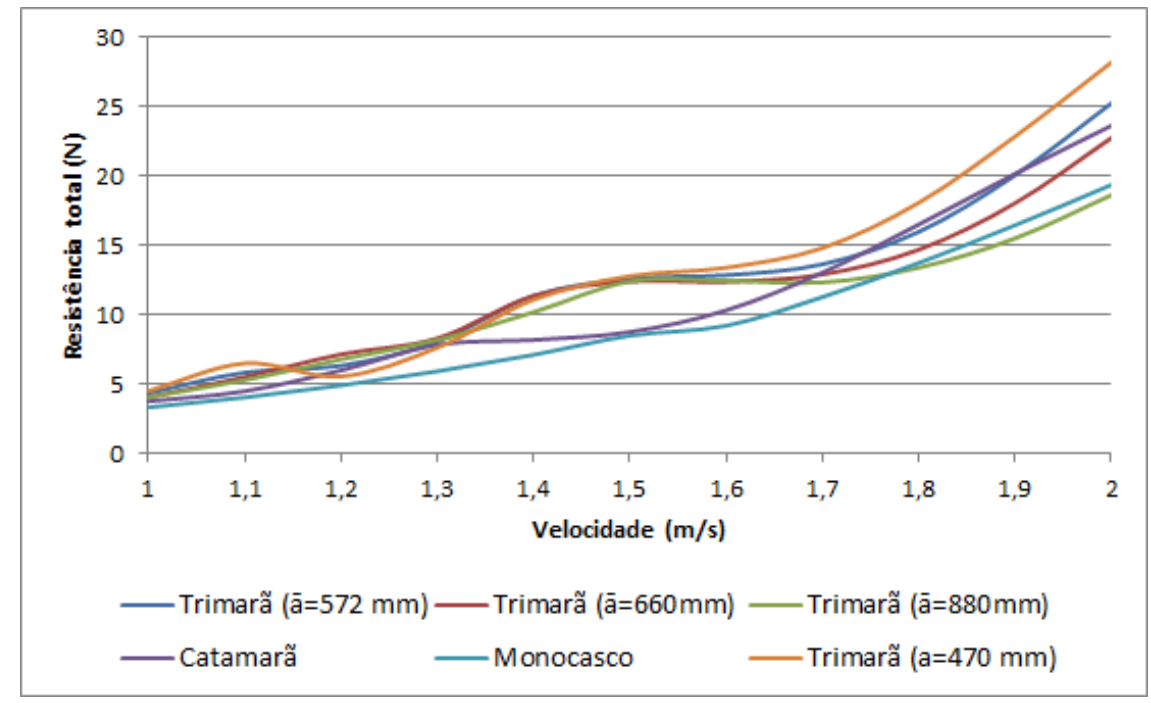

Gráfico 2 - Comparação da resistência total em função da velocidade. Fonte: autor

- Embarcações multicascos tem maior área de convés que pode ser aproveitada para instalação painéis solares e mais equipamentos;

- Essas embarcações apresentam maior estabilidade longitudinal devido a distância transversal dos cascos com o plano de simetria;

- Na análise de resistência de ondas de multicascos, deve-se levar em consideração a influência entre os cascos. Para embarcações com 3 cascos, o efeito trimarã corresponde a uma grande parcela na redução da resistência de ondas dependendo da distância longitudinal estabelecida entre os cascos [DUBROVSKY; LYAKHOVITSKY, 2001];

- O sensor acústico de velocidade (DVL) mede a velocidade linear do veículo com relação ao leito aquático e precisa que seus transdutores fiquem submersos na água. Além disso, quanto mais próximo do centro de massa melhor a medição da velocidade do veículo. Em uma embarcação do tipo trimarã, pode-se realizar um corte no casco central para posicionar o sensor o mais próximo do centro de massa;

- Posicionando o sensor acústico no casco central não causa assimetrias nem necessita de complexas estruturas para manter o equipamento submerso;

- O veículo do tipo trimarã pode ser projetado de forma a operá-lo com diferentes configurações de distância longitudinal $(\bar{a})$. No caso deste trabalho, fez-se a convés superior para comportar duas configurações diferentes.

- Melhora-se também a manobrabilidade do veículo em baixa velocidade, que pode ser atendida com a disposição de propulsores nos cascos laterais.

Com a escolha pelo trimarã tomada, foi possível fazer análises comparando os resultados de manobrabilidade esperados para diferentes valores da distância longitudinal $(\bar{a})$, 
como é mostrado na Tabela 12 e cujos cálculos e modelos utilizados são apresentados na subseção 4.6.1. Enquanto que um aumento na distância longitudinal diminui a resistência total do veículo, ele também deteriora os resultados de manobrabilidade, aumentando o raio de giro.

Tabela 12 - Raio de giro sobre o comprimento do veículo para diferentes soluções de trimarã

\begin{tabular}{|c|c|}
\hline Distância longitudinal entre os cascos $(\bar{a})$ & $\mathrm{R} / \mathrm{L}$ \\
\hline $440 \mathrm{~mm}$ & 4 \\
\hline $572 \mathrm{~mm}$ & 4,5 \\
\hline $660 \mathrm{~mm}$ & 5 \\
\hline $880 \mathrm{~mm}$ & 6,3 \\
\hline
\end{tabular}

O veículo será construído de forma modular para facilitar o transporte e as operações de lançamento e resgate. Além disso, o veículo terá uma estrutura responsável pela união dos cascos, pela resistência estrutural e como base para instalação dos painéis fotovoltaicos.

\subsubsection{Caracterização da interface humano-máquina}

A interação humano-máquina ocorre através de uma interface gráfica desenvolvida para funcionar em notebooks usados como estação base de operação das missões. Estes notebooks podem se conectar com ou sem cabo com controle para realização de manobras manuais.

A interface gráfica é dividida em abas com diferentes funções:

- Configuração de manobras;

- Configuração de parâmetros de controle;

- Leitura em tempo real dos sensores;

- Localização em tempo real do veículo no mapa .

Para facilitar o desenvolvimento e teste dos algoritmos de navegação, na tela de localização, além da posição do veículo, obtida pelo GPS, também é mostrada a posição do veículo estimada pelos algoritmos de navegação.

\subsubsection{Caracterização da eletrônica embarcada}

Sistema eletrônico deve apresentar interfaces ou portas adequadas, em número e em especificação, para a aquisição dos dados fornecidos pelos sensores considerados para o 
sistema de navegação: unidade de medição inercial (IMU), sensor de rumo (bússola), sensor acústico de velocidade (DVL), profundímetro e GPS.

A maioria dos sensores de navegação apresenta comunicação serial com taxa de aquisição que depende do tipo do sensor. Logo, a eletrônica embarcada precisa ter portas de comunicação com taxas de aquisição de variados (valor ditado pela aquisição e préprocessamento dos dados inerciais).

Sensores de pressão normalmente apresentam portas analógicas ou digitais. Além disso, é possível que, dependendo da missão do USV, equipamentos da carga paga precisem de canais analógicas. Por isso, o sistema eletrônico tem canais analógicos, apesar dos sensores de pressão atualmente utilizados serem do tipo digital.

Além da aquisição dos sensores de navegação, o sistema eletrônico embarcado deve ter interface seriais para o rádio, responsável pela comunicação entre o veículo e a base. O sistema também precisa de portas para sensores de inundação em cada módulo do veículo para aumentar a segurança do veículo.

O sistema eletrônico é dividido em módulos de acordo com a função realizada. A comunicação interna entre os módulos pode ser realizada via 2 barramentos CAN diferentes. Atualmente o veículo usa apenas um dos barramentos CAN para a comunicação interna entre os módulos. O segundo barramento CAN pode ser utilizado por módulos de interface com a carga paga ou durante o teste de novas funcionalidades do veículo que ainda não estejam suficientemente confiáveis para ser adicionado ao no barramento principal de operação.

O deslocamento do USV requer o acionamento e controle dos seus sistemas de propulsão e manobra. Para propulsão, considerou-se o controle independente de 2 motores responsáveis pela rotação dos hélices do veículo. Para execução das manobras propostas, o veículo também precisará de um motor elétrico responsável pela movimentação de uma superfície de controle (leme). A comunicação com os controladores e sensores dos motores é realizada via barramento CAN.

\subsubsection{Caracterização do sistema de propulsão e de manobra}

O sistema de propulsão e de manobra será composto por:

- Um microcontrolador;

- Dois motores de propulsão;

- Dois hélices;

- Um motor do leme;

- Um leme 
O microcontrolador do sistema de propulsão e manobra é responsável pela trasmissão dos valores de referência, ditados por outra unidade eletrônica do sistema, para os sensores e controladores dos motores dos atuadores. O microcontrolador foi posicionado no casco central e realiza a comunicação via barramento CAN com os demais subsistemas do veículo.

Cada um dos cascos laterais terá um hélice e um motor de propulsão com seu respectivo sistema de controle com sensores de velocidade angular e corrente. O valor de referência de rotação do motor será obtido de acordo com a operação do veículo: no caso de manobra pré-programada, a rotação será definida antes do início da manobra, enquanto que para manobras manuais, a rotação será fornecida pelo usuário em tempo real, via canal de telemetria e telecomando.

O projeto do hélice foi realizado a partir das curvas de empuxo, torque e eficiência da família BTroost, amplamente utilizadas no meio naval, e é detalhadamente explicado na subseção 4.5.1. Com essas curvas e com as informações de resistência ao avanço e velocidade de operação foi possível dimensionar o hélice da família BTroost com a maior eficiência na condição de operação do veículo. O processo de integração casco-hélice-motor é mais detalhado na seção 4.5.

O leme e seu respectivo motor, controlador de posição angular e sensor de posição angular foram posicionados no casco central. O valor de referência de posição angular do motor será estabelecido da mesma forma que o sistema de propulsão: definido antes da manobra ou pelo usuário controlando o veículo remotamente.

\subsubsection{Caracterização do sistema de energia}

As baterias foram posicionadas nos cascos laterais, próximas aos motores de propulsão e dentro de um compartimento para sua fixação. Já as placas solares foram colocadas na parte superior da estrutura de conexão entre os cascos.

A principal fonte de energia do veículo são as baterias de polímero de lítio, enquanto que painéis fotovoltaicos são utilizados para aumentar a autonomia total do veículo. A quantidade de baterias embarcada foi estabelecida de forma que o requisito de navegar por 3 horas a $2 \mathrm{~m} / \mathrm{s}$ fosse atendido apenas com as baterias.

Em cada casco lateral o sistema apresenta um sistema de gerenciamento da bateria (BMS), responsável por proteger a bateria de atuar fora da sua área segura de operação, monitorar seu estado e gerenciar sua carga. Cada BMS apresenta uma chave de 3 posições que possibilitam a comutação da bateria entre o BMS, o conector de recarga e uma condição de desligamento total da bateria. O acionamento geral do veículo é realizado por uma chave no casco central, entretanto, o veículo só é ligado de fato quando os BMSs verificam que o conjunto de baterias de cada casco lateral esta conectado ao sistema. 


\subsubsection{Caracterização do sistema de navegação}

O sistema de navegação do USV recebe os dados dos seguintes sensores:

- Unidade de medição inercial (IMU): fornece os dados de rotação angular e aceleração linear;

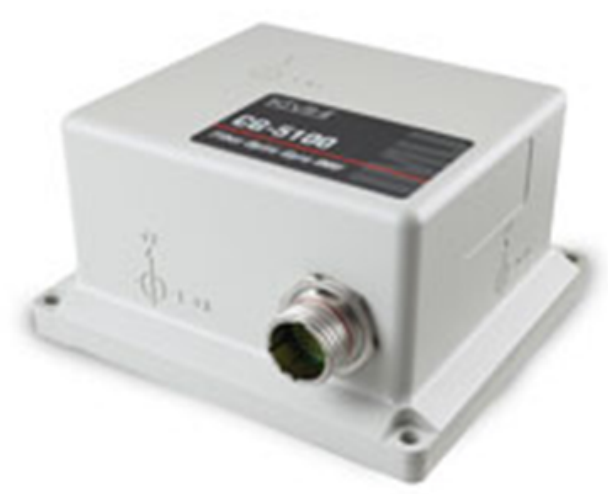

Figura 3.20 - Unidade de medição inercial modelo KVH CG-5100. Fonte: [KVH, 2017]

- Sensor de rumo (bússola): proporciona o ângulo de rumo a partir da direção do campo magnético sentido pelos magnetômetros;

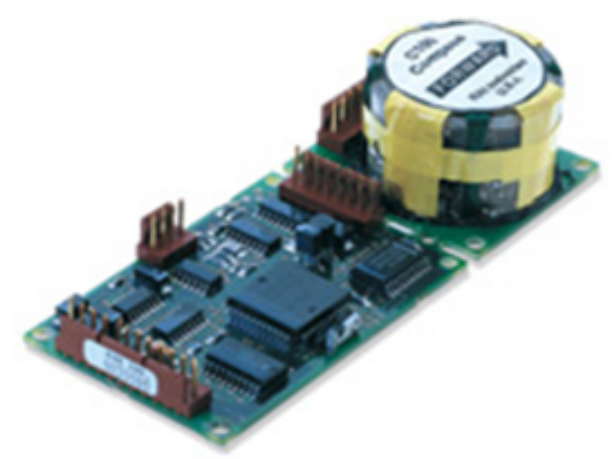

Figura 3.21 - Bússola modelo KVH C100. Fonte: [KVH, 2010]

- Sensor acústico de velocidade (DVL): é um transmissor e receptor de ondas acústicas que estima a velocidade linear do veículo pelo efeito Doppler, a partir da frequência da onda refletida no leito aquático; 


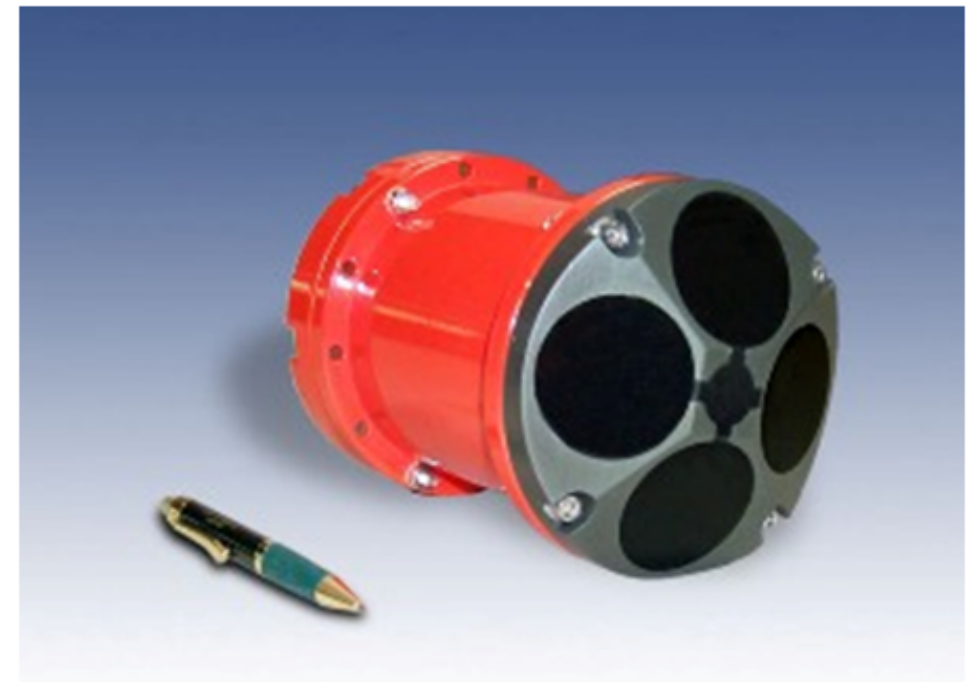

Figura 3.22 - DVL do modelo NavQuest 600 Micro. Fonte: [NAVQUEST MODELS, 2009]

- Sensor de pressão: provê a pressão exercida pela coluna d'água. Com a informação da densidade da água é possível converter esse valor para metros e por isso o sensor também é chamado de profundímetro. Como o USV só opera na superfície da água não há necessidade de um profundímetro. No entanto, para testar melhor o sistema de navegação projetado para um AUV, ter o mesmo sensor de pressão que será usado no AUV é essencial para validar o algoritmo de navegação;

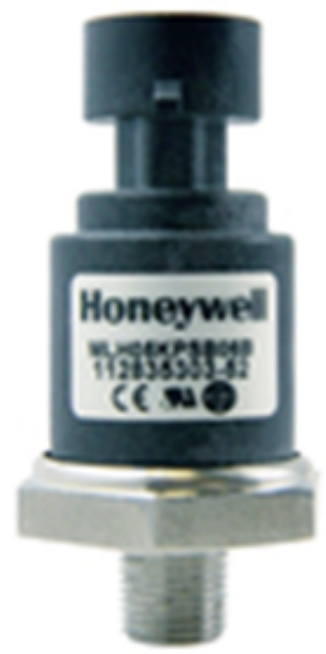

Figura 3.23 - Sensor de pressão MLH050PGB01B. Fonte: [HONEYWELL, 2016]

- Sistema de posicionamento global (GPS): disponibiliza a posição do veículo e velocidade referenciados ao WGS84, junto de informações como quantidade de satélites, data, hora e precisão estimada da posição.

A implementação do módulo de navegação foi realizada em um microcontrolador dedicado, uma vez que os algoritmos de fusão sensorial necessitam de grande capacidade 


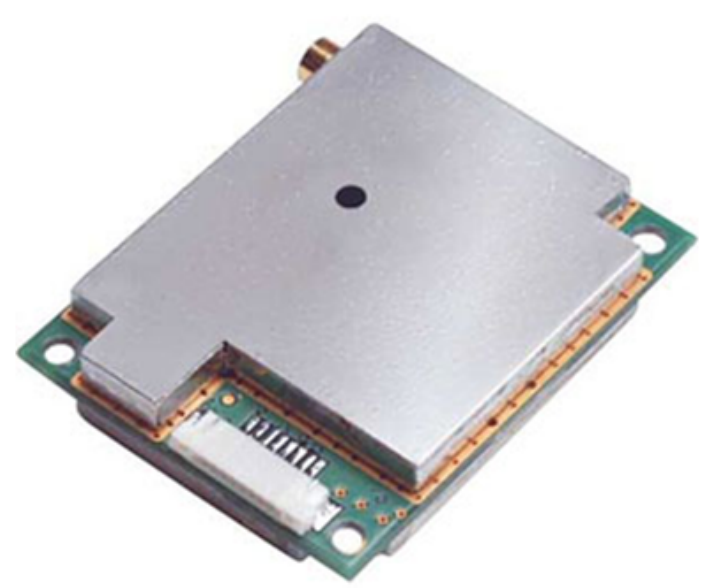

Figura 3.24 - Sistema de posicionamento global (GPS) Garmin 15xH. Fonte: [GARMIN, 2009]

computacional.

Um dos objetivos deste trabalho é produzir um veículo como plataforma de testes de navegação principalmente para algoritmos a serem implantados em AUVs que não acesso aos dados do GPS durante as manobras submersas. Desta forma, alguns algoritmos de navegação em desenvolvimento não serão os mais adequados para um USV, e por isso, ele também possui um algoritmo completo, que usa informação de todos os sensores. 


\section{Projeto naval do USV proposto}

Como foi explicado sobre a representação da Espiral de Projeto na seção 3.2, até que o projeto convirja, de fato, para a solução final que será adotada, cada etapa da espiral é realizada diversas vezes, tanto por motivos internos, como externos do projeto, como por exemplo, modificações dos requisitos básicos ou dos equipamentos embarcados.

No caso do USV deste trabalho, nas etapas iniciais a solução que havia sido considerada para o tipo de casco era de catamarã e seus requisitos, como peso da carga paga e velocidade de operação, eram diferentes. Com o desenrolar do projeto, os requisitos básicos foram mais bem definidos para aqueles listados na seção 3.1. Com isso, a solução do casco foi reavaliada e verificou-se de que havia mais vantagens no uso de um casco do tipo trimarã.

Etapas como análise da resistência ao avanço e projeto do sistema de manobras também foram revisitadas inúmeras vezes para se adequar aos requisitos básicos definidos. Por consequência, as etapas de definição das dimensões principais e do espaçamento entre os cascos também eram refeitas.

Durante o projeto do trimarã percebeu-se que a distância longitudinal dos cascos laterais tinha grande impacto nas etapas relacionadas à manobrabilidade e à resistência ao avanço, resultando em conflito de soluções, uma vez que, o aumento da distância longitudinal diminuía a resistência ao avanço, porém, aumentava o raio de giro. Por isso, fez-se a escolha pelo projeto do convés principal de forma que o veículo pudesse operar em duas configurações, com diferentes distâncias longitudinais entre os cascos. Assim, o operador pode, dependendo do tipo de missão, escolher a configuração que prioriza a manobrabilidade (diminui o raio de giro) ou a que prioriza a autonomia (diminui a resistência ao avanço).

Na subseção 3.2.1, é apresentada uma espiral de projeto adaptado para o caso do USV deste trabalho com uma ordem das etapas de projeto. Entretanto, nesta seção, considerouse necessário a alteração desta ordem para aprimorar o entendimento do projeto como um todo.

\subsection{Dimensionamento dos cascos}

Como já fora mencionado na subseção 3.3.1, a geometria dos cascos é descrita pelo plano de balizas (Figura 4.25) da série sistemática NPL apresentada em [BAILEY, 1976]. O plano de balizas representa o casco por cortes transversais por todo os comprimento da embarcação.

Dos modelos disponíveis na série sistemática NPL, os cascos do veículo deste trabalho são o 100A pois entre os disponíveis era o que apresentava um dos maiores L/B, 


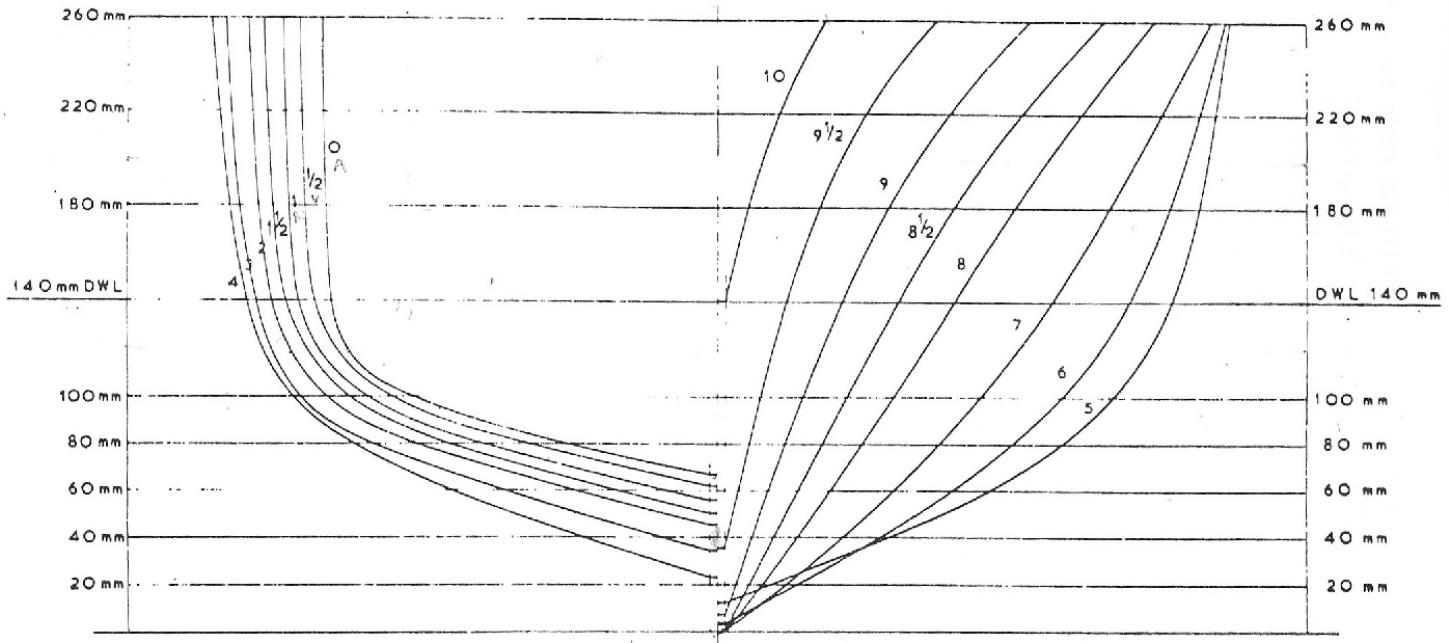

Figura 4.25 - Plano de balizas da série sistemática NPL do modelo 100A. Fonte: [BAILEY, 1976]

importante adimensional para os cascos laterias de um trimarã pois possibilita um aumento na estabilidade do veículo sem aumentar muito a resistência total. Os valores dos adimensionais de forma do modelo são mostrados na Tabela 13.

Tabela 13 - Adimensionais de forma do modelo 100A

\begin{tabular}{|c|c|}
\hline $\mathrm{L} / \mathrm{B}$ & 6,25 \\
\hline $\mathrm{B} / \mathrm{T}$ & 2,9 \\
\hline $\mathrm{T} / \mathrm{L}$ & 0,055 \\
\hline$C_{B}$ & 0,397 \\
\hline $\mathrm{M}$ & 6,59 \\
\hline
\end{tabular}

Para determinar os valores de comprimento (L), boca (B) e calado (T) de cada um dos cascos é necessário, além dos valores dos adimensionais de forma, a definição da divisão do deslocamento total entre os cascos. Para isso, fez-se uma análise de resistência total e de resistência de onda para algumas soluções possíveis apresentadas na Tabela 14.

$\mathrm{Na}$ análise de resistência total, foram usadas as equações e gráficos obtidos empiricamente de [BAILEY, 1976], que não consideram a influência entre os cascos no valor da resistência total. E, como era de se esperar, a solução mais adequada foi aquela com mais deslocamento no casco central (solução 6) já que essa solução apresenta menor área molhada, fator de grande relevância para a resistência ao avanço.

Já na análise de resistência de onda, considerando a interferência entre os cascos, fezse uso das formulações apresentadas em [DUBROVSKY; LYAKHOVITSKY, 2001] para estimar, baseado na teoria linear de ondas, a resistência para trimarãs com distribuição 
Tabela 14 - Soluções de divisão do deslocamento total entre os cascos analisadas

\begin{tabular}{|c|c|c|}
\hline Solução & Deslocamento Casco Principal (kg) & Deslocamento Casco Lateral $(\mathrm{kg})$ \\
\hline 1 & 20 & 20 \\
\hline 2 & 26 & 17 \\
\hline 3 & 32 & 14 \\
\hline 4 & 38 & 11 \\
\hline 5 & 44 & 8 \\
\hline 6 & 50 & 5 \\
\hline
\end{tabular}

arbitrária de deslocamento. A partir dessa estimativa pôde-se verificar as soluções que apresentam resistência de onda favorável, ou seja, a interferência entre as ondas geradas pelos cascos se anulam. Para a faixa de operação de Froude do veículo deste trabalho (entre 0,11 e 0,43), as soluções 5 e 6 apresentam essa interferência desfavorável.

Outro fator que foi decisivo na escolha da solução adotada foi a dimensão da boca do casco lateral. Com base nas baterias disponíveis no LVNT, utilizadas no AUV Pitajuba, foi selecionada a solução com a menor boca possível do casco lateral de forma que essas baterias pudessem ser embarcadas. Assim, o sistema de energia do veículo é instalado nos cascos laterais, e nos cascos centrais ficam os sistemas eletrônicos responsáveis pela operação do veículo e a carga paga.

Assim, levando em consideração todos esses fatores, definiu-se que o deslocamento de cada um dos cascos laterais seria de $11 \mathrm{~kg}$, e do casco central, de $38 \mathrm{~kg}$. Logo, baseado nos adimensionais mostrados na Tabela 13 obtém-se os cascos com as dimensões principais indicadas na Tabela 15.

Tabela 15 - Dimensões principais dos cascos

\begin{tabular}{|c|c||c|}
\cline { 2 - 3 } \multicolumn{1}{c|}{} & Casco central & Casco lateral \\
\hline $\mathrm{L}$ & $2200 \mathrm{~mm}$ & $1450 \mathrm{~mm}$ \\
\hline $\mathrm{B}$ & $352 \mathrm{~mm}$ & $233 \mathrm{~mm}$ \\
\hline $\mathrm{T}$ & $121 \mathrm{~mm}$ & $80 \mathrm{~mm}$ \\
\hline
\end{tabular}

Na Figura 4.26a é exibida a geometria do casco central gerada no software de CAD e CAE SolidWorks. Com essa representação 3D do casco, tarefas como posicionamento de equipamentos e projeto de estruturas do veículo são facilitadas. Na Figura 4.26b pode-se observar o casco central fabricado em fibra de vidro.

Na Figura 4.27 é possível observar a diferença de dimensões entre o casco central e os cascos laterais.

A determinação das distâncias relativas entre os cascos foi realizada através de um processo iterativo de análise das consequências na resistência ao avanço e na manobrabilidade do veículo. A distância longitudinal é a que apresenta maior influência nesses dois fatores para a faixa de velocidade considerada (entre $0,5 \mathrm{~m} / \mathrm{s}$ e $2 \mathrm{~m} / \mathrm{s}$ ): diminuir essa 


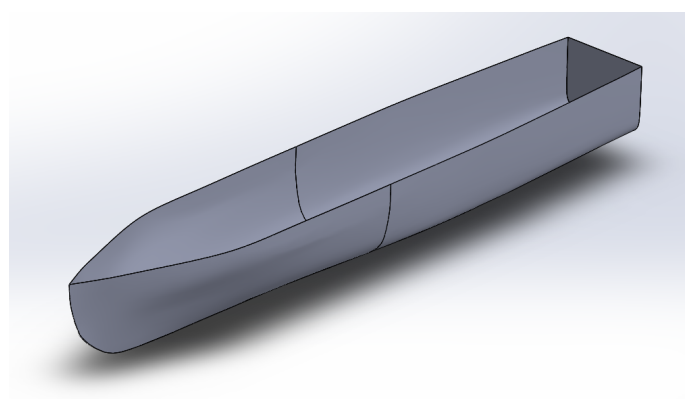

(a) Casco central representado no SolidWorks. Fonte: autor

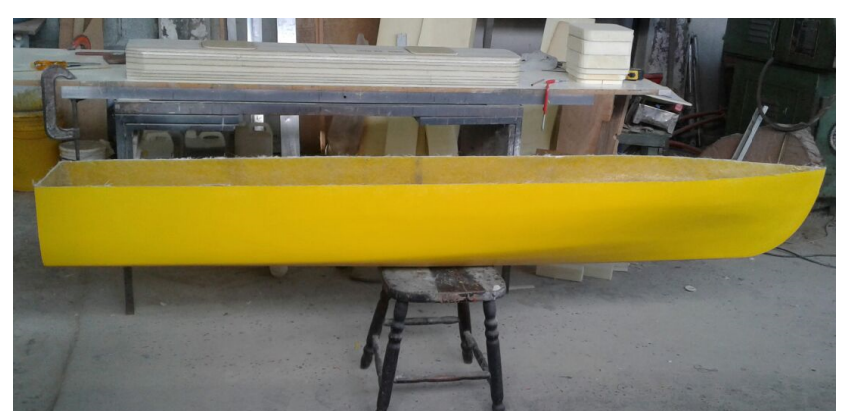

(b) Casco central fabricado em fibra de vidro. Fonte: autor

Figura 4.26 - Casco central do trimarã

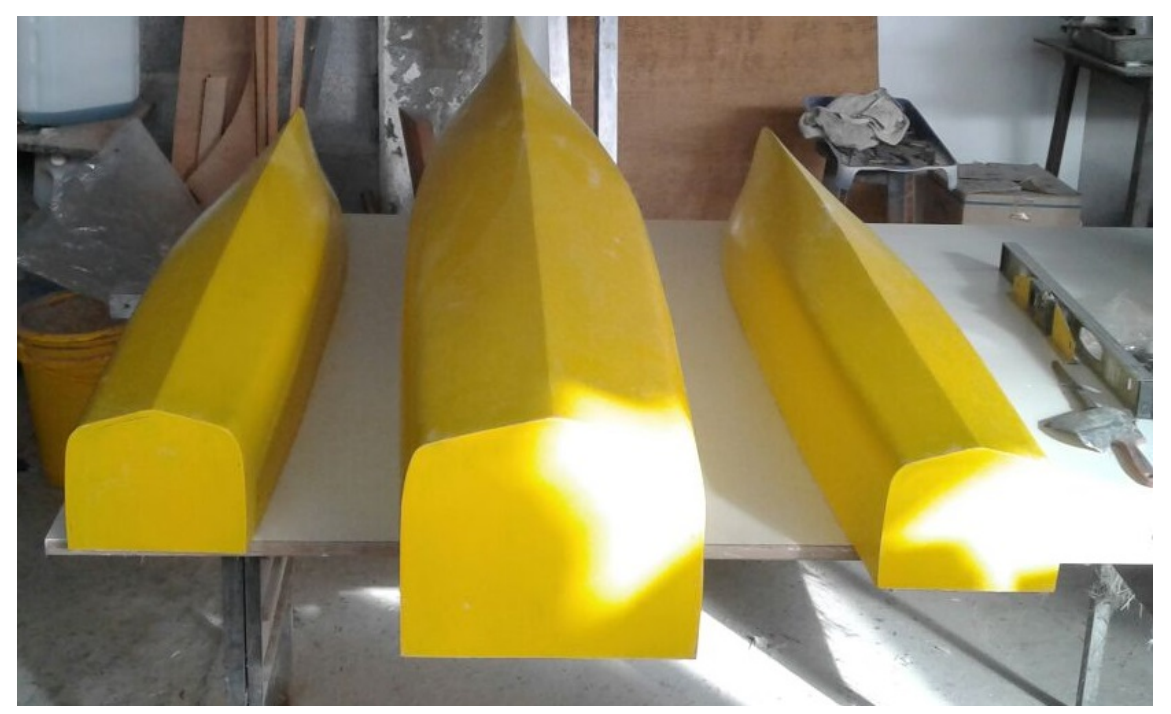

Figura 4.27 - Casco central e cascos laterais fabricados em fibra de vidro. Fonte: autor

distância melhora a manobrabilidade, no entanto, a resistência de onda aumenta. Ampliar a distância abaixa a resistência de onda, mas piora a manobrabilidade do veículo. Em síntese, os valores estabelecidos para as distâncias relativas entre os cascos são os mostrados na Tabela 16. A distância longitudinal $(\bar{a})$ corresponde ao espaçamento entre a meia nau do casco lateral e central, e a distância transversal $(\bar{b})$ ao espaçamento entre os planos de simetria do casco lateral e central.

Tabela 16 - Distância relativa entre os cascos

\begin{tabular}{|l|l|l|}
\hline Distância longitudinal & $\bar{a}=\frac{a}{L_{C E N T R A L}}=0,26$ & $\mathrm{a}=576 \mathrm{~mm}$ \\
\hline Distância transversal & $\bar{b}=\frac{b}{L_{C E N T R A L}}=0,2$ & $\mathrm{~b}=440 \mathrm{~mm}$ \\
\hline
\end{tabular}




\subsection{Análise de estabilidade}

O estudo das propriedades hidrostáticas da embarcação projetada foi realizado utilizando a definição das propriedades presentes em [LEWIS, 1988a]. Essas informações são importantes tanto na fase de projeto como durante a operação do veículo. Os gráficos das curvas hidrostáticas são todos mostrados no Apêndice A.

\subsubsection{Curvas hidrostáticas}

O Gráfico 13 apresenta a área do plano de linha d'água $\left(A_{W P}\right)$. Essa propriedade permite definir a alteração do calado para pequenas adições ou remoções de peso na embarcação.

O centro de flutuação longitudinal (LCF) é a posição longitudinal do centróide do plano de linha d'água e esta mostrado no Gráfico 14 presente no Apêndice A. A adição de massa, relativamente pequena, nessa posição não produz alteração no trim da embarcação.

A altura do centro de carena $(\overline{K B})$ é a distância vertical entre o centro de carena (centro de gravidade do volume de água deslocada) e a linha base (quilha). Essa propriedade é apresentada no Gráfico 15.

O raio metacêntrico transversal $\left(\overline{B M}_{T}\right)$ é a distância entre o centro de carena e o metacentro transversal e o raio metacêntrico longitudinal $\left(\overline{B M}_{L}\right)$ é a distância entre o centro de carena e o metacentro transversal. Eles são calculados através da Equação 4.1 e da Equação 4.2, onde $I_{T}$ é o momento de inércia transversal do plano de linha d'água e $I_{L}$ é o momento de inércia longitudinal do plano de linha d'água.

$$
\begin{aligned}
& \overline{B M}_{T}=\frac{I_{T}}{\nabla} \\
& \overline{B M}_{L}=\frac{I_{L}}{\nabla}
\end{aligned}
$$

O Gráfico 16 e o Gráfico 17 apresentam, respectivamente, o raio metacêntrico transversal e longitudinal do veículo em função do calado. Essas propriedades são úteis para avaliar a estabilidade da embarcação.

O Gráfico 18 mostra o deslocamento em kg da embarcação em função do calado.

O centro de carena longitudinal (LCB) é a posição longitudinal do centro de massa do volume deslocado de água. O centro de carena longitudinal do veículo pode ser visto no Gráfico 19.

O Gráfico 20 apresenta a área molhada de toda embarcação, enquanto que o Gráfico 21 e o Gráfico 22 são, respectivamente, a área molhada do casco central e do casco lateral. Essa informação é importante tanto no cálculo da resistência ao avanço como para as características de manobrabilidade. 


\subsubsection{Análise das curvas hidrostáticas}

A partir dos dados anteriores apresentados no Apêndice A, chega-se a conclusão que a embarcação apresenta estabilidade tanto transversal como longitudinal, uma vez que as somas $\overline{K B}+\overline{B M}_{T}$ e $\overline{K B}+\overline{B M}_{L}$ apresentam valores relativamente altos, portanto, a altura metacêntrica transversal $\left(\overline{G M}_{T}\right)$ e a altura metacêntrica longitudinal $\left(\overline{G M}_{L}\right)$ apresentarão valores positivos, já que estes são calculados pela Equação 4.3 e pela Equação 4.4, onde $\overline{K G}$ é a altura do centro de gravidade da embarcação.

$$
\begin{aligned}
& \overline{G M}_{T}=\overline{K B}+\overline{B M}_{T}-\overline{K G} \\
& \overline{G M}_{L}=\overline{K B}+\overline{B M}_{L}-\overline{K G}
\end{aligned}
$$

Os Gráfico 23 e Gráfico 24 apresentam estimativas conservadoras do $\overline{G M}_{T}$ e do $\overline{G M}_{L}$ supondo o valor de $\overline{K G}$ sendo igual ao pontal da embarcação para a primeira volta da espiral. Com o desenvolvimento do projeto, foi possível melhorar a estimativa do valor do $\overline{K G}$ após as informações sobre centros e pesos dos equipamentos e sistemas eletrônicos embarcados.

\subsection{Análise estrutural do veículo}

A resistência estrutural foi separada em duas partes: a primeira, relativa aos cascos individualmente, e a segunda, focada no convés que une o casco principal aos cascos laterais. Com relação a primeira parte, esta foi realizada com o auxílio de referências de sociedades classificadoras com algumas modificações sempre no sentido de tornar o projeto do veículo mais conservador possível. Já a segunda, foram consultadas referências de sociedades classificadoras mas, devido à particularidade da geometria e de como seria feita a manufatura, a análise estrutural foi baseada em cálculos de resistência dos materiais e mecânica dos sólidos.

\subsubsection{Critério para disposição das anteparas}

A disposição das anteparas foi realizada priorizando a compartimentagem dos equipamentos e sistemas eletrônicos que seriam embarcados. No caso do casco central, a necessidade de instalar o sensor Doppler, impôs, por motivos de segurança, duas anteparas próximas que separariam o DVL (em contato com a água) dos outros equipamentos. A presença do leme no casco central também impôs uma antepara de segurança a ré. Com relação às outras anteparas do casco central, estas foram dispostas de forma a possibilitar a separação entre sistemas eletrônicos essenciais ao veículo da carga paga.

A partir dessas informações, verificou-se a viabilidade estrutural de tal configuração de anteparas baseado em sociedades classificadoras, cujas informações mais detalhadas são 
apresentadas na subseção 4.3.2. Para manter uma continuidade estrutural, foi decidido que as anteparas dos cascos laterais ficariam dispostas nas mesmas posições longitudinais das anteparas do casco central.

Com a disposição das anteparas estabelecidas, fez-se, em seguida, o projeto do convés principal, responsável pela conexão estrutural dos cascos. Durante o projeto do convés, percebeu-se que, com algumas modificações, o convés poderia ser manufaturado de maneira a possibilitar duas configurações, com distâncias longitudinais entre os cascos diferentes. Desta forma, uma configuração priorizaria a diminuição do raio de giro e a outra a diminuição da resistência ao avanço.

\subsubsection{Análise estrutural dos cascos}

A solução disponível para manufatura dos cascos que apresentava melhor custo-benefício para o LVNT foi de fibra de vidro. A partir disso, foram consultadas referências de sociedades classificadoras que fossem referentes a fabricação em fibra de vidro. Com relação às sociedades classificadoras utilizadas, vale lembrar que estas tem como escopo cascos de lazer em fibra, e por isso, alguns dos resultados obtidos tiveram que ser adaptados para a situação de um USV uma vez que os resultados obtidos pelas sociedades classificadoras para as dimensões das estruturas eram relativamente baixos, impossíveis de serem adotados para manufatura.

Uma das primeiras estimativas realizadas pelas sociedades classificadoras é referente às propriedades mecânicas da fibra de vidro em função da razão entre a massa de reforçadores no laminado e a massa total.

A Tabela 17 apresenta os cálculos das propriedades mecânicas de [LLOYDS, 2008], em MPa, em que $f_{c}$ é razão da massa de reforçadores sobre a massa total do laminado, para valores entre 0,4 e 0,7. Fora dessa faixa são analisados de forma diferente.

Tabela 17 - Cálculos das propriedades mecânicas de [LLOYDS, 2008]. Fonte: adaptado de [LLOYDS, 2008]

\begin{tabular}{|l|l|}
\hline Propriedades mecânicas & $\mathrm{N} / \mathrm{mm}^{2}$ \\
\hline Módulo de elasticidade longitudinal & $\left(50,5 f_{c}-6,87\right) \cdot 10^{3}$ \\
Módulo de elasticidade transversal & $\left(19,6 f_{c}^{2}-15,7 f_{c}+6,6\right) \cdot 10^{3}$ \\
Módulo de cisalhamento no plano & $\left(7,3 f_{c}^{2}-5,9 f_{c}+2,4\right) \cdot 10^{3}$ \\
Resistência à tração longitudinal & $656 f_{c}-89,3$ \\
Resistência à compressão longitudinal & $530 f_{c}-72,1$ \\
Resistência à tração transversal & $68,4 f_{c}^{2}-55 f_{c}+23$ \\
Resistência à compressão transversal & $196 f_{c}^{2}-157 f_{c}+65,6$ \\
Resistência ao cisalhamento no plano & $73,4 f_{c}^{2}-59,2 f_{c}+24,5$ \\
\hline
\end{tabular}

Já a Tabela 18 mostra os cálculos das propriedades mecânicas de [INA, 1994], em $\mathrm{MPa}$, em que $G_{c}$ tem a mesma definição de $f_{c}$. Na coluna numerada 2, são mostrados os 
valores mínimos, correspondentes a $G_{c}=0,3$.

Tabela 18 - Cálculos das propriedades mecânicas de [RINA, 1994]. Fonte: adaptado de [RINA, 1994]

\begin{tabular}{|cll|c|}
\hline & & 1 & 2 \\
\hline$R_{m}$ & Resistência à tração & $1278 G_{c}^{2}-510 G_{c}+123$ & 85 \\
$E$ & Módulo de elasticidade à tração & $\left(37 G_{c}-4,75\right) \cdot 10^{3}$ & 6350 \\
$R_{m c}$ & Resistência à compressão & $150 G_{c}+72$ & 117 \\
$E_{c}$ & Módulo de elasticidade à compressão & $\left(40 G_{c}-6\right) \cdot 10^{3}$ & 6000 \\
$R_{m f}$ & Resistência à flexão & $\left(502 G_{c}^{2}+107\right)$ & 152 \\
$E_{f}$ & Módulo de elasticidade de flexão & $\left(33,4 G_{c}^{2}+2,2\right) \cdot 10^{3}$ & 5200 \\
$R_{m t}$ & Resistência ao cisalhamento & $80 G_{c}+38$ & 62 \\
$G$ & Módulo de cisalhamento de elasticidade & $\left(1,7 G_{c}+2,24\right) \cdot 10^{3}$ & 2750 \\
$R_{m t i}$ & Resistência ao cisalhamento interlaminar & $22,5-17,5 G_{c}$ & 17 \\
\hline
\end{tabular}

Os valores das propriedades mecânicas do laminado de fibra de vidro utilizado neste trabalho foi o da Tabela 17 pois este apresentava menores valores, logo, os resultados foram mais conservadores. Além disso, para estimativa do dimensionamento da quilha, do convés inferior e das anteparas, foram usados os seguintes cálculos como base, obtidos de [RINA, 1994] pois apresentavam os resultados mais conservadores.

\subsubsection{Carregamentos}

Em [RINA, 1994], a forma de calcular os carregamentos é dividido em cascos de deslocamento e de planeio ou semi-planeio. Para este trabalho, foram usadas as formulações para cascos de deslocamento.

Com relação à pressão de projeto, ela é calculada pela Equação 4.5, em em kN/m².

$$
p=0,24 \cdot L^{0,5} \cdot \frac{2 \cdot T-h_{0}}{2 \cdot T}+10 \cdot\left(h_{0}+a \cdot L\right)
$$

Em que, $L$ é o comprimento do casco, $T$ é o calado, $h_{0}$ é a distância vertical com relação ao ponto de referência do painel que esta sendo analisado e $a$ é um coeficiente em função da posição longitudinal do ponto de referência do painel que esta sendo analisado.

\subsubsection{Quilha}

O comprimento da quilha deve ser de toda extensão do casco com largura mínima calculada em Equação 4.6 em milímetros, onde L é o comprimento, em metros, do casco.

$$
b_{C H}=30 . L
$$


$\mathrm{Na}$ Equação 4.7, $t_{C H}$ é a espessura mínima da quilha em milímetros, em que $t_{b}$ é o menor valor entre $t_{1}$ e $t_{2}$, obtidos pelas Equação 4.8 e Equação 4.9.

$$
\begin{gathered}
t_{C H}=1,4 \cdot t_{b} \\
t_{1}=k_{1} \cdot k_{a} \cdot s \cdot k_{o f} \cdot p^{0,5} \\
t_{2}=16 . s \cdot k_{o f} \cdot D^{0,5}
\end{gathered}
$$

Em que, $k_{1}$ é um coeficiente relativo às cargas no casco devido à pressão hidrostática, $k_{a}$ um coeficiente em função da razão entre tamanho dos painéis e do intervalo entre enrijecedores, s é o intervalo entre enrijecedores transversais ou longitudinais, em metros, $k_{o f}$ é um coeficiente relativo à propriedade mecânica do laminado de fibra, $p$ é a pressão de projeto, em kN/m², calculado em Equação 4.5.

\subsubsection{Convés inferior}

Em [RINA, 1994], são apresentados os cálculos referentes ao valor mínimo que o módulo de cada seção deve apresentar com relação à linha de centro. Na Equação 4.10 é mostrado o cálculo para o convés inferior, e, na Equação 4.11 para os enrijecedores longitudinais, responsáveis por suportar o convés inferior.

$$
\begin{array}{r}
Z_{M}=k_{1} \cdot b \cdot S^{2} \cdot k_{0} \cdot p \\
Z_{P C}=k_{1} \cdot b_{P C} \cdot S^{2} \cdot k_{0} \cdot p
\end{array}
$$

Em que, $b$ é metade da distância, em metros, dos conveses inferiores adjacentes ao analisado, $B_{P C}$ é metade da distância, em metros, entre os enrijecedores laterais, $S$ é a distância, em metros, entre os membros que suportam o convés inferior (no caso, os enrijecedores),

\subsubsection{Anteparas}

Com relação às anteparas, a Equação 4.12, de [RINA, 1994], apresenta a espessura mínima.

$$
t_{B}=k_{1} \cdot s \cdot k_{o f} \cdot h^{0,5}
$$

Em que, $s$ é o espaçamento entre os enrijecedores, em metros, e $h$ é um coeficiente em função do tipo de antepara. 


\subsubsection{Resultados da análise estrutural dos cascos}

Nas seções anteriores, foram apresentados os cálculos das estruturas dos cascos. A partir disso, em conjunto com o responsável pela manufatura dos cascos, foram estipuladas as dimensões das estruturas. Em alguns casos, foram utilizados os valores obtidos nos cálculos, enquanto que, em outros, foram usados valores mais conservadores para possibilitar a manufatura destas estruturas em fibra de vidro.

\subsubsection{Análise estrutural do convés principal}

A solução adotada para o convés do veículo foi de uma placa de fibra de vidro com suportes para fixação dos painéis solares como esquematizado na Figura 4.28. A fixação dos cascos seria realizada com parafusos nos cascos na posição longitinal das anteparas, e com furações no convés, de forma a possibilitar o deslocamento longitudinal dos cascos laterais.

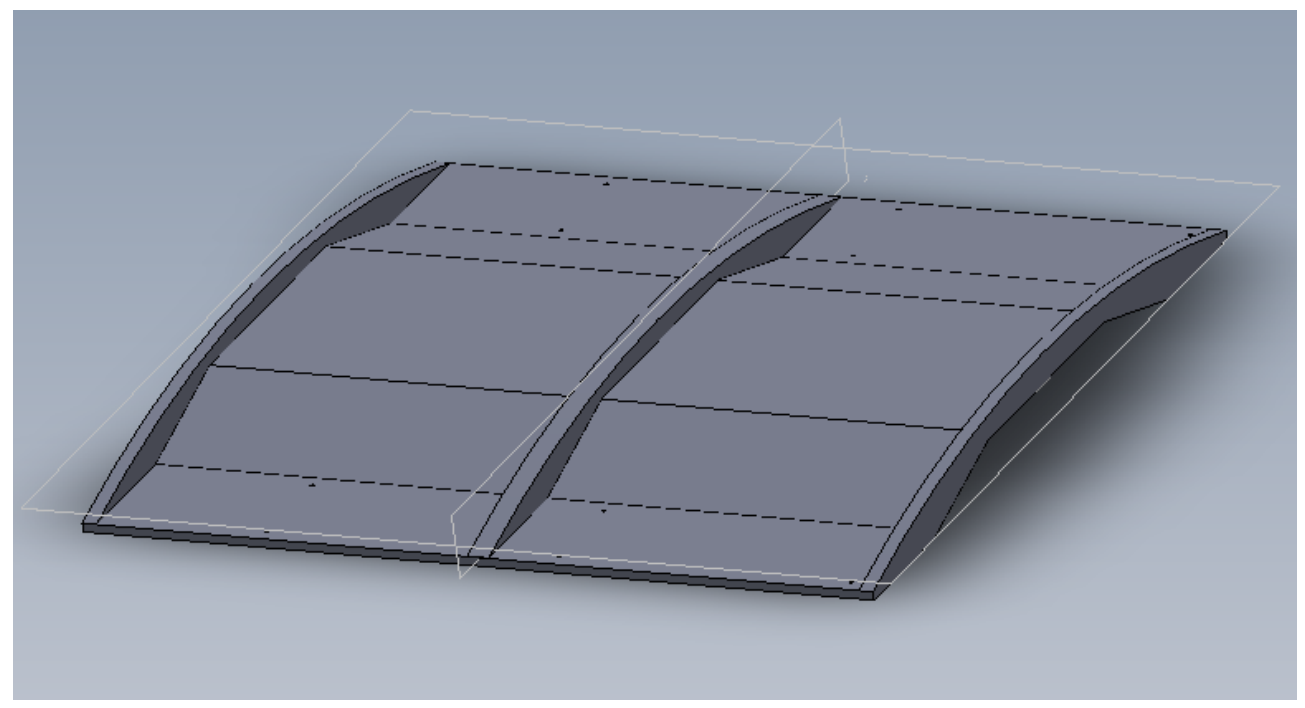

Figura 4.28 - Esquemático do convés. Fonte: autor

A Figura 4.29 apresenta, a esquerda da imagem, a configuração do convés com distância longitudinal entre os cascos de $470 \mathrm{~mm}(\bar{a}=0,21)$ e distância transversal de 440 mm $(\bar{a}=0,2)$, sendo que as linhas tracejadas mostram a posição das anteparas, e as letras A, B e C quais são as anteparas que estão sendo usadas para fixação do convés. A mesma Figura 4.29 apresenta, a direita da imagem, a configuração do convés com distância longitudinal entre os cascos de $880 \mathrm{~mm}(\bar{a}=0,4)$ e distância transversal de $440 \mathrm{~mm}$ $(\bar{a}=0,2)$, sendo que as linhas tracejadas mostram a posição das anteparas, e as letras A, B e C quais são as anteparas que estão sendo usadas para fixação do convés.

A partir das configurações, foram realizados os gráficos dos carregamentos, da cortante e do momento fletor para os dois piores casos possíveis: carregar o veículo apenas pelo casco central ou pelos cascos laterais. No Apêndice B são apresentados esses diagramas para cada um dos casos em cada uma das configurações. 

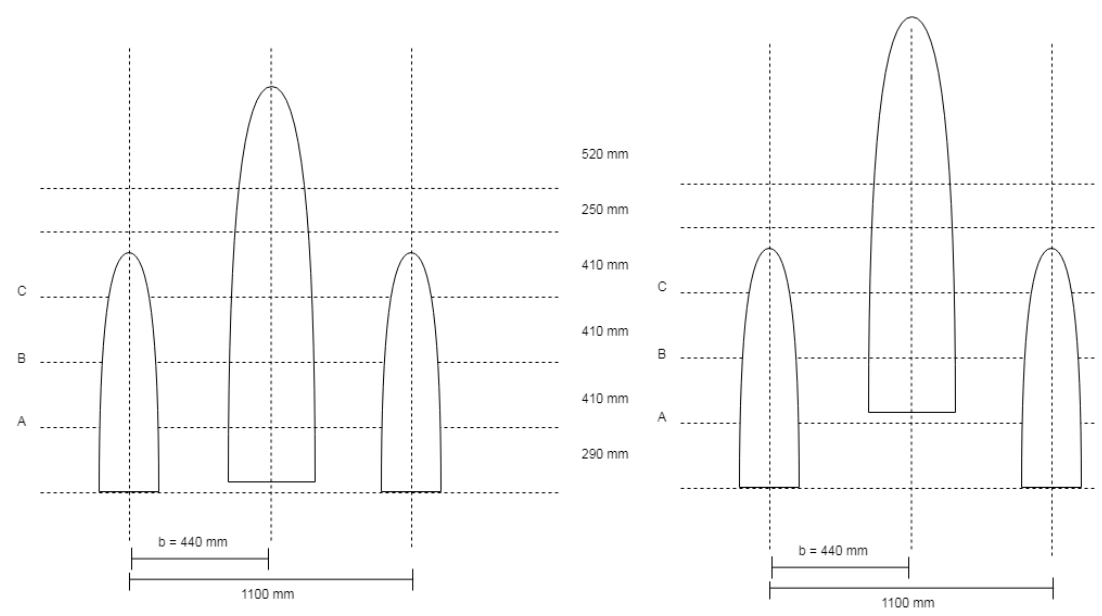

Figura 4.29 - Configuração do convés com $\bar{a}=0,21$ a esquerda e com $\bar{a}=0,4$ a direita. Fonte: autor

Com os esforços relativos às piores situações possíveis de carregamento, fez-se, em seguida, a análise da resistência estrutural de um painel sanduíche, que é composto por três camadas: duas camadas finas com material denso, separadas por uma camada intermediária de baixa densidade. Neste trabalho, as camadas densas são de fibra de vifro, enquanto que o núcleo de espuma.

No painel sanduíche, a rigidez de flexão aumenta com o acréscimo da espessura do núcleo. De [ALMEIDA, 2009], a teoria das vigas pode ser adaptada às vigas sanduíches, cujas dimensões são mostradas na Figura 4.30.
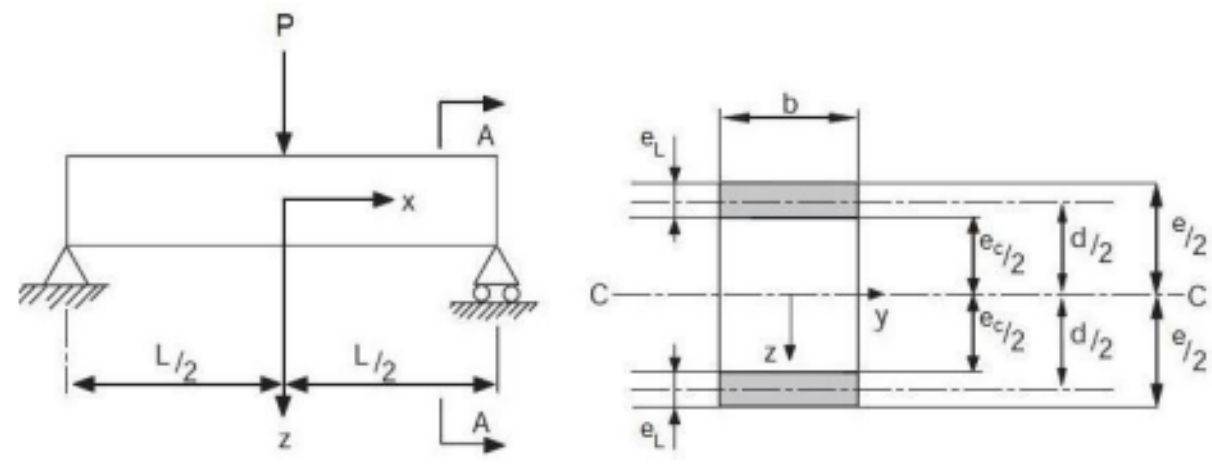

Figura 4.30 - Dimensões da viga sanduíche e corte AA à direita. Fonte: [ALMEIDA, 2009]

Pela teoria das vigas, a rigidez de flexão é o produto entre o módulo de elasticidade e o momento de inércia. Na viga sanduíche, a rigidez de flaxão é a soma da rigidez de cada elemento que a constitui, com relação ao eixo centroidal da seção. Para o caso deste trabalho, foi considerada uma viga sanduíche retangular, logo, a rigidez total pode ser 
calculada pela Equação 4.13.

$$
D=E_{L} \cdot \frac{b \cdot e_{L}^{3}}{6}+E_{L} \cdot \frac{b \cdot e_{L} \cdot d^{2}}{2}+E_{C} \cdot \frac{b \cdot e_{C}^{3}}{12}
$$

Em que, $D$ é a rigidez de flexão da viga, $E_{L}$ o módulo de elasticidade do material das lâminas, $E_{C}$ o módulo de elasticidade do material do núcleo, $b$ a largura da viga, $e_{L}$ a espessura das lâminas, $e_{C}$ a espessura do núcleo e $d$ a distância entre os centros das lâminas. A Equação 4.13 pode ser dividida em três termos, em que o primeiro corresponde à rigidez de flexão das lâminas com relação ao próprio centróide e o segundo à trasposição da rigidez da lâmina para o centróide da seção. Já o terceiro termo corresponde à rigidez de flexão do núcleo com relação ao próprio centróide que coincide com o da seção.

Neste trabalho, o primeiro termo foi desprezado pois, de [ALMEIDA, 2009], esse termo corresponde a menos de $1 \%$ do segundo quando $d / e_{L}>5,77$. O terceiro termo também foi desprezado pois este correponde a menos de $1 \%$ do segundo quando a condição 4.14 é satisfeita.

$$
D=\frac{E_{L} \cdot e_{L} \cdot d^{2}}{E_{C} \cdot e_{C}^{3}}>16,7
$$

Desta forma, o cálculo da tensão axial nas lâminas é dado pela Equação 4.15, em que $M$ é o momento fletor e $z$ a distância do ponto ao centróide da seção.

$$
\sigma=\frac{M \cdot z \cdot E_{L}}{D}
$$

E a tensão de cisalhamento pela Equação 4.16, em que $V$ é o esforço cortante e $S$ o momento estático do elemento.

$$
\tau=\frac{V \cdot S \cdot E_{L}}{D . b}
$$

\subsection{Cálculo da resistência ao avanço}

A estimativa da resistência ao avanço total do veículo foi obtida pela soma das resistências de cada casco, calculadas com os dados e as formulações presentes em [BAILEY, 1976]. Desta forma, não é considerada a interferência entre os cascos na resistência de onda. No entanto, pela análise de resistência de onda obteve-se que, para a distância longitudinal definida, a interferência é favorável. Assim, usar a estimativa sem influência entre os cascos é uma atitude mais conservadora.

A resistência total pode ser dividida em friccional e residual conforme a Equação 4.17.

$$
R_{T}=R_{F}+R_{R}
$$

O Gráfico 3 é da resistência residual em função do $M$, razão entre comprimento e deslocamento da embarcação deste trabalho, e do $F_{\nabla}$, número de Froude volumétrico, 
para o valor de 6,25 de L/B. Os valores de L/B e M já foram definidos na seção 4.1 na Tabela 13, e $F_{\nabla}$ é calculado pela Equação 4.18 , onde $\mathrm{V}$ é a velocidade em nós e $\Delta$ é o deslocamento em toneladas. O número de Froude é um adimensional importante no projeto de embarcações pois a resistência total da embarcação pode ser dividida em duas parcelas, a de friccional, dependente do número de Reynolds, e a residual, relativa ao número de Froude [NEWMAN, 2018].

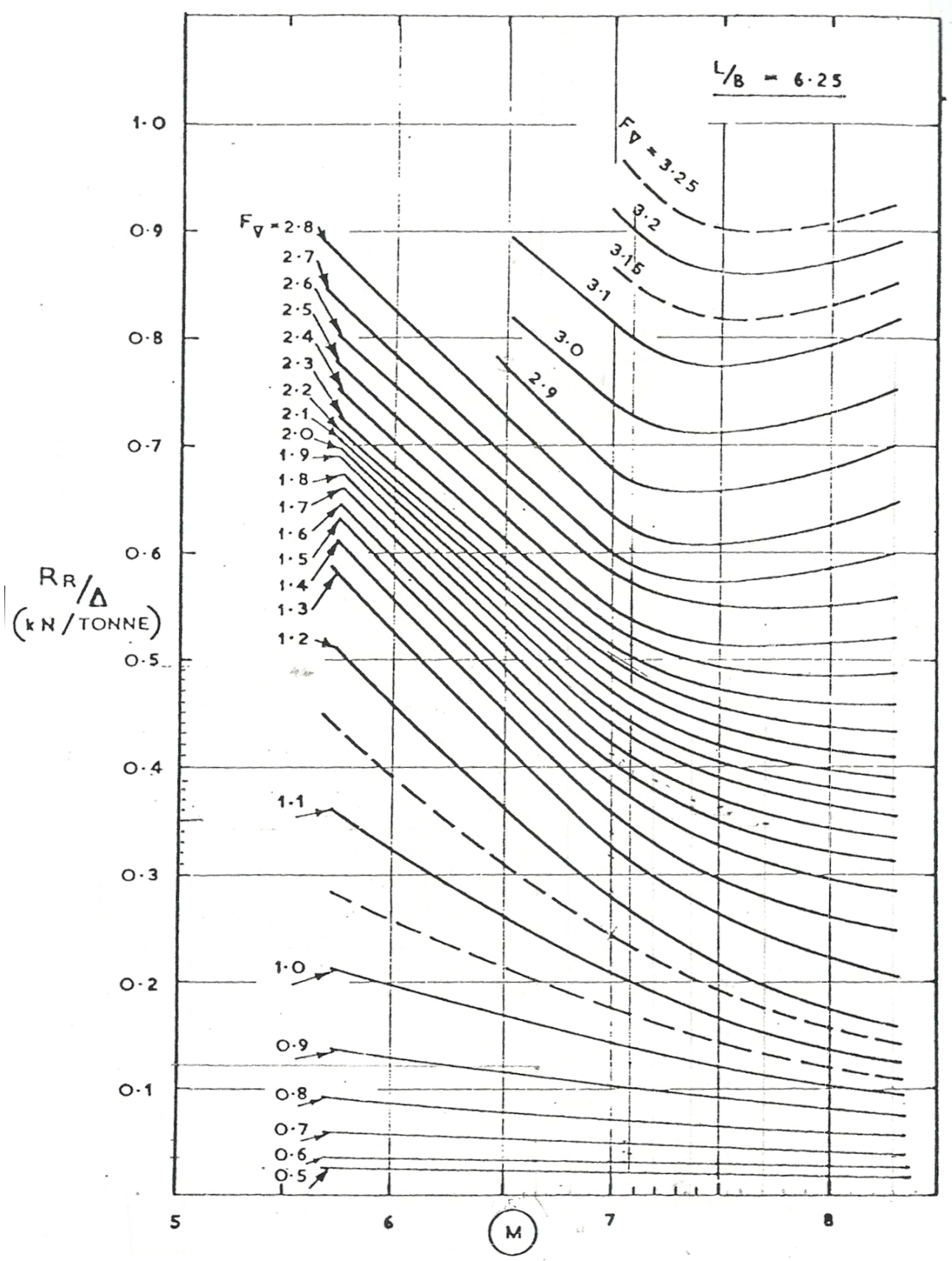

Gráfico 3 - Resistência residual. Fonte: [BAILEY, 1976]

$$
F_{\nabla}=\frac{0,165 V}{\Delta^{1 / 6}}
$$


A Tabela 19 apresenta os valores obtidos pelo gráfico e pelas equações descritas previamente.

Tabela 19 - Valores para calcular a resistência residual

\begin{tabular}{|c|c|c|}
\cline { 2 - 3 } \multicolumn{1}{c|}{} & Casco central & Casco lateral \\
\hline$F_{\nabla}$ & 1,1063 & 1,3602 \\
\hline$R_{R} / \Delta$ & $0,259 \mathrm{~N} / \mathrm{kg}$ & $0,418 \mathrm{~N} / \mathrm{kg}$ \\
\hline $\mathbf{R}_{\mathbf{R}}$ & $\mathbf{9 , 8 5} \mathbf{N}$ & $\mathbf{4 , 6 0} \mathbf{N}$ \\
\hline
\end{tabular}

Assim como em [ZHANG, 1997], a resistência friccional é calculada para a velocidade de $2 \mathrm{~m} / \mathrm{s}$ a partir da formulação proveniente da ITTC 1957, mostrada na Equação 4.19, onde o coeficiente da resistência friccional depende do número de Reynolds.

$$
C_{F}=\frac{0,075}{\left(\log _{10} R_{N}-2\right)^{2}}
$$

Pela Equação 4.20 é possível calcular a resistência friccional em função do coeficiente de resistência friccional, da densidade da água, da velocidade da embarcação e da área molhada do veículo.

$$
R_{F}=0,5 C_{F} \rho A V^{2}
$$

Nas primeiras voltas da Espiral de Projeto, quando não havia representação CAD dos cascos, a área molhada era obtida pela Equação 4.21 que utiliza um valor proveniente do Gráfico 4. Para a embarcação com as dimensões descritas neste trabalho, usou-se 1,04 $\mathrm{m}^{2}$ como valor do Gráfico 4. Desta forma, a estimativa da área molhada do casco central foi de $0,77 \mathrm{~m}^{2}$ e do casco lateral é de $0,34 \mathrm{~m}^{2}$.

$$
A=(\text { Valor do gráfico })\left(\frac{L}{2,54}\right)^{2}
$$

Com a evolução do projeto, fez-se a representação tridimensional dos cascos em CAD e, por conseguinte, as propriedades hidrostáticas do veículo puderam ser obtidas de forma precisa. Uma destas propriedades é a área molhada dos cascos em função do calado. Logo, estima-se que a área molhada do casco central é de $0,76 \mathrm{~m}^{2}$ e do casco lateral de 0,33 $\mathrm{m}^{2}$ a partir do Gráfico 21 e do Gráfico 22. As estimativas das áreas molhadas pela Equação 4.21 e pelo Gráfico 4 apresentam valores maiores e, portanto, o valores de resistência friccional calculados com base neles são mais conservadores.

Desta forma, observa-se pela Tabela 20 os valores usados para calcular a resistência friccional.

Com cada uma das parcelas de resistência de cada casco calculada, pode-se determinar a resistência total da embarcação pela Equação 4.24. Este valor é apresentado na Tabela 21. 


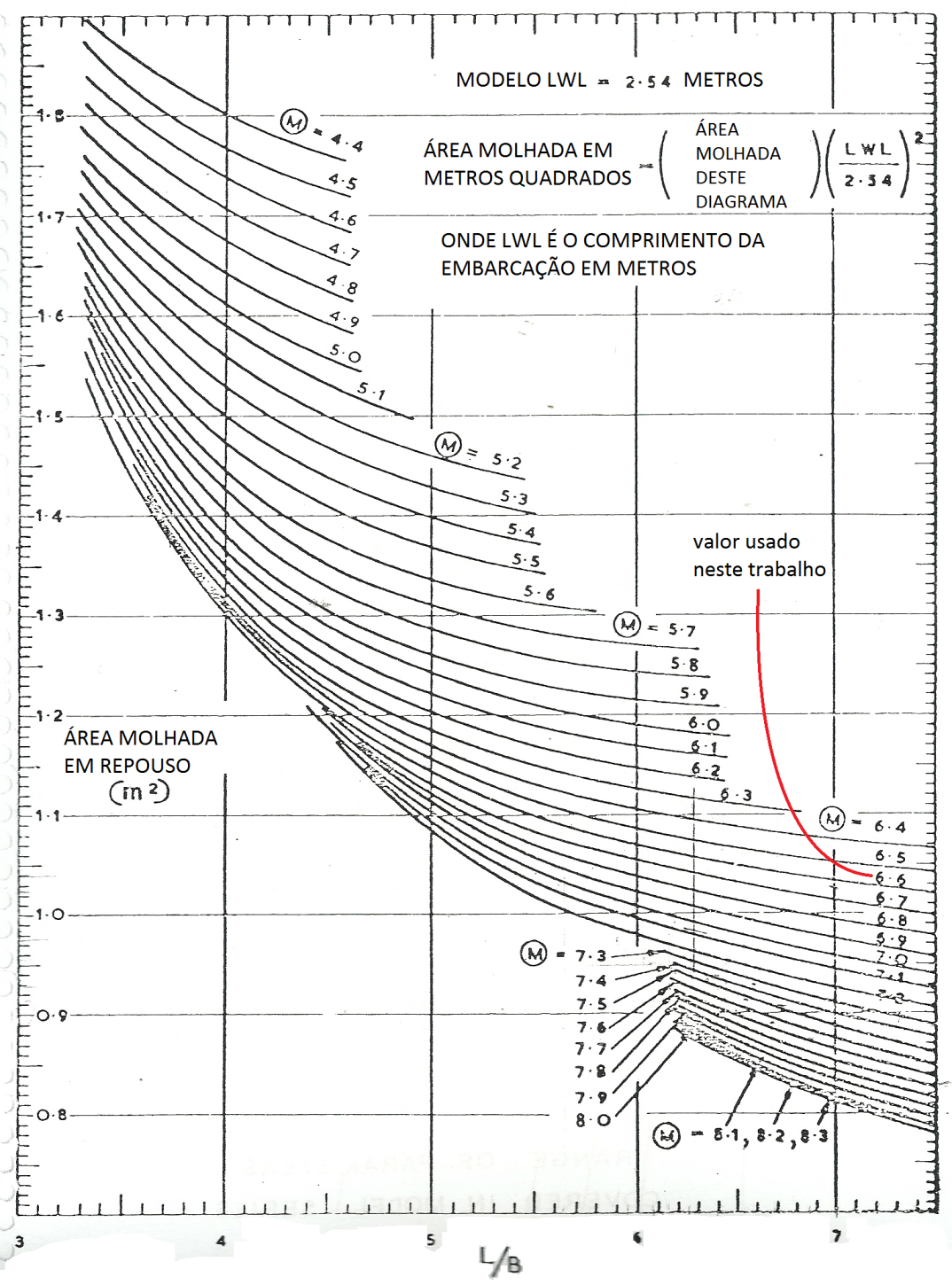

Gráfico 4 - Área Molhada. Fonte: adaptado de [BAILEY, 1976]

Tabela 20 - Valores para calcular a resistência friccional

\begin{tabular}{|c|c||c|}
\cline { 2 - 3 } \multicolumn{1}{c|}{} & Casco central & Casco lateral \\
\hline$C_{F}$ & 0,00359 & 0,00389 \\
\hline Área molhada & $0,77 \mathrm{~m}^{2}$ & $0,34 \mathrm{~m}^{2}$ \\
\hline $\mathbf{R}_{\mathbf{F}}$ & $\mathbf{5 , 6 0} \mathbf{N}$ & $\mathbf{2 , 6 5} \mathbf{N}$ \\
\hline
\end{tabular}

$$
\begin{array}{r}
\left(R_{T}\right)_{\text {CENTRAL }}=\left(R_{R}\right)_{\text {CENTRAL }}+\left(R_{F}\right)_{\text {CENTRAL }} \\
\left(R_{T}\right)_{\text {LATERAL }}=\left(R_{R}\right)_{\text {LATERAL }}+\left(R_{F}\right)_{\text {LATERAL }} \\
R_{T}=\left(R_{T}\right)_{\text {CENTRAL }}+2\left(R_{T}\right)_{\text {LATERAL }}
\end{array}
$$


Tabela 21 - Resistência total do veículo

\begin{tabular}{|c|c|}
\cline { 2 - 2 } \multicolumn{1}{c|}{} & Resistência total \\
\hline Casco central & $15,4 \mathrm{~N}$ \\
\hline Cada casco lateral & $7,25 \mathrm{~N}$ \\
\hline Trimarã & $\mathbf{2 9 , 9} \mathbf{~ N}$ \\
\hline
\end{tabular}

\subsection{Integração casco-hélice-motor}

$\mathrm{Na}$ etapa de integração casco-hélice-motor fez-se uma estimativa do sistema propulsivo do veículo utilizando os dados de resistência ao avanço obtidos na seção 4.4 pelas formulações empíricas presentes em [BAILEY, 1976] para cascos da série NPL.

Em etapas iniciais da Espiral de Projeto, fora considerado a possibilidade de instalação de hélices de nautimodelismo pela praticidade. Entretanto, para esse tipo de hélice, dificilmente encontra-se informações confiáveis do seu desempenho. Além disso, atualmente o LVNT possui acesso a prototipadoras 3D capazes de fabricar geometrias complexas, porém, os materiais utilizados não apresentam resistência compatíveis com as aplicações do laboratório. No entanto, apesar dos problemas do material, foi priorizada a solução de produzir os hélices em impressoras 3D pois isso permitia a seleção da geometria mais adequada às missões do veículo. Desta forma, a integração casco-hélice-motor foi realizada considerando hélices da família BTroost que apresentam diversos gráficos do empuxo e torque gerados pelo propulsor em função da condição de operação.

\subsubsection{Projeto do hélice}

Neste trabalho, o projeto do hélice foi realizado a partir das curvas de empuxo e torque dos hélices da família BTroost. Com essas curvas é possível determinar a condição de operação, ou seja, a rotação para que, na velocidade de serviço, o veículo produza empuxo com a mesma intensidade da resistência ao avanço. Para isso, é preciso igualar o adimensional de empuxo do hélice $\left(K_{T}\right)$ ao adimensional do empuxo necessário para movimentar a embarcação $\left(\left(K T_{T}\right)_{C A S C O}\right)$, e verificar o ponto de operação $(\mathrm{J})$ correspondente a essa igualdade. A partir da definição do ponto de operação, obtém-se o adimensional de torque $\left(K_{Q}\right)$ e a eficiência em água aberta do hélice $\left(\eta_{p_{0}}\right)$. O cálculo dos adimensionais descritos previamente são apresentados pelas equações $\underline{4.25}, \underline{4.26}$ e $\underline{4.27}$. O objetivo do projeto é conseguir o hélice com maior eficiência e que não apresente cavitação.

$$
\begin{aligned}
K_{T} & =\frac{T}{\rho N^{2} D^{4}} \\
K_{Q} & =\frac{Q}{\rho N^{2} D^{5}}
\end{aligned}
$$




$$
J=\frac{V_{a}}{N D}
$$

\subsubsection{Obtenção da geometria do hélice}

A Equação 4.28 mostra o cálculo do adimensional do empuxo necessário para movimentar a embarcação, em que MR é margem de resistência, e t e w são, respectivamente, o fator de redução da resistência e o coeficiente de esteira, sendo que, de [BAILEY, 1976], tem-se que $t=0,1$ e $w=0$.

$$
\left(K_{T}\right)_{C A S C O}=\frac{R_{T}(1+M R)}{(1-t) \rho V_{S}^{2}(1-w)^{2}\left(D_{H E L I C E}\right)^{2}} J^{2}
$$

Com relação às curvas de desempenho dos hélices, para a família BTroost, elas foram interpoladas em função da geometria e da condição de operação como mostram as equações $\underline{4.29}, \underline{4.30}$ e $\underline{4.31}$. Os valores de $C_{n}, s_{n}, t_{n}, u_{n}$ e $v_{n}$ foram obtidos de [CARLTON, 2012], e $\mathrm{Z}$ é o número de pás, $\mathrm{P} / \mathrm{D}$ a razão entre o passo e o diâmetro e $A_{E} / A_{0}$ a razão entra a área expandida das pás e a área da circunferência com o diâmetro do hélice.

$$
\begin{gathered}
K_{T}=\sum_{n=1}^{39} C_{n}(J)^{s_{n}}(P / D)^{t_{n}}\left(A_{E} / A_{0}\right)^{u_{n}}(Z)^{v_{n}} \\
K_{Q}=\sum_{n=1}^{47} C_{n}(J)^{s_{n}}(P / D)^{t_{n}}\left(A_{E} / A_{0}\right)^{u_{n}}(Z)^{v_{n}} \\
\eta_{p_{0}}=\frac{K_{T} J}{2 \pi K_{Q}}
\end{gathered}
$$

Desta forma, é possível obter numericamente as curvas de hélices em uma faixa de valores de $\mathrm{Z}$, de $\mathrm{P} / \mathrm{D}$ e de $A_{E} / A_{0}$ e verificar qual deles apresenta a maior eficiência para a condição de operação do veículo. Neste trabalho, fez-se a análise para hélices com 3 e 4 pás, com $\mathrm{P} / \mathrm{D}$ entre 0,6 e 1,4 e $A_{E} / A_{0}$ entre 0,5 e 1,05. Entretanto, observou-se que, para hélices com diâmetro dessa grandeza, as soluções com 4 pás apresentavam espessura muito baixa, inviabilizando sua utilização devido à sua resistência mecânica reduzida.

Na Tabela 22 são apresentados os valores usados para obtenção das curvas do casco e dos hélices.

A partir destes valores, chegou-se que o hélice com maior eficiência entre aqueles dentro das faixas consideradas de Z, P/D e $A_{E} / A_{0}$ tem a geometria mostrada na Tabela 23.

O Gráfico 5 apresenta as curvas dos adimensionais $K_{T}, K_{Q}$ e $\eta_{p_{0}}$ do hélice selecionado e a curva de $\left(K_{T}\right)_{C A S C O}$, evidenciando o ponto de operação. A condição de operação desse hélice é indicada na Tabela 24. 
Tabela 22 - Valores para realização da integração casco-hélice

\begin{tabular}{|c|c|}
\hline$R_{T}$ & $15 \mathrm{~N}$ \\
\hline$\rho$ & $1025 \mathrm{~kg} / \mathrm{m}^{3}$ \\
\hline$D_{H E L I C E}$ & $100 \mathrm{~mm}$ \\
\hline$V_{S}$ & $2 \mathrm{~m} / \mathrm{s}$ \\
\hline $\mathrm{MR}$ & $15 \%$ \\
\hline $\mathrm{t}$ & 0,1 \\
\hline $\mathrm{w}$ & 0 \\
\hline
\end{tabular}

Tabela 23 - Características geométricas do hélice com maior eficiência

\begin{tabular}{|c|c|}
\hline$Z$ & 3 \\
\hline $\mathrm{P} / \mathrm{D}$ & 0,9 \\
\hline$D_{\text {HELICE }}$ & $90 \mathrm{~mm}$ \\
\hline$A_{E} / A_{0}$ & 0,5 \\
\hline
\end{tabular}

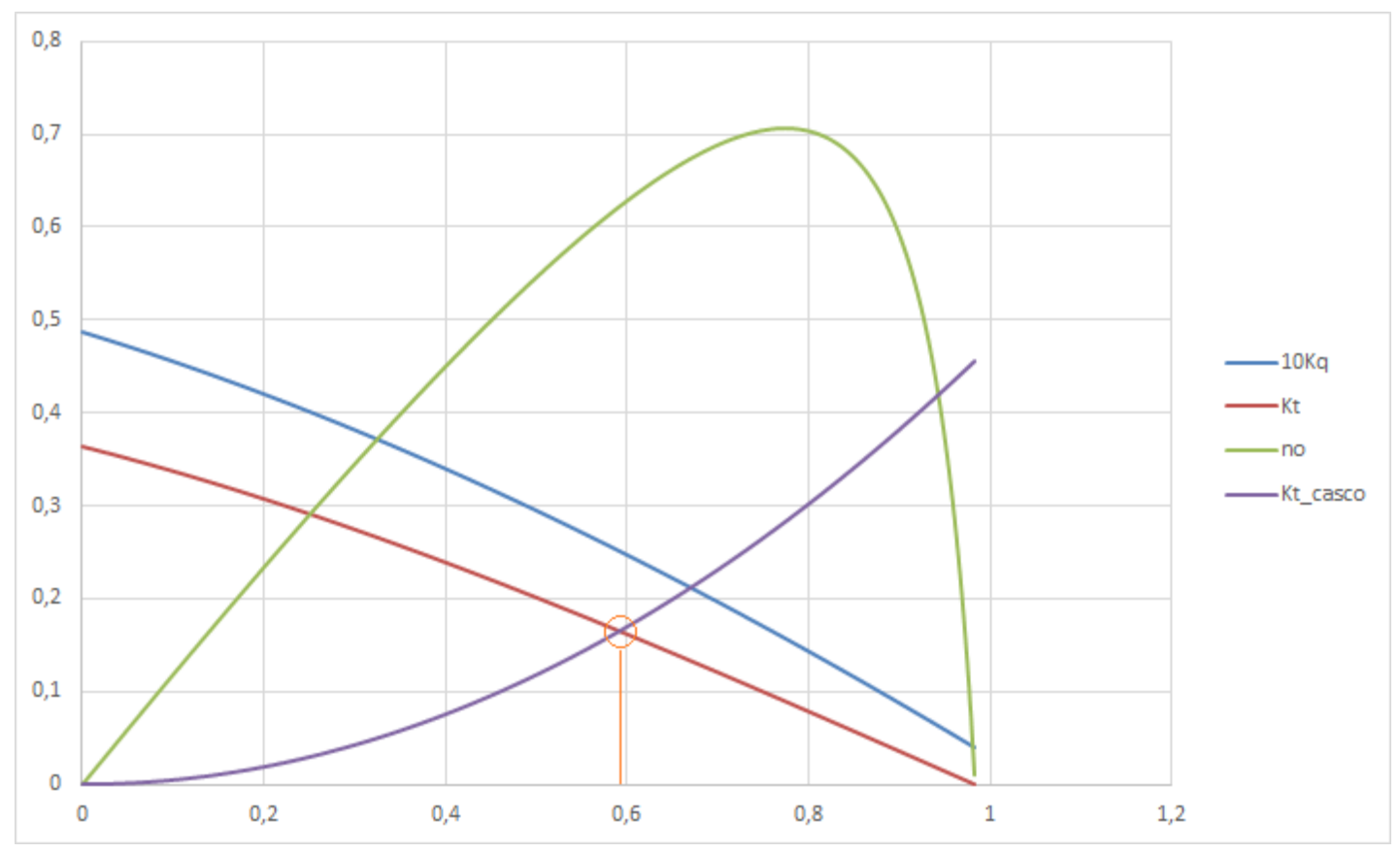

Gráfico 5 - Integração casco-hélice. Fonte: autor

\subsubsection{Análise de cavitação}

Um aspecto importante que deve ser considerado no projeto do sistema propulsivo é a cavitação, que pode ter como consequências, a queda do rendimento devido à perda do empuxo, gerando, às vezes, problemas de vibração.

No caso do escoamento da água em torno das pás do hélice, com o aumento de velocidade, a pressão diminui muito até alcançar a pressão de ebulição do fluido a essa temperatura, ocorrendo uma mudança de estado físico. Formam-se cavidades cheias de vapor, as quais, ao serem arrastadas pela corrente para zonas de maior pressão, colapsam 
Tabela 24 - Condição de operação do hélice

\begin{tabular}{|c|c|}
\hline $\mathrm{J}$ & 0,591 \\
\hline$K_{T}$ & 0,166 \\
\hline$K_{Q}$ & 0,0251 \\
\hline$\eta_{p_{0}}$ & 0,621 \\
\hline $\mathrm{P}$ & $62,69 \mathrm{~W}$ \\
\hline $\mathrm{Q}$ & $294,8 \mathrm{mN} . \mathrm{m}$ \\
\hline $\mathrm{N}$ & $33,83 \mathrm{rps}$ \\
\hline $\mathrm{N}$ & $2030 \mathrm{rpm}$ \\
\hline
\end{tabular}

e desaparecem, o que é conhecido como cavitação.

Um dos métodos para prevenir a cavitação é o de Keller. Ele estabelece o valor mínimo para a razão de área expandida para evitar a cavitação, mostrado na Equação 4.32 [LEWIS, 1988b], em que $p_{0}$ é a pressão na linha de centro do propulsor, $p_{v}$ é a pressão de vaporização da água e k é uma constante determinada pelo tipo de popa e número de propulsores da embarcação. Essa constante varia entre 0 e 0,2 , logo, para ser mais conservador, foi usado o valor de 0,2 .

$$
\frac{A_{E}}{A_{0}}=\frac{(1,3+0,3 Z) T}{\left(p_{0}-p_{v}\right) D^{2}}+k
$$

Da equação, tem-se que o valor mínimo para a razão de área expandida é de aproximadamente 0,22 . Uma vez que o valor da razão de área expandida do hélice selecionado é maior do que o calculado pelo método de Keller, conclui-se que não haverá cavitação.

Posteriormente, com a manufatura do sistema propulsivo será possível obter resultados mais conclusivos com relação a cavitação do hélice.

\subsubsection{Seleção do motor de propulsão}

Na subseção 4.5.1.1 foi obtida a condição de operação do hélice e, a partir desta informação, iniciou-se a procura por conjuntos de motor e redução que atendessem a necessidade do veículo. Foram pesquisados motores da Maxon Motor, uma fabricante suíça cujos motores já são empregados no AUV Pirajuba, e da Faulhaber, uma companhia alemã que possui representantes no Brasil. Apenas a Maxon Motor apresentava motores que satisfizessem a condição de operação do hélice. Desta forma, chegou-se no conjunto motor e redução cujas informações estão contidas na Tabela 25.

Com as informações do motor e da redução verificou-se pelo Gráfico 6 que a condição de operação do hélice era atendida pelo motor na região de operação contínua, logo, o motor e a redução selecionados são capazes de fornecer ao hélice rotação e torque de modo que o veículo atenda os requisitos básicos. 
Tabela 25 - Informações do motor e da redução

\begin{tabular}{|c|c|}
\hline \multicolumn{2}{|c|}{ Motor } \\
\hline Potência máxima & $150 \mathrm{~W}$ \\
\hline Tensão nominal & $24 \mathrm{~V}$ \\
\hline Constante de torque & $30,2 \mathrm{mN} \cdot \mathrm{m} / \mathrm{A}$ \\
\hline Constante de velocidade & $317 \mathrm{rpm} / \mathrm{V}$ \\
\hline Eficiência máxima & $91 \%$ \\
\hline \multicolumn{2}{|c|}{ Massa } \\
\hline \multicolumn{2}{|c|}{ Redução } \\
\hline Relação de redução & $3,5: 1$ \\
\hline Torque contínuo máximo & $3 \mathrm{~N} \cdot \mathrm{m}$ \\
\hline Eficiência máxima & $90 \%$ \\
\hline Massa & $260 \mathrm{~g}$ \\
\hline
\end{tabular}

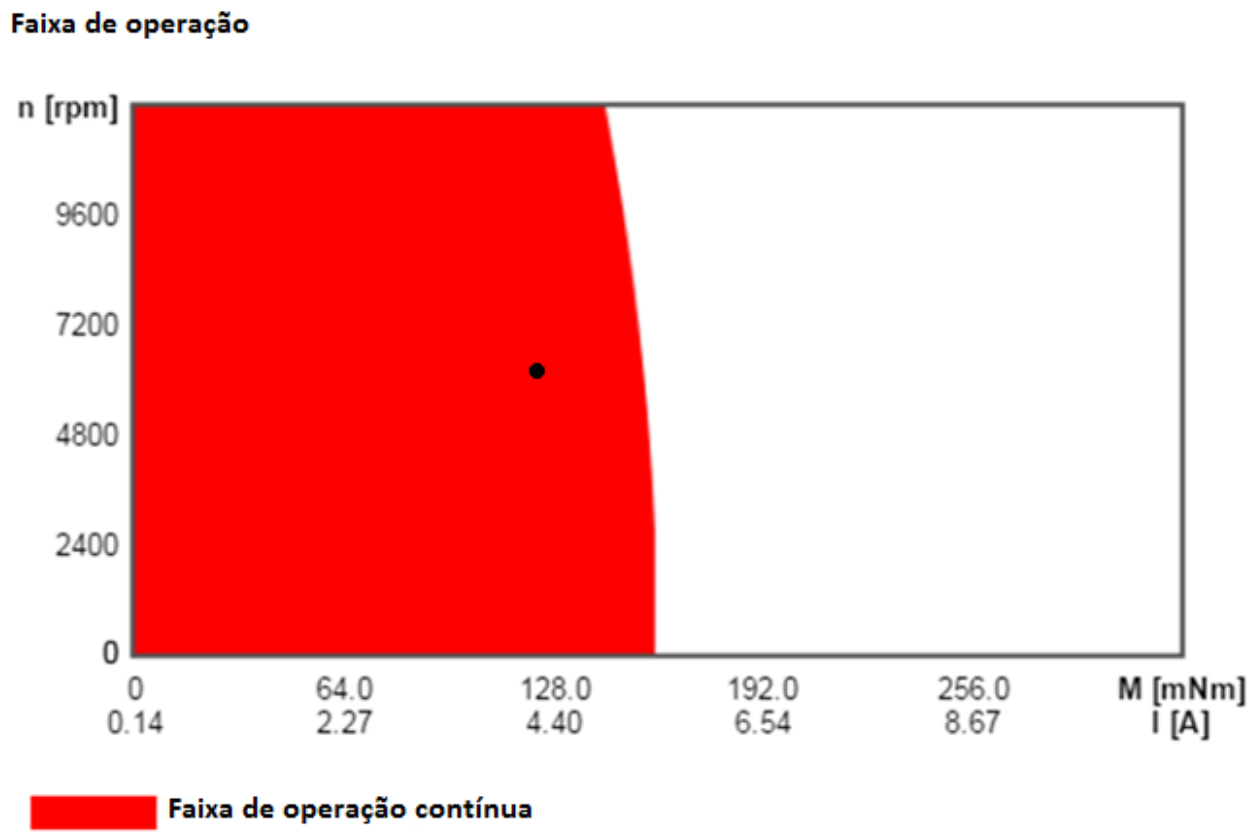

Gráfico 6 - Faixa de operação do motor selecionado para o hélice. Fonte: adaptado de [MAXON MOTOR, 2017b]

Além do motor e da redução da Maxon Motor, selecionou-se também um encoder, para realizar a leitura da rotação e da corrente do motor, e um driver, para receber o valor de referência de rotação e enviá-lo para o motor.

\subsection{Projeto do sistema de manobra}

O projeto do sistema de manobra apresenta duas etapas: dimensionar o leme de forma que o veículo realize as manobras previamente estabelecidas na seção 3.1 e selecionar o conjunto motor e redução que resista aos esforços solicitados pelo leme. 
Na etapa de dimensionamento do leme, fez-se uso das equações de movimento, das forças e de momentos mostradas em [ZHANG, 1997] para obter o raio de giro do veículo em função das características geométricas do leme. Para o projeto deste veículo, foi estabelecido que o objetivo do sistema de manobra era obter um raio de giro menor que cinco vezes o comprimento do casco central do trimarã.

Com uma geometria definida que atendesse o requisito de manobra, foram calculados os esforços gerados no leme de acordo com as formulações apresentadas em [WHICKER;

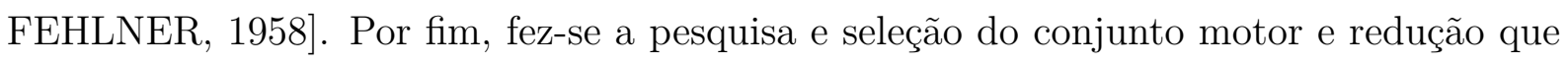
resistissem aos esforços no eixo do leme.

\subsubsection{Projeto do leme}

Da segunda lei de Newton, o movimento de um trimarã na superfície da água em relação ao sistema de coordenadas fixo $O x_{o} y_{o} z_{o}$, mostrado na Figura 4.31, pode ser descrito pelas equações $\underline{4.33}, \underline{4.34}$ e $\underline{4.35}$, onde $X_{o}$ e $Y_{o}$ são, respectivamente, as somatórias das forças no eixo $x_{o}$ e $y_{o}, N$ é a soma dos momentos no eixo $z_{o}$, m é a massa do veículo, $I_{z}$ é o momento de inércia de massa em relação ao eixo $z_{o}$ e $\psi$ é o ângulo de rumo da embarcação.

$$
\begin{aligned}
X_{o} & =m \ddot{x}_{o} \\
Y_{o} & =m \ddot{y}_{o} \\
N & =I_{z} \ddot{\psi}
\end{aligned}
$$

Alterando para o sistema de coordenadas oxyz fixo ao veículo e desconsiderando o movimento de surge (direção x), pode-se reescrever as equações do movimento como:

$$
\begin{array}{r}
Y=m\left(\dot{v}+u r+x_{G} \dot{r}\right) \\
N=I_{z} \dot{r}+m x_{G}(\dot{v}+u r)
\end{array}
$$

onde Y é a somatória das forças em sway (direção y), $x_{G}$ é a posição do centro de massa em relação ao eixo x, u e v são, respectivamente, a velocidade longitudinal e transversal e r a velocidade angular.

\subsubsection{Forças e momentos exercidos no veículo}

Para obter as equações relativas ao movimento de giro do trimarã a partir das equações $\underline{4.36}$ e $\underline{4.37}$, há a necessidade de identificar as forças e momentos que agem no barco. $\mathrm{O}$ veículo deste trabalho apresenta propulsores do tipo hélice nos cascos laterais e leme no casco central. Assumindo que a embarcação esta girando com velocidade constante, a força e o momento total podem ser descritos pelas equações $\underline{4.38}$ e $\underline{4.39}$, onde $Y_{H}$ e $N_{H}$ 


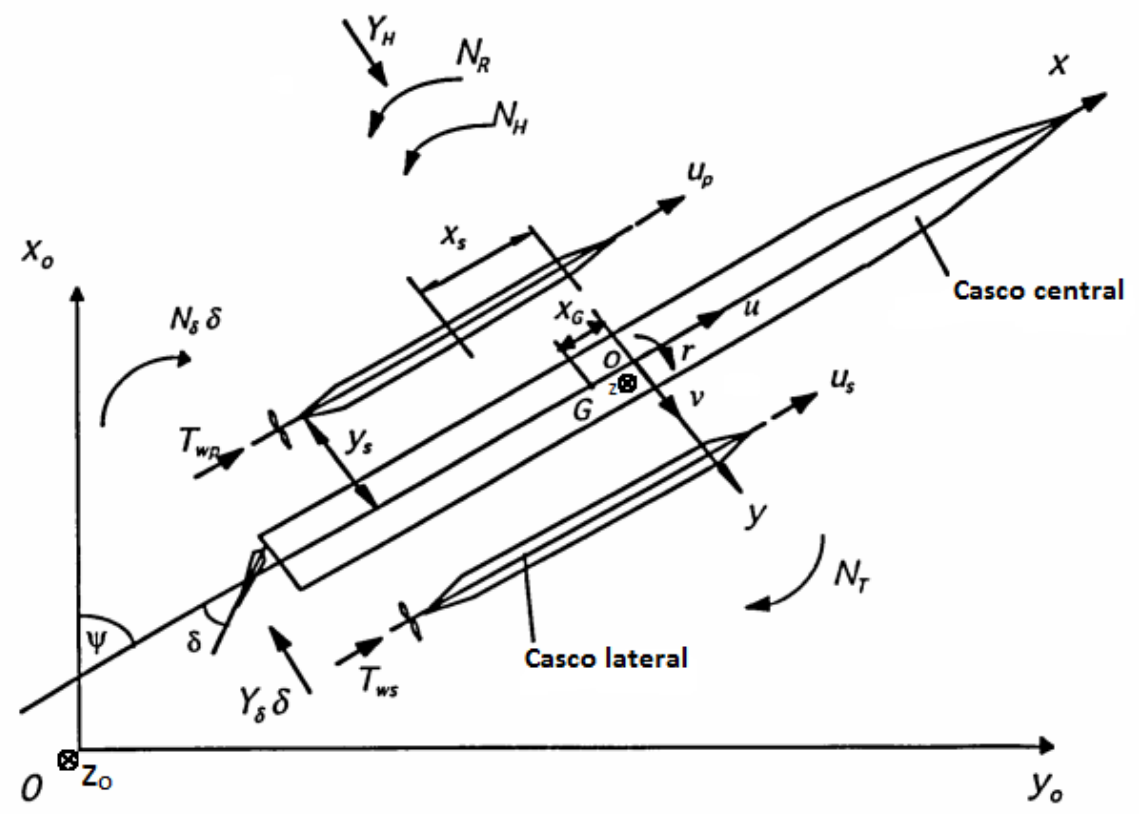

Figura 4.31 - Sistema de coordenads e forças externas no trimarã. Fonte: adaptado de [ZHANG, 1997]

são a força e o momento hidrodinâmico, $N_{T}$ é o momento produzido pelos hélices devido à diferença de empuxo gerado entre eles, $N_{R}$ é o momento induzido pela diferença entre a resistência ao avanço dos cascos laterais durante o movimento de giro e a força e momento produzidos pelo lemes são representados pelo produto das derivadas de controle $Y_{\delta}$ e $N_{\delta}$ com a deflexão do leme $\delta$.

$$
\begin{array}{r}
Y=Y_{H}+Y_{\delta} \delta \\
N=N_{H}+N_{T}+N_{R}+N_{\delta} \delta
\end{array}
$$

\section{Forças e momentos hidrodinâmicos}

A força hidrodinâmica $Y_{H}$ e o momento $N_{H}$ ocorrem devido ao movimento do navio na água e podem ser aproximados por funções lineares das velocidades e acelerações da embarcação. As equações $\underline{4.40}$ e $\underline{4.41}$ mostram essas funções lineares que, para o caso do movimento de giro com velocidade constante, dependem apenas de $Y_{v}, N_{v}$, $Y_{r}$ e $N_{r}$, que são as derivadas parciais da força com relação as velocidades.

$$
\begin{gathered}
Y_{H}=Y_{v} v+Y_{r} r \\
N_{H}=N_{v} v+N_{r} r
\end{gathered}
$$


As forças e momentos hidrodinâmicos dependem do cálculo dessas derivadas parciais. Na subseção 4.6.1.3 é apresentado um método para estimar essas derivadas para o trimarã.

\section{Momento dos hélices}

O momento gerado pelos hélices ocorre devido à diferença da condição de operação entre os hélices durante o movimento de giro. Desta forma, o empuxo fornecido por eles é diferente causando o aparecimento de um momento que pode ser expresso pela Equação 4.42, onde $T_{b e}$ e $T_{b b}$ são, respectivamente, o empuxo do hélice a boreste $(\mathrm{BE})$ e do hélice a bombordo (BB) e $y_{s}$ é a distância entre o eixo do hélice e o plano de simetria do veículo.

$$
N_{T}=\left(T_{b e}-T_{b b}\right) y_{s}
$$

\section{Momento da resistência ao avanço}

Durante o movimento de giro, as velocidades dos cascos laterais são diferentes pois a distância entre eles até o raio do movimento é desigual, vide equações $\underline{4.43}$ e $\underline{4.44}$, onde $u_{b e}$ e $u_{b b}$ são, nessa ordem, a velocidade de avanço do casco a boreste e do casco a bombordo.

$$
\begin{aligned}
& u_{b e}=u+r y_{s} \\
& u_{b b}=u-r y_{s}
\end{aligned}
$$

Consequentemente, a resistência ao avanço em cada um dos cascos também é diferente e depende das velocidades de avanço. A Equação 4.45 apresenta o cálculo do momento gerado por essa desigualdade, onde $X_{R}$ é a resistência do casco em função da velocidade de avanço.

$$
N_{R}=-\left(X_{R}\left(u_{b e}\right)-X_{R}\left(u_{b b}\right)\right) y_{s}
$$

\subsubsection{Raio de giro}

Com o cálculo das forças agindo no veículo, as equações do movimento para o giro em velocidade constante podem ser obtidas a partir das equações $\underline{4.36}$ e $\underline{4.37} \mathrm{com}$ a remoção das acelerações:

$$
\begin{array}{r}
m u r-Y_{v} v-Y_{r} r=Y_{\delta} \delta \\
m x_{G} u r-N_{v} v-N_{r} r=\left(T_{b e}-T_{b b}\right) y_{s}-\left(X_{R}\left(u_{b e}\right)-X_{R}\left(u_{b b}\right)\right) y_{s}+N_{\delta} \delta
\end{array}
$$


Desta forma, a velocidade angular do veículo é obtida pelas equações 4.46 e $\underline{4.47}$ :

$$
r=\frac{\left(T_{b e}-T_{b b}\right) y_{s}-\left(X_{R}\left(u_{b e}\right)-X_{R}\left(u_{b b}\right)\right) y_{s}+N_{\delta} \delta+\frac{N_{v} Y_{\delta} \delta}{Y_{v}}}{m x_{G} u-N_{r}-\frac{N_{v}}{Y_{v}}\left(m u-Y_{r}\right)}
$$

E assim, a Equação 4.49 apresenta o cálculo do raio do movimento de giro com velocidade constante.

$$
R=\frac{u}{r}
$$

\subsubsection{Estimativas das derivadas hidrodinâmicas dos cascos da força e do momento em função das velocidades}

Não existem métodos analíticos para estimar os coeficientes hidrodinâmicos de trimarãs. Entretanto, para monocascos há décadas de pesquisa sobre manobrabilidade que produziram métodos teóricos e empíricos para estabelecer valores das derivadas. Essas teorias desenvolvidas para monocascos podem ser extrapoladas para casos de trimarãs, mas é necessário calcular as derivadas do casco central e dos laterais separadamente, desprezando os efeitos causados pela interação entre eles.

Em [ZHANG, 1997], as estimativas das derivadas foram realizadas de formas diferentes para os cascos laterais e central pois, para o caso analisado, os cascos laterais apresentavam valores muito altos de razão L/B e, por isso, podiam ser aproximados por finos estabilizadores que apresentam teorias específicas para os cálculos da força e do momento. Para o casco central foram usadas fórmulas empíricas desenvolvidas em [INOUE; HIRANO; KI-

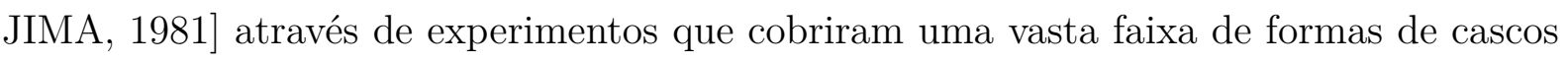
em várias condições de carregamento. As equações $\underline{4.50}$ até a $\underline{4.53}$ apresentam as fórmulas em função da geometria do casco sem considerar a embarcação com trim.

$$
\begin{array}{r}
Y_{v}=-\frac{1}{2} \rho L T u\left(\pi \frac{T}{L}+1,4 C_{B} \frac{B}{L}\right) \\
Y_{r}=\frac{1}{2} \rho L^{2} T u\left(\frac{\pi}{2} \frac{T}{L}\right) \\
N_{v}=-\frac{1}{2} \rho L^{2} T u\left(\frac{2 T}{L}\right) \\
N_{r}=-\frac{1}{2} \rho L^{3} T u\left(0,54 \frac{2 T}{L}-\left(\frac{2 T}{L}\right)^{2}\right)
\end{array}
$$

Neste trabalho estas equações serão usadas tanto para o casco central como para os cascos laterais. 


\subsubsection{Estimativas das derivadas do leme em função da sua deflexão}

Para obter o raio do movimento de giro em velocidade constante é necessário estimar as derivadas das força e do momento gerado pelo leme. As equações $\underline{4.54}$ e $\underline{4.55}$ apresentam uma estimativa onde $A_{R}$ é a área do leme e $x_{r}$ a distância entre o leme e a meia nau do casco central.

$$
\begin{array}{r}
Y_{\delta}=\frac{1}{2} \rho u^{2} A_{R}\left(\frac{\partial C_{L}}{\partial \delta}\right) \\
N_{\delta}=x_{r} Y_{\delta}
\end{array}
$$

O termo $\partial C_{L} / \partial \delta$ corresponde a derivada da curva de sustentação do leme e ele pode ser computado através da fórmula semi-empírica desenvolvida em [WHICKER; FEHLNER, 1958] apresentada na Equação 4.56, em que $a$ é a razão de aspecto efetiva, calculada pela divisão entre a envergadura ao quadrado e a área do leme, e $\gamma$ é, do inglês, o sweep angle da linha de um quarto da corda.

$$
\left(\frac{\partial C_{L}}{\partial \delta}\right)=\frac{1,8 \pi a}{(\cos (\gamma)) \sqrt{\frac{a^{2}}{\cos ^{4}(\gamma)}+4}+1,8}
$$

\subsubsection{Dimensionamento do leme}

Como primeira análise das dimensões do leme, fez-se a comparação do raio de giro sobre o comprimento (R/L) em função de diferentes ângulos de deflexão para alguns valores de razão de aspecto e área. No Gráfico 7 são mostrados os resultados da razão $\mathrm{R} / \mathrm{L}$ relativos aos lemes com razão de aspecto de 1 e área variando entre $55 \mathrm{~cm}^{2}$ e $75 \mathrm{~cm}^{2}$.

Já no Gráfico 8 são mostrados os resultados da razão R/L relativos aos lemes com razão de aspecto de 2 e área variando entre $55 \mathrm{~cm}^{2}$ e $75 \mathrm{~cm}^{2}$.

Por esses gráficos, percebe-se que o resultado procurado de raio de giro sobre o comprimento $(\mathrm{R} / \mathrm{L})$ menor que 5 só é alcançado para valores de deflexão superiores a $20^{\circ}$, região onde a análise linear formulada em [WHICKER; FEHLNER, 1958] pode não ser mais válida pois para estes ângulos de deflexão as froças não apresentam mais caráter linear. A solução tomada foi avaliar outro leme disponível no LVNT que já havia sido testado experimentalmente em condição de operação e podia ser utilizado. As dimensões desse leme são apresentado na Tabela 26 e valores referentes aos coeficiemtes adimensionais hidrodinâmicos que foram obtidos de forma numérica e experimental são apresentados em [DANTAS; BARROS, 2013]. No Gráfico 9 é possível observar os valores dos adimensionais, bem como o ângulo de estol que é por volta de $15^{\circ}$ e $20^{\circ}$.

A partir dos coeficientes hidrodinâmicos foi possível estimar o raio de giro do veículo com esse leme para diferentes âmgulos de deflexão do leme, como é possível observar no Gráfico 10. Para este leme, o R/L menor que 5 é obtido com uma deflexão menor que $20^{\circ}$ e dentro de uma região que havia sido analisada em [DANTAS; BARROS, 2013]. 


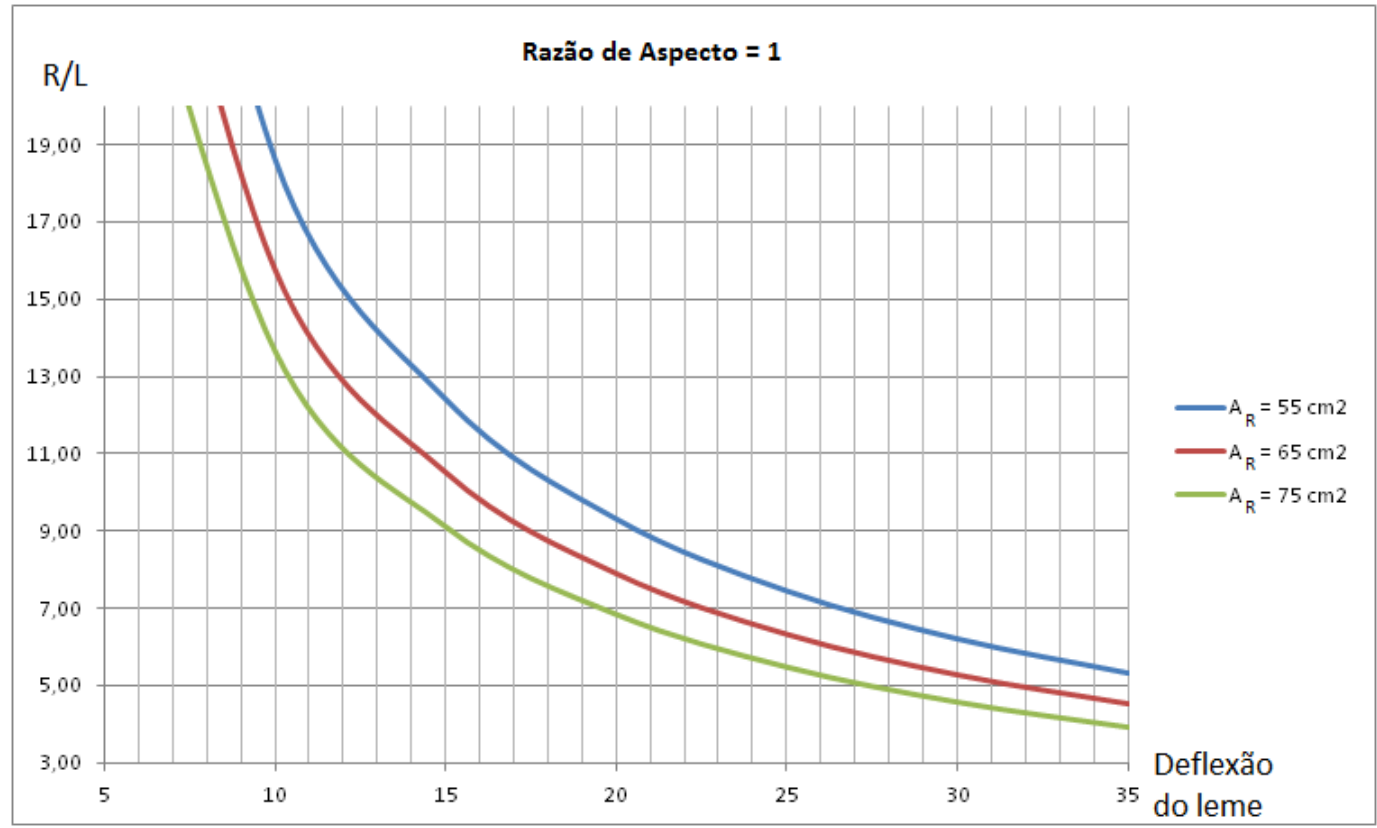

Gráfico 7 - R/L em função do ângulo de deflexão do leme para diferentes áreas e razão de aspecto 1. Fonte: autor

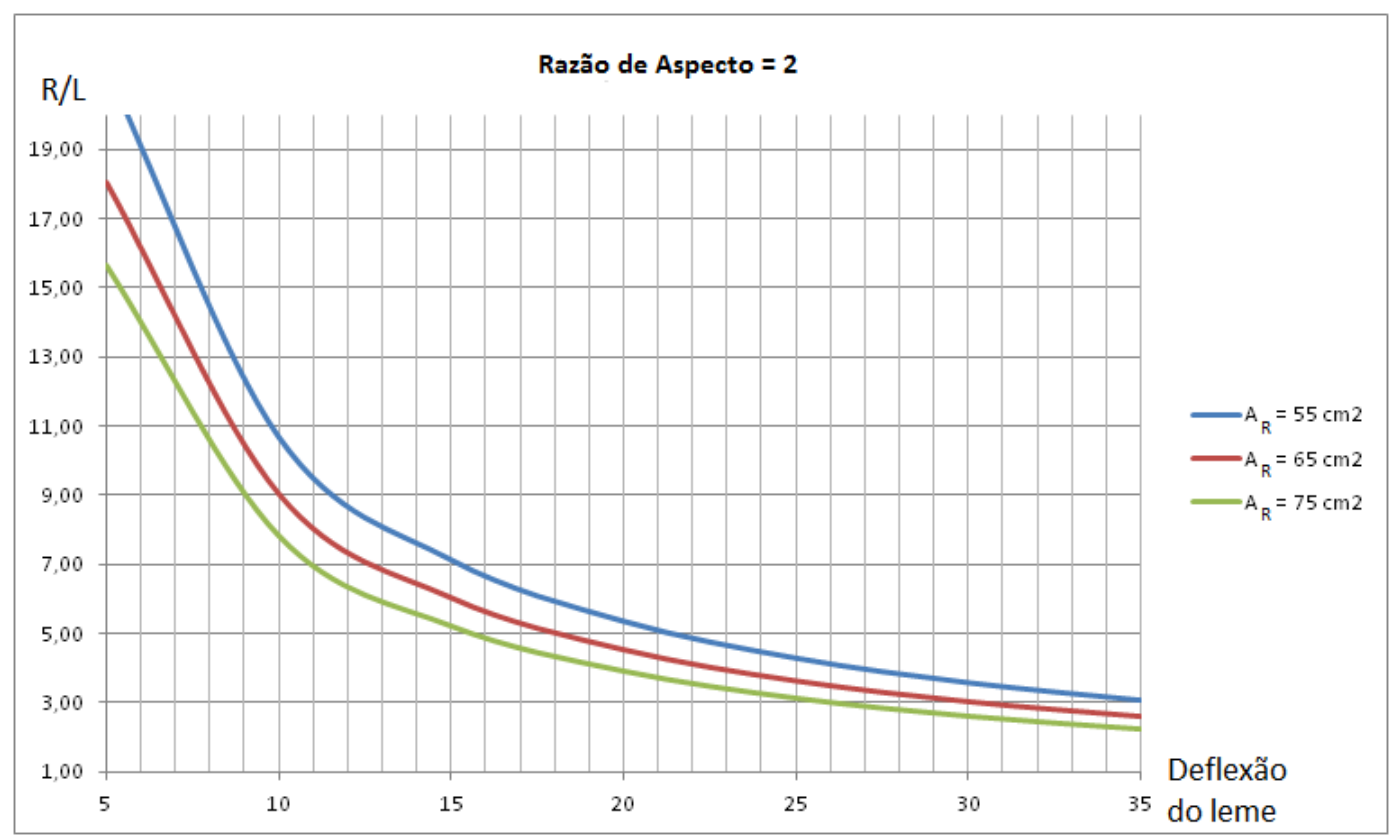

Gráfico 8 - R/L em função do ângulo de deflexão do leme para diferentes áreas e razão de aspecto 2. Fonte: autor

\subsubsection{Seleção do motor de manobra}

Assim como na subseção 4.5.2, para o conjunto motor e redução do sistema de manobra também foram pesquisados motores da Faulhaber e da Maxon Motor. A partir dos esforços exigidos pelo leme, chegou-se a um conjunto motor e redução cujas informações estão mostradas na Tabela 27.

Com as informações do motor e da redução verificou-se pelo Gráfico 11 que a condição 

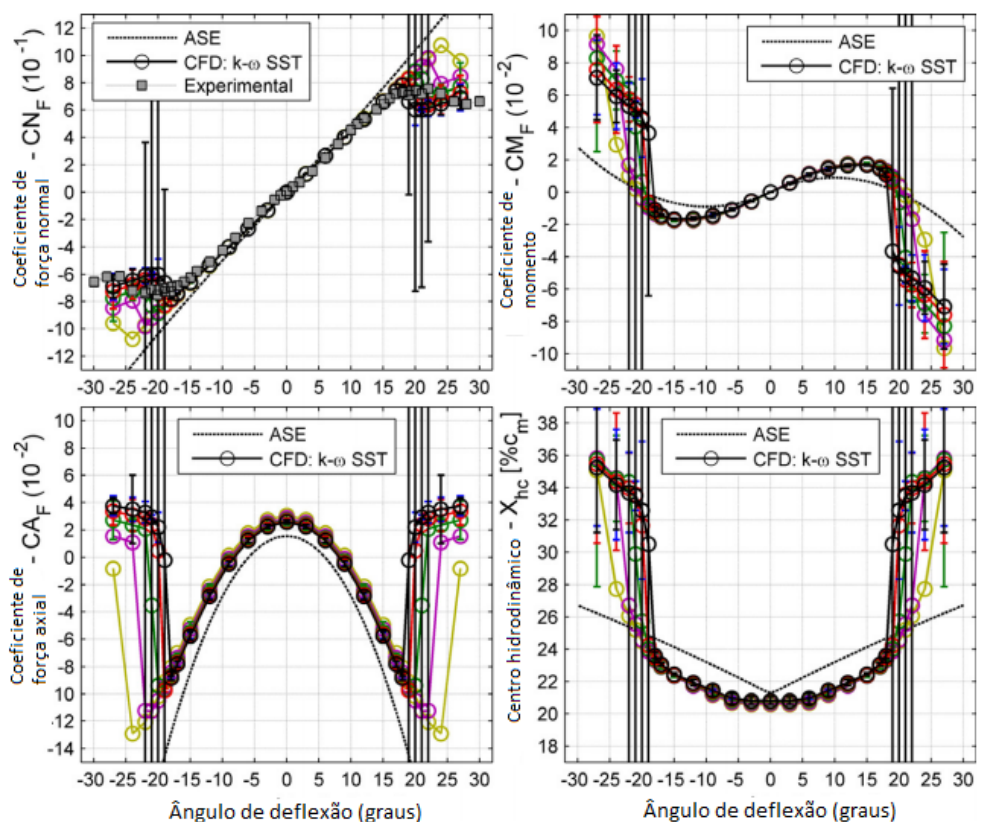

Gráfico 9 - Resultados numéricos e esperimentais dos coeficientes adimensionais do leme. Fonte:[DANTAS; BARROS, 2013]

Tabela 26 - Parâmetros geométricos do leme

\begin{tabular}{|c|c|}
\hline Corda média & $0,132 \mathrm{~m}$ \\
\hline Área & $0,017 \mathrm{~m}^{2}$ \\
\hline Razão de aspecto & 1,03 \\
\hline sweep angle & $0^{\circ}$ \\
\hline Perfil & NACA0015 \\
\hline
\end{tabular}

Tabela 27 - Informações do motor e da redução selecionada

\begin{tabular}{|c|c|}
\hline \multicolumn{2}{|c|}{ Motor } \\
\hline Potência máxima & $4,5 \mathrm{~W}$ \\
\hline Tensão nominal & $12 \mathrm{~V}$ \\
\hline Constante de torque & $16,2 \mathrm{mN} . \mathrm{m} / \mathrm{A}$ \\
\hline Constante de velocidade & $589 \mathrm{rpm} / \mathrm{V}$ \\
\hline Eficiência máxima & $80 \%$ \\
\hline \multicolumn{2}{|c|}{ Massa } \\
\hline \multicolumn{2}{|c|}{ Redução } \\
\hline Relação de redução & $29: 1$ \\
\hline Torque contínuo máximo & $0,15 \mathrm{~N} . \mathrm{m}$ \\
\hline Eficiência máxima & $81 \%$ \\
\hline Massa & $20 \mathrm{~g}$ \\
\hline
\end{tabular}

de operação do leme era atendida pelo motor na região de operação contínua, logo, o motor e a redução selecionados são capazes de fornecer ao leme o torque de modo que o veículo atenda os requisitos básicos. 


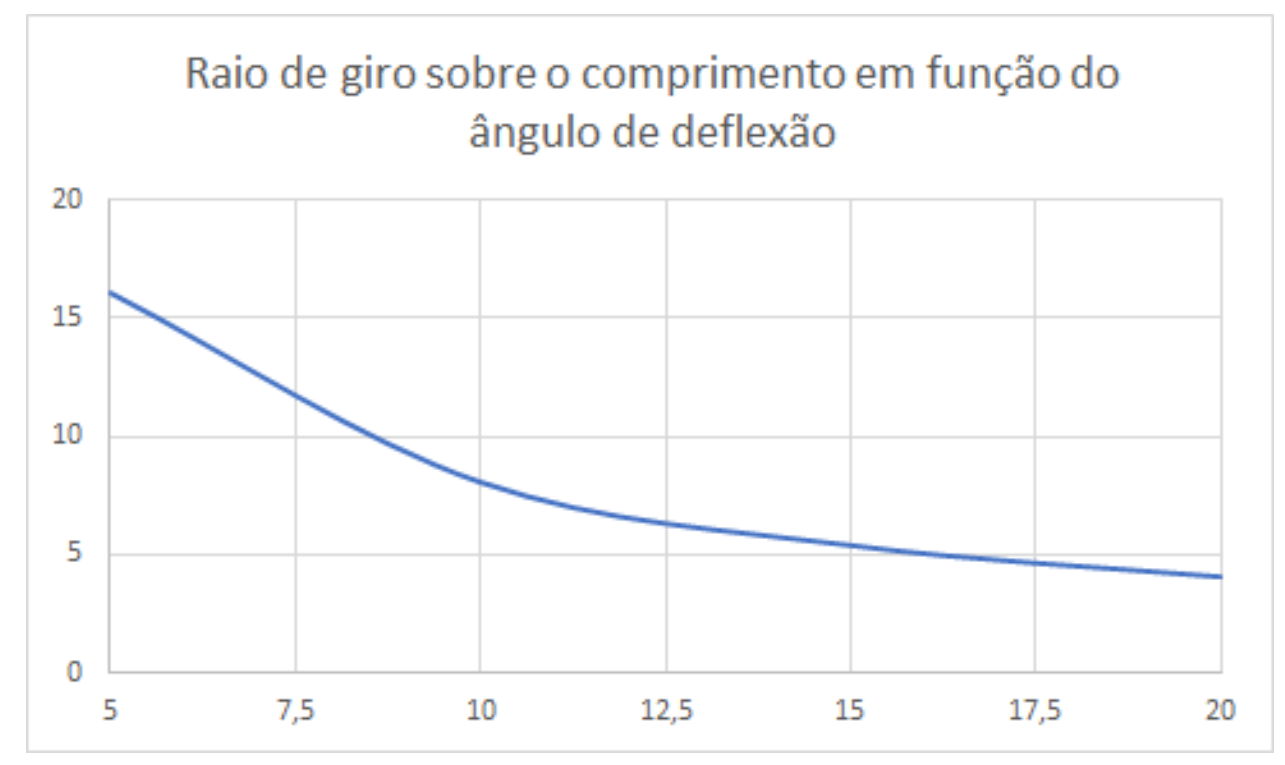

Gráfico 10 - R/L em função do ângulo de deflexão do leme disponível no LVNT. Fonte: autor

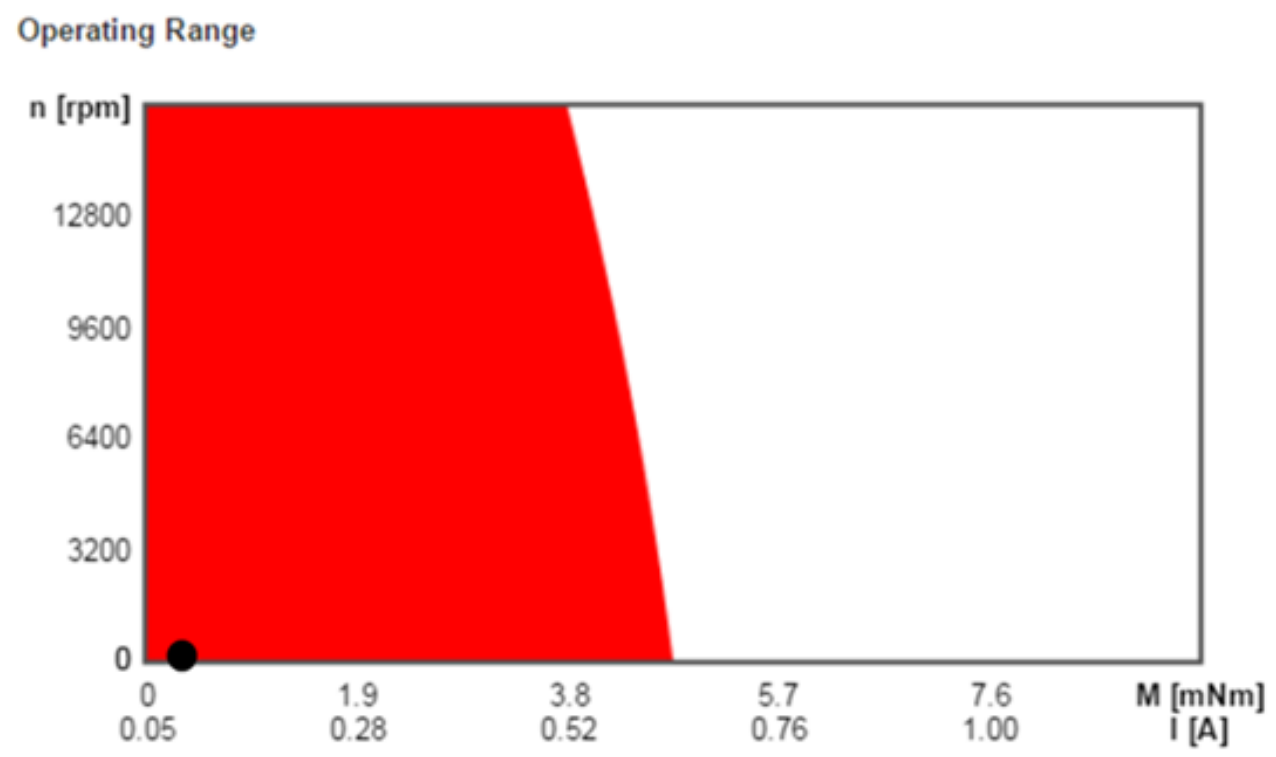

Faixa de operação contínua

Gráfico 11 - Faixa de operação do motor selecionado para o leme. Fonte: adaptado de [MAXON MOTOR, 2017a]

Fez-se também a seleção de um encoder para realizar a leitura de posição e da corrente do motor, e um driver para receber a posição de referência do leme e enviá-lo para o motor.

\subsection{Configurações do trimarã}

Como havia sido mencionado na introdução do Capítulo 4, durante o projeto do trimarã foram consideradas algumas possíveis configurações do veículo variando a distância 
longitudinal dos cascos laterais.

Com relação à resistência ao avanço, quanto menor a distância longitudinal dos cascos laterais, pior era a interferência de ondas, logo, a resistência total do veículo aumentava. O Gráfico 12 apresenta a comparação para os valores da distância longitudinal dos cascos laterais das possíveis configurações do veículo.

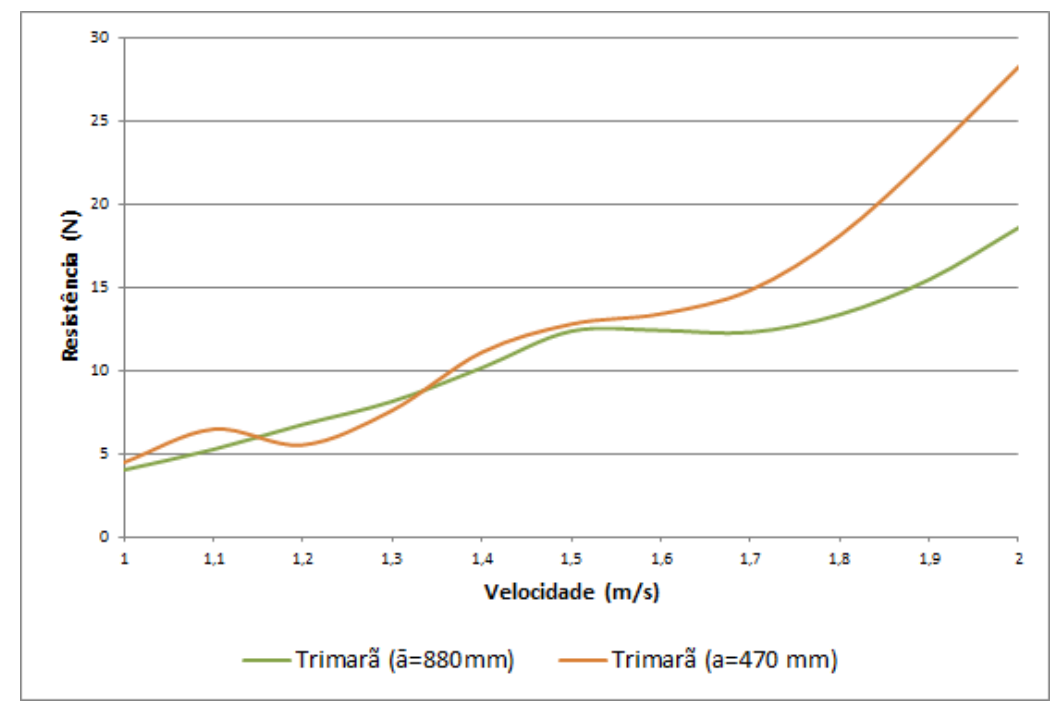

Gráfico 12 - Comparação da resistência ao avanço entre as possíveis configurações do trimarã. Fonte: autor

No que diz respeito à manobrabilidade do veículo, quanto menor a distância longitudinal dos cascos laterais, menor o raio de giro. A Tabela 28 apresenta o valor da razão raio de giro pelo comprimento para alguns valores de $\bar{a}$. para deflexão do leme igual a $20^{\circ}$.

Tabela 28 - Comparação do raio de giro entre as possíveis configurações do trimarã.

\begin{tabular}{|c|c|}
\hline Distância longitudinal (m) & $\mathrm{R} / \mathrm{L}$ \\
\hline 0,47 & 4,0 \\
\hline 0,88 & 6,3 \\
\hline
\end{tabular}

O convés foi projetado de tal forma que é possível realizar testes em campo tanto com a configuração com a distância longitudinal entre os cascos laterais igual a 0,47 $\mathrm{m}(\bar{a}=0,21)$ como igual a $0,88 \mathrm{~m}(\bar{a}=0,4)$. Desta forma, com a alternativa de duas configurações, pode-se escolher a mais adequada especificamente para cada missão, dando mais versatilidade para o veículo. 


\section{Sistema embarcado}

Para atender os requisitos básicos definidos na seção 3.1 é necessário, além da parte física projetada no Capítulo 4, de um sistema embarcado para realizar a leitura dos sensores de navegação, gerenciamento das manobras, controle da dinâmica do veículo, comunicação com a estação base, entre outras tarefas. A seguir são apresentados os detalhes do sistema embarcado que será utilizado no veículo deste trabalho.

\subsection{Arquitetura de controle}

\subsubsection{Arquitetura de hardware}

Baseado na arquitetura de controle do AUV Pirajuba, as funcionalidades do veículo foram divididas em módulos. Enquanto que no Pirajuba são usados microcontroladores de arquitetura ARM LPC 2148, no USV deste trabalho são usados microcontroladores STM32F439ZIT em placas projetadas especificamente para as necessidades do LVNT. Essas novas placas (chamadas de placas universais) apresentam um microcontrolador da família ARM Cortex-M4 que possuem muito mais poder de processamento, essencial para computar algoritmos de navegação em tempo real, além da maior quantidade de periféricos disponíveis. No próprio Pirajuba, o módulo de navegação foi substituído por um kit STM32F discovery com ARM Cortex-M4 para efetuar os cálculos.

Essas placas foram desenvolvidas por um consultor externo ao LVNT e as maiores vantagens dela são:

- Disponibilidade de 2 controladores CAN integrado no próprio chip do microcontrolador;

- Presença de FPU que permite a rápida manipulação de números em ponto flutuante, essencial para a implementação de algoritmos de navegação em tempo real;

- Controlador Ethernet integrado ao microcontrolador;

- Microcontrolador com interface SDIO para SDCard com transmissão paralela de dados;

- Presença de DMA no microcontrolador, possibilitando aos periféricos o acesso à memória diretamente, diminuindo a sobrecarga no microprocessador.

No quesito de arquitetura de controle, o sistema de um AUV é bem parecido com o de um USV, por isso, é possível aproveitar estudos realizados para AUV. Em [FREIRE, 2013], a arquitetura de hardware pode ser classificada em três categorias: 
- Centralizada: o sistema apresenta apenas um módulo responsável pelo gerenciamento de todo o o veículo, e por isso, seu desenvolvimento é facilitado pois não é necessário se preocupar com comunicação entre módulos e sua sincronia. No entanto, o sistema não apresenta muita versatilidade e fica dependente da capacidade de processamento e a quantidade de conexões de entrada e saída;

- Descentralizada: o sistema apresenta diversos módulos que se comunicam entre si. Neste caso a arquitetura é mais flexível pois para adicionar novas caraterísticas basta inserir mais um módulo ao sistema. O problema é a maior complexidade devido à comunicação entre os módulos;

- Mista: o sistema é composto por módulos de processadores menores, responsáveis por tarefas simples, e módulos com mais processamento, que se comunicam com os outros e são encarregados das tarefas mais complexas. Esta arquitetura busca maximizar as vantagens e minimizar as desvantagens das outras duas.

Neste trabalho foi adotado a arquitetura de hardware mista uma vez que, para as funções de comunicação com a estação base, gerenciamento das manobras, cálculo dos algoritmos de navegação foram utilizadas as placas universais, e para o BMS, encarregado de proteger, monitorar e gerenciar a carga das baterias, foram utilizadas placas mais compactas com o microcontrolador STM32F407VGT6, com menos pinos.

\subsubsection{Estrutura dos módulos}

Com a experiência adquirida durante as operações em campo e os testes em laboratório, foi possível assimilar tendências e necessidades com relação às interfaces de comunicação dos sensores e equipamentos embarcados. Grande parte deles apresenta interfaces no padrão RS-232, como é o caso da bússola, do GPS, do DVL e de alguns tipos de drivers dos atuadores e de IMUs (outros tipos de IMUs apresentam comunicação no padrão RS-485). Um dos motivos da seleção dos drivers utilizados nesse projeto é a possibilidade integrá-los à rede CAN do próprio veículo, resultando em um sistema mais robusto. Outros tipos de interfaces de comunicação são importantes para aumentar a flexibilidade do veículo, possibilitando assim sua utilização em diversas aplicações.

A Tabela 29 apresenta os tipos e as quantidades de conexões disponíveis na placa universal.

Além disso, a placa universal contém um RTC para sincronizar os dados de navegação com os da carga paga no pós-processamento. Para facilitar a fase de desenvolvimento, foram inclusos na placa 5 leds e 4 switches que auxiliam o processo de ajuste e depuração do código embarcado.

Com relação ao posicionamento e fixação das placas, no Pirajuba as placas eram empilhadas uma em cima da outra, dificultando bastante o processo de remoção das 
Tabela 29 - Quantidades e tipos de conexões da placa universal

\begin{tabular}{|c|c|}
\hline Tipo de conexão & Quantidade disponível na placa \\
\hline RS-232 & 3 \\
\hline TTL & 1 \\
\hline RS-485 & 1 \\
\hline I2C & 1 \\
\hline CAN & 2 \\
\hline Ethernet & 1 \\
\hline SPI & 1 \\
\hline Entradas digitais optoacopladas & 4 \\
\hline Saídas digitais & 8 \\
\hline Entradas analógicas & 4 \\
\hline Saídas analógicas & 2 \\
\hline
\end{tabular}

placas inferiores. Por isso, para as placas universais, fez-se apoios laterais para colocá-las em prateleiras. Assim, qualquer placa pode ser removida independentemente das demais.

\subsubsection{Conectores}

Para aumentar a confiabilidade do sistema e diminuir a possibilidade de erro humano, nas placas universais foram usados conectores diferentes para cada tipo de conexão. Esses conectores são de dois tipos, ambos da fabricante Molex:

- DuraClick que apresenta um mecanismo de trava audível para avisar ao usuário sua conexão correta. Os conectores são polarizados e não permitem fisicamente a ligação incorreta;

- MicroFit também são polarizados para impossibilitar a conexão na orientação incorreta.

\subsubsection{Arquitetura de software}

Em [VALAVANIS et al., 1997] são apresentadas os quatro tipos principais de arquitetura de controle desenvolvidas para atender os requisitos de AUVs:

- Arquitetura Hierárquica: o sistema é dividido em níveis. Os níveis superiores são responsáveis pelos objetivos gerais da missão, enquanto que os inferiores são encarregados dos problemas particulares. A comunicação entre níveis é direta, ou seja, só ocorre entre níveis adjacentes. O nível superior envia comandos para o inferior que responde com informações de sensores e de atuadores. A simplicidade e a separação em níveis são as vantagens desse sistema, pois facilitam a verificação 
de controlabilidade e estabilidade do sistema. Já a desvantagem é a falta de flexibilidade, pois o alto grau de acoplamento entre os níveis dificulta a modificação de qualquer funcionalidade.

- Arquitetura Heterárquica: ao contrário da arquitetura hierárquica, a heterárquica tem uma estrutura paralela em que todos os módulos se comunicam entre si, sem supervisão ou intermediários. As vantagens são a flexibilidade e a baixa sobrecarga de comunicação já que qualquer comunicação pode ser acessada a partir de qualquer módulo. As desvantagens são que, pela ausência de supervisão, a comunicação entre os módulos pode ser bastante intensa e a verificação da controlabilidade é mais complicada.

- Arquitetura de Camadas: contém um conjunto de comportamentos trabalhando em paralelo, sem supervisão. Estes comportamentos são camadas da arquitetura de controle que são ativadas por ações específicas sentidas pelos sensores. Se duas camadas são ativadas paralelamente, aquela com maior prioridade assume o comando. A informação e controle estão disponíveis para todas as camadas, e cada uma delas processa as informações necessárias. as vantagens dessa arquitetura são a flexibilidade, a robustez e baixa sobrecarga computacional. Além disso, ela apresenta dinâmica de comportamento reativa. A dificuldade de sincronização e a complexidade do sistema com o aumento dos comportamentos são as desvantagens da arquitetura.

- Arquitetura Híbrida: o objetivo dessa arquitetura é obter uma solução combinando as características das arquiteturas anteriores que atenda os requisitos do veículo.

Neste trabalho foi desenvolvida uma arquitetura de controle híbrida discutida a seguir.

\subsubsection{Distribuição das funcionalidades do veículo}

No AUV Pirajuba os módulos foram divididos e nomeados segundo as funcionalidades de realizadas por eles. No Pirajuba, por causa da menor quantidade de conexões nas placas, era necessário dividir algumas funcionalidades em duas placas como, por exemplo, a leitura de sensores. Neste trabalho, com a utilização da placa universal, foi possível agrupar algumas tarefas em apenas uma placa.

A seguir são apresentados os módulos que, assim como no Pirajuba, foram implementados no trimarã e deste trabalho.

\section{Capitão}

O módulo Capitão coordena as transições de estado de todas as placas, o início e o fim das manobras. Além disso, quando o veículo esta em modo de guiamento manual, este módulo envia pelo barramento CAN os dados de rotação do motor e deflexão do leme, configurados pelo usuário pelo controle remoto, para os drivers dos atuadores. Para 
aumentar a robustez e flexibilidade do veículo, também foi adicionado um módulo celular que transmite via GSM a informação da posição da embarcação e também pode receber mensagens pré-estabelecidas para iniciar ou finalizar uma manobra. No início da manobra o DVL são acionados, e isso também é feito pelo módulo Capitão.

\section{Piloto}

As únicas responsabilidades do módulo Piloto são a execução dos algoritmos de controle e de manobra, e o gerenciamento da ordem dos trechos de manobra pré-programados. Este módulo utiliza as informações de navegação como entrada de controle e retorna os valores de referência da rotação do hélice e da deflexão do leme, de acordo com o trecho de manobra pré-programada.

No AUV Pirajuba a manobra, como um todo, era pré-programada, deixando apenas como opção para o usuário a alteração de parâmetros como tempo de manobra, deflexão do leme, rotação do hélice. Com o objetivo de aumentar a flexibilidade do usuário em campo, será desenvolvido para o veículo deste trabalho uma interface gráfica que permitirá a customização da manobra a partir de trechos pré-programados. Além da melhora para o usuário, esta alteração torna o desenvolvimento das manobras mais modular e facilita sua expansão.

\section{Sensores}

O módulo Sensores é encarregado da leitura dos sensores que podem ser embarcados como bússola, DVL, IMU, profundímetro, AHRS (Attitude and Heading Reference System), entre outros.

\section{Navegador}

O módulo Navegador é responsável pelo processamento dos algoritmos de navegação. Por isso, foram implementadas funções matemáticas específicas para sistemas embarcados com restrições de tempo. Em [GANSSLE, 2008] foram descritas o funcionamento dessas funções. Uma vez que o veículo deste trabalho será usado como plataforma de teste de algoritmos de navegação, esse módulo realizará, além do algoritmo principal de navegação, outros em paralelo.

\section{Diário de Bordo}

É de essencial importância salvar os dados lidos pelos sensores durante as manobras. Por isso, o módulo Diário de Bordo apresenta entrada para um SDCard onde são guardados a informação dos sensores. Assim como o módulo Capitão, o Diário de Bordo também tem o módulo celular para enviar a posição do veículo via GSM.

\section{Comunicador}

Este módulo é responsável pela comunicação entre a estação base e o veículo. Esta pode ser feita por rádio frequência para enviar comandos de manobra e receber dados de sensores e dos algoritmos de navegação em tempo real. Além disso, apresenta um modem $W i$-fi capaz de enviar todos os dados salvos pelo Diário de Bordo no SDCard em poucos segundos. 


\section{BMS}

A responsabilidade do módulo BMS é proteger as baterias de operar fora da região segura de operação, monitorar seu estado e gerenciar a carga das baterias.

No veículo deste trabalho, os módulos serão organizados de acordo com a Figura 5.32, em que os módulos Capitão e Piloto ficaram juntos em uma placa, assim como o Sensores e Navegação. Haverão dois módulos BMSs, um para cada conjunto de baterias nos cascos laterais. Todos esses módulos se comunicam através do barramento principal. Para aumentar a robustez do sistema, será usado o segundo barramento CAN da placa universal para tarefas não essenciais a operação do veículo como, por exemplo, sistemas de aquisição de dados de equipamentos considerados cargas pagas (sondas oceanográficas, câmeras, entre outros).

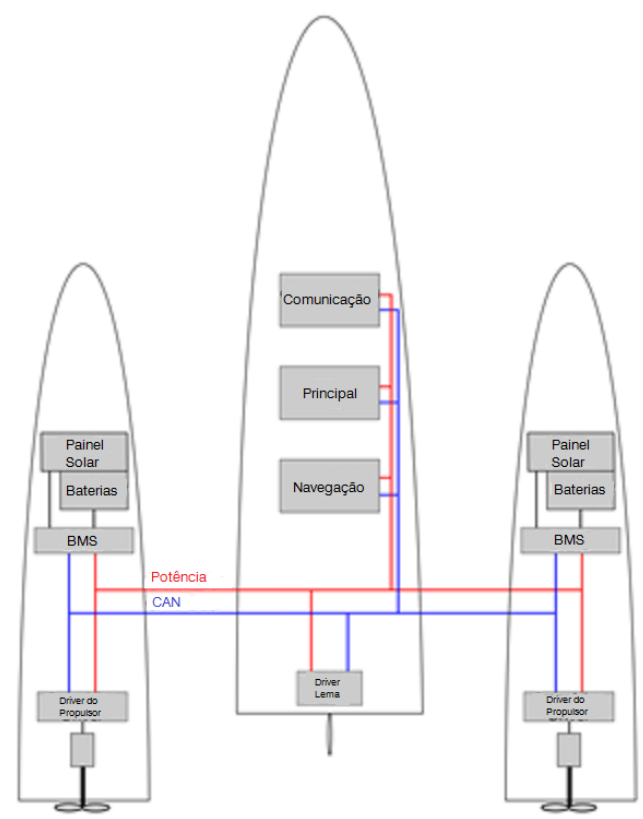

Figura 5.32 - Organização dos módulos. Fonte: [SILVA et al., 2018]

Com relação aos sinais dos sensores de navegação, na Figura 5.33 é representado as grandezas mensuradas com os equipamentos instalados no veículo. Esses valores são transmitidos pela CAN para tarefas como navegação e controle do veículo.

Esses sinais são usados nos cálculos dos algoritmos de navegação de acordo com a metodologia utilizada. Atualmente, no AUV Pirajuba, dois algoritmos de estimação foram implementados em tempo real, realizando a integração pura dos dados dos sensores. Eles são:

- Integração da IMU: para obter a orientação tridimensional do veículo (ângulos de roll, pitch e yaw) são usados as medições de velocidade angular realizadas pela IMU. Esse método precisa ser inicializado com a orientação do veículo proveniente 


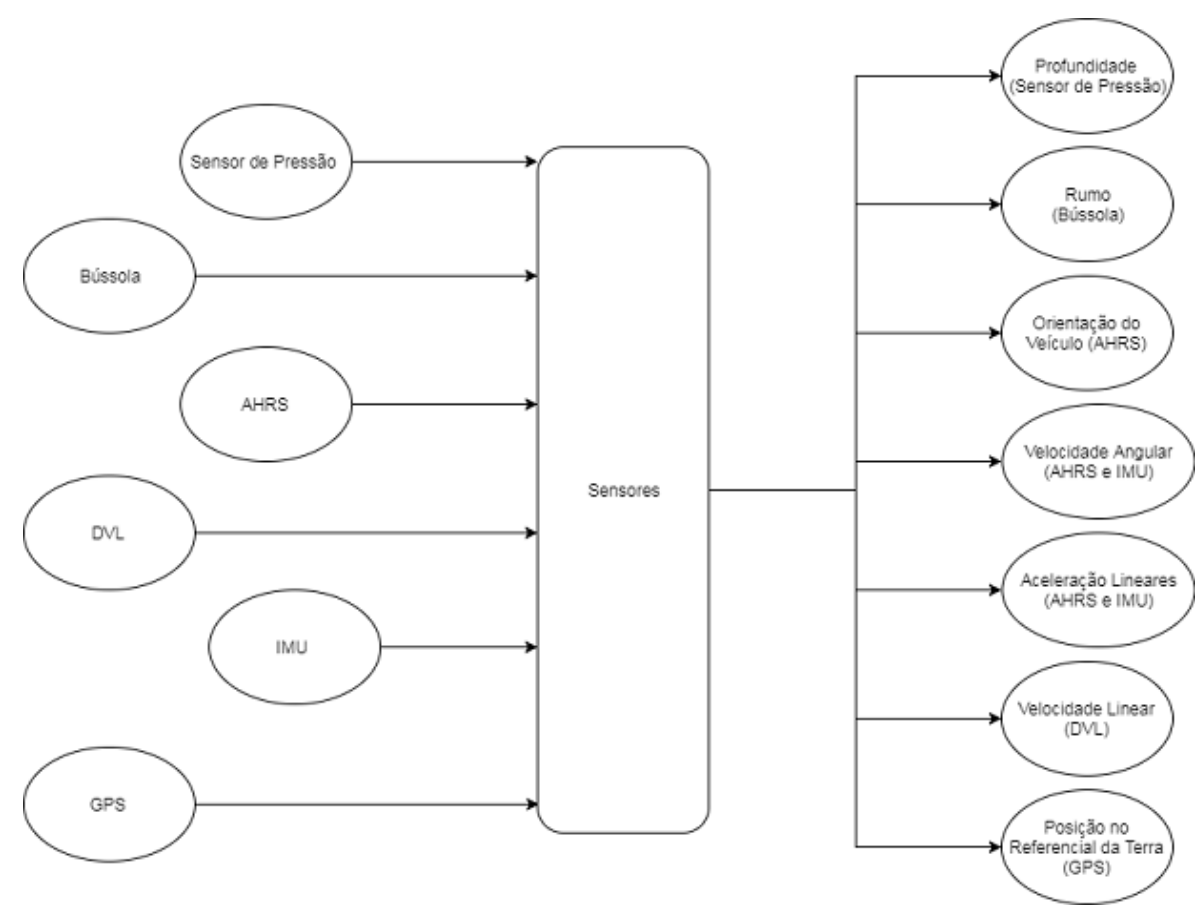

Figura 5.33 - Sinais de entrada do módulo sensores. Fonte: autor

de algum sensor: roll e pitch são lidos da AHRS ou estimados pela leitura dos acelerômetros da própria IMU, e yaw pode ser lido tanto da AHRS como da bússola. O conceito desse método é mostrado na Figura 5.34, em que o resultado é transmitido pela rede CAN do veículo e pode ser utilizado pelo módulo Piloto ou até mesmo pelo Navegador como entrada do outro método de estimação;

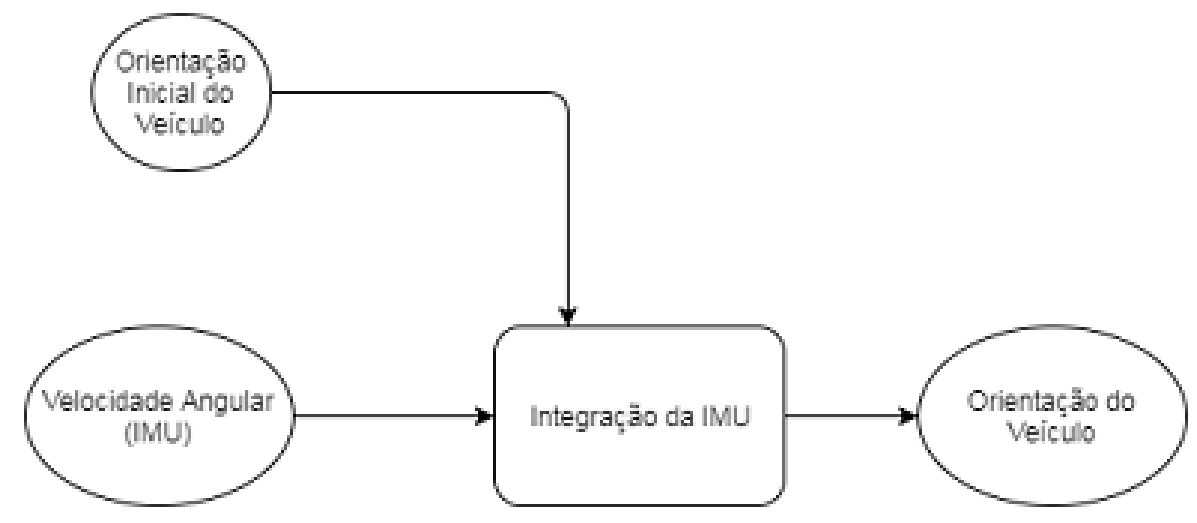

Figura 5.34 - Integração da IMU. Fonte: autor

- Dead reckoning por integração pura: na inicialização desse método a posição inicial do veículo é obtida do GPS no início da manobra. A atualização da posição é realizada usando os dados de orientação - proveniente ou de sensores, como AHRS e bússola, ou da integração da IMU — e dados da velocidade linear do veículo oriundos da leitura do DVL. Esse método é ilustrado na Figura 5.35, em que o valor de posição estimada é usado em controle, no módulo Piloto, durante manobras de guiamento. 


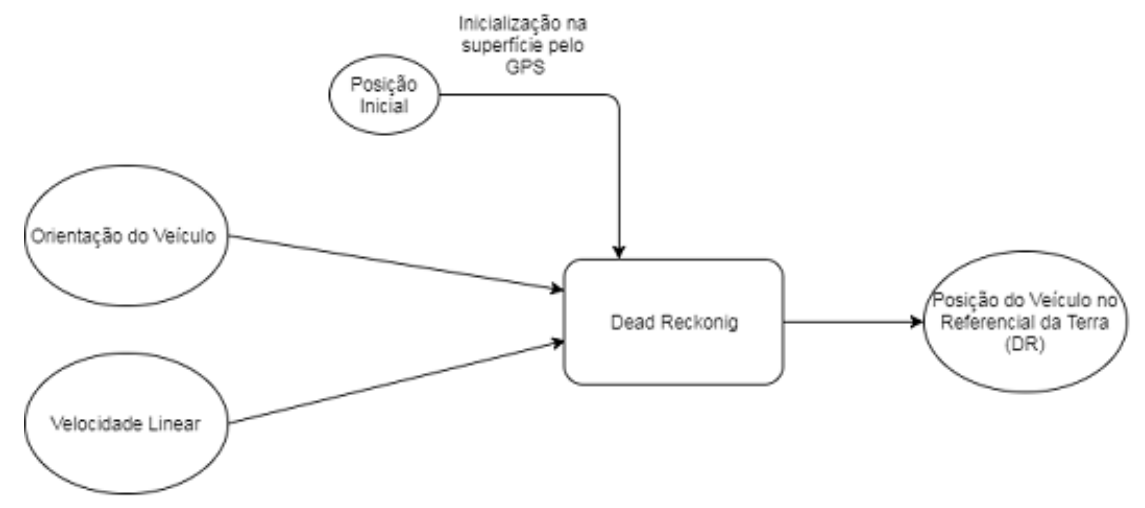

Figura 5.35 - Integração da IMU. Fonte: autor

\subsubsection{Manobras}

O veículo pode operar de duas formas: controlado remotamente ou com manobras autônomas. No modo de controle remoto, as entradas das superfícies de controle (leme e propulsor) são fornecidas por um operador humano através de um joystick que possibilita a alteração na velocidade de rotação dos propulsores e no ângulo de deflexão do leme. No modo autônomo, o veículo se move de acordo com manobras pré-programadas cujos parâmetros são atualizados pela estação base via rádio frequência.

Com experiências obtidas através do manuseio do AUV Pirajuba, manutenção de sua interface gráfica e implementação dos módulos de manobra, fez-se algumas alterações com o intuito de melhorar a operação na estação base, dando mais flexibilidade e acessibilidade ao usuário. Assim, ao invés de manobras totalmente pré-programadas, fez-se pequenas partes pré-programadas (giro, zigue-zague e controle de rumo) que poderiam ser arranjadas de acordo com a missão desejada. Além disso, o veículo é capaz de realizar manobras com pontos de referência dados por coordenadas geoestacionárias.

\subsubsection{Robustez do sistema}

O USV são operados em ambientes hostis à parte eletrônica embarcada e falhas no sistema podem ocasionar grandes perdas, danificando componentes ou sensores. Por isso, é importante levar em consideração a segurança do veículo durante o desenvolvimento do hardware e do software embarcado. Assim como é adotado no AUV Pirajuba, no veículo deste trabalho também será adotada a norma MISRA-C, que faz recomendações para o desenvolvimento de código mais legível, evita problemas já conhecidos da linguagem e diminuem a probabilidade de falha humana.

O principal objetivo do veículo é servir como plataforma de testes de algoritmos de navegação. Entretanto, será possível também desenvolver métodos mais seguros que, no caso de um AUV, são de difícil teste em campo. Por exemplo, adicionar tarefas de redundância nas placas que verificariam se os módulos primários estavam funcionando corretamente. Em caso de falhas, essas tarefas redundantes realizariam as atividades do 
módulo em falha e o veículo poderiam continuar funcionando até seu resgate. desta forma ele não iria para de funcionar apenas por causa dessa falha. 


\section{Considerações finais}

\subsection{Conclusões}

O estado da arte do projeto de USVs em instituições acadêmicas pouco enaltece as etapas de arquitetura naval das embarcações, realizando-as de forma conservadora com a preocupação de atender os requisitos para realização das missões planejadas. Neste trabalho, foram seguidas etapas de projeto semelhantes às usadas em navios de larga escala, realizando as adaptações necessárias de acordo com as dificuldades encontradas. A seguir, fez-se uma comparação entre as etapas de projeto usadas neste trabalho para o caso de um USV e as comumente utilizadas em embarcações tripuladas comuns.

\subsubsection{Metodologia de Projeto}

Mesmo durante a escolha da metodologia a ser utilizada foi necessária a análise desta no caso específico de um USV. Métodos de otimização de projeto com problemas multiobjetivos eram mais adequados para obtenção da melhor solução, entretanto, apresentavam dificuldades relativas à modelagem do problema no ambiente acadêmico, com particularidades como insuficiência de verba e componentes mecânicos e eletrônicos restritos aos encontrados em mercado. Mesmo assim, foram identificadas situações de projeto que poderiam ser estudadas a partir da otimização, como a definição da distância longitudinal entre os cascos central e laterais, cuja influência afetava a resistência ao avanço e a manobrabilidade de forma inversa. Para esse problema específico, neste trabalho, foi adotada a possibilidade de duas configurações do veículo, cada uma priorizando ou a resistência ao avanço ou a manobrabilidade. Tal solução só pode ser adotada para veículos pequenos como é o caso do USV pois o convés principal não foi manufaturado em conjunto com os cascos.

Com relação à metodologia adotada da espiral de projeto, buscou-se adaptá-la de forma a atender todos os requisitos de um USV no ambiente de um laboratório acadêmico com restrições de equipamentos, verba e manufatura dos cascos praticamente artesanal.

\subsubsection{Dimensionamento dos cascos}

A respeito do dimensionamento do veículo, por se tratar de um multicasco do tipo trimarã, para minimizar a resistência ao avanço, foi buscada uma solução de divisão de deslocamento com os menores cascos laterais que pudessem embarcar as baterias pois pretendia-se separar o sistema de energia nos cascos laterais do sistema eletrônico e da carga paga no casco central. 
Devido às dimensões reduzidas do veículo, foi possível projetar o convés principal que possibilitasse dois tipos de arranjo da embarcação: uma que priorizasse a manobrabilidade do veículo e a outra a autonomia, através da diminuição da resistência de onda.

\subsubsection{Sistema de Propulsão}

O projeto de um USV apresenta algumas vantagens como maior facilidade de controle sobre o motor elétrico e a possibilidade de acoplamento direto entre o motor de propulsão e o hélice. Entretanto, problemas enfrentados com relação à fabricação dos hélices são específicos do projeto do USV. Métodos de fabricação clássicos não são possíveis devido à geometria complexa dos hélices, assim como os a resistência dos materiais utilizados não atende às necessidades de operação. Neste trabalho, foi necessário fixar o número de pás do hélice em 3 e aumentar sua razão de área para aumentar a espessura das pás, obtendo hélice mais robusto.

\subsubsection{Cálculo hidrodinâmico}

Assim como em embarcações tripuladas, faz-se necessário levar em consideração a resistência ao avanço de apêndices. Porém, no caso de um USV, a influência destes apêndices na resistência total é relativamente maior e depende do tipo de missão e dos equipamentos embarcados.

Acerca do dimensionamento do leme, após a análise com base em formulações lineares para modelos testados em Reynolds superiores aos relativos à este trabalho, concluiuse que é mais adequada a verificação da manobrabilidade do veículo usando resultados experimentais ou, pelo menos, simulações numéricas (CFD) que levam em consideração as dimensões reais do leme e sua condição de operação.

\subsubsection{Análise Estrutural}

Para a análise estrutural dos cascos, verificou-se que a adoção de referências de sociedades classificadoras de embarcações de lazer feitas em fibra de vidro produzia valores de dimensões estruturais com espessuras muito pequenas cuja manufatura é impraticável. Logo, a adoção de valores superiores tornam o projeto estrutural mais conservador.

Além disso, durante a análise estrutural, foram considerados como piores casos de carregamentos aqueles relativos ao transporte do veículo fora da água. Diferentemente das embarcações tripuladas, o USV deve ser lançado ao mar e resgatado toda vez que vai realizar uma missão, desta forma, os maiores esforços no convés principal e nas estruturas de fixação dos cascos ocorre durante seu transporte. 


\subsubsection{Sistema de energia}

O sistema de energia de um USV depende muito da tecnologia empregada nas baterias e, neste trabalho, a seleção foi realizada com base na densidade de energia e o tamanho pois, por definições de projeto, decidiu-se por embarcar as baterias nos cascos laterais, separados do sistema de controle do veículo e da carga paga. O veículo também apresenta painéis solares que auxiliam diretamente na alimentação do motor e da eletrônica embarcada e que, através de testes preliminares, mostram-se bem eficazes em operações em locais tropicais, como o Brasil, com alta intensidade solar.

Assim, percebe-se que em diversas etapas do projeto do USV foram necessárias adaptações para possibilitar o atendimento dos requisitos estabelecidos. Algumas destas adaptações foram tomadas usando os recursos já disponíveis no laboratório. Outras foram empregadas com o objetivo de manter o projeto mais conservador, aumentando a segurança e robustez do veículo.

\subsection{Trabalhos futuros}

Por conta da impossibilidade de finalização da manufatura do veículo a tempo e, por consequência, a ausência da validação dos resultados por meio de testes em campo, temse como principal objetivo futuro realizar tais experimentos. Com relação à trabalhos futuros, que podem ser realizados a partir do veículo desenvolvido e da metodologia apresentada, espera-se que:

- Análise dos dados de navegação lidos pelos sensores do veículo, para em seguida, aperfeiçoar o sistema responsável pela navegação do trimarã;

- Com o veículo disponível no laboratório, pode-se estudar parâmetros hidrodinâmicos do casco e de suas superfícies de controle (leme e propulsor);

- Como trabalho mais pretensioso, pode-se também imaginar uma cooperação de veículos aquáticos entre o AUV Pirajuba e o USV deste trabalho, possibilitando novos desenvolvimentos na área de navegação e comunicação acústica. 


\section{Referências}

ALMEIDA, M. I. Comportamento estrutural de painéis sanduíche compósitos para aplicações na indústria da construção. Instituto Superior Técnico, 2009. Citado 3 vezes nas páginas $\underline{\mathrm{v}}, \underline{44}$ e $\underline{45}$.

ALMEIDA, T. E. P. d. Sistema de sensoriamento de orientação para um veículo aquático de superfície utilizando sensores de baixo custo. Dissertação (Mestrado) - Universidade de São Paulo, 2014. Citado 2 vezes nas páginas iv e 15.

ALVES, J. et al. Vehicle and mission control of the Delfim autonomous surface craft. In: IEEE. Control and Automation, 2006. MED'06. 14th Mediterranean Conference on. [S.l.], 2006. p. 1-6. Citado 3 vezes nas páginas iv, 11 e 12.

BAILEY, D. The NPL High Speed Round Bilge Displacement Hull Series: Resistance, Propulsion, Manoevring and Seakeeping Data. [S.1.]: Royal Institution of Naval Architects, 1976. Citado 10 vezes nas páginas iv, vii, 26, 34, 35, 45, 46, $\underline{48}, \underline{49}$ e $\underline{50}$.

BRUZZONE, G. et al. Autonomous mine hunting mission for the charlie USV. In: IEEE. OCEANS, 2011 IEEE-Spain. [S.1.], 2011. p. 1-6. Citado na página 11.

CACCIA, M. Autonomous surface craft: prototypes and basic research issues. In: IEEE. null. [S.1.], 2006. p. 1-6. Citado 3 vezes nas páginas $\underline{8}, \underline{12}$ e $\underline{14}$.

CACCIA, M. et al. Design and preliminary sea trials of SESAMO an autonomous surface vessel for the study and characterization of the air-sea interface. CNR-IAN, Technology. Report, 2003. Citado 3 vezes nas páginas iv, $\underline{10}$ e $\underline{11}$.

CARLTON, J. Marine propellers and propulsion. [S.l.]: Butterworth-Heinemann, 2012. Citado na página 50.

CHRIST, D.; WERNLI, L. The ROV manual: A user guide for observation class remotely operated vehicles. 2007. Citado 2 vezes nas páginas iv e $\underline{3}$.

CODIGA, D. L. A marine autonomous surface craft for long-duration, spatially explicit, multidisciplinary water column sampling in coastal and estuarine systems. Journal of Atmospheric and Oceanic Technology, v. 32, n. 3, p. 627-641, 2015. Citado 2 vezes nas páginas iv e $\underline{9}$.

CURCIO, J.; LEONARD, J.; PATRIKALAKIS, A. SCOUT - A low cost autonomous surface platform for research in cooperative autonomy. In: IEEE. OCEANS, 2005. Proceedings of MTS/IEEE. [S.1.], 2005. p. 725-729. Citado 2 vezes nas páginas iv e $\underline{8}$.

DANTAS, J. L. D.; BARROS, E. D. Numerical analysis of control surface effects on auv manoeuvrability. Applied Ocean Research, Elsevier, v. 42, p. 168-181, 2013. Citado 3 vezes nas páginas vii, $\underline{58}$ e $\underline{60}$.

DUBROVSKY, V.; LYAKHOVITSKY, A. Multi-hull Ships. [S.l.]: Backbone Publishing Company, 2001. Citado 3 vezes nas páginas $\underline{26}, \underline{27}$ e $\underline{35}$.

EVANS, J. H. Basic design concepts. Naval Engineers Journal, Wiley Online Library, v. 71, n. 4 , p. $671-678,1959$. Citado 3 vezes nas páginas iv, 22 e 24. 
FERREIRA, H. et al. Autonomous bathymetry for risk assessment with ROAZ robotic surface vehicle. In: IEEE. OCEANS 2009-EUROPE. [S.l.], 2009. p. 1-6. Citado na página 13.

FERREIRA, H. et al. ROAZ autonomous surface vehicle design and implementation. Robotica, 2006. Citado na página 13.

FERREIRA, Í. O.; NETO, A. A.; MONTEIRO, C. S. O uso de embarcações não tripuladas em levantamentos batimétricos. Revista Brasileira de Cartografia, v. 68, n. 10, 2016. Citado na página 1 .

FREIRE, L. O. Desenvolvimento de uma arquitetura de controle descentralizada para veículos submarinos baseada em CAN, ARM e Engenharia de Sistemas - CANARMES. Dissertação (Mestrado) — Universidade de São Paulo, 2013. Citado na página 63.

GANSSLE, J. The art of designing embedded systems. [S.l.]: Newnes, 2008. Citado na página $\underline{67}$.

GARMIN. GPS 15xH/15xL Techinical Specifications. [S.l.], 2009. Disponível em: <http://static.garmin.com/pumac/GPS15xH_15xL_TechnicalSpecifications.pdf > . Acesso em: 4 de julho de 2017. Citado 2 vezes nas páginas iv e 33.

HONEYWELL. Heavy Duty Pressure Transducers. [S.l.], 2016. Disponível em: <http://www.link-quest.com/html/models_nq.htm>. Acesso em: 3 de julho de 2017.

Citado 2 vezes nas páginas iv e $\underline{32}$.

INOUE, S.; HIRANO, M.; KIJIMA, K. Hydrodynamic derivatives on ship maneuvering. International Shipbuilding Progress, v. 28, p. 321, 1981. Citado na página 57.

KVH. KVH CG-5100 IMU. [S.1.], 2010. Disponível em: <http://www.kvh.com/ ViewAttachment.aspx?guidID=E302567F-78CE-45F4-A3FF-6863664B324D >. Acesso em: 3 de julho de 2017. Citado 2 vezes nas páginas iv e 31.

KVH. KVH CG-5100 IMU. [S.l.], 2017. Disponível em: <http://www.kvh. com/Military-and-Government/Gyros-and-Inertial-Systems-and-Compasses/ Gyros-and-IMUs-and-INS/IMUs/CG-5100.aspx>. Acesso em: 3 de julho de 2017. Citado 2 vezes nas páginas iv e 31.

L3 ASV. 2019. Disponível em: <https://www.asvglobal.com/>. Acesso em: 02/06/2019. Citado 3 vezes nas páginas iv, $\underline{16}$ e $\underline{17}$.

LEE, P.-M. et al. Simulation of an inertial acoustic navigation system with range aiding for an autonomous underwater vehicle. IEEE Journal of Oceanic Engineering, IEEE, v. 32, n. 2, p. 327-345, 2007. Citado na página $\underline{3}$.

LEWIS, E. V. Principles of Naval Architecture, Second Revision, Volume I: Stability and Strength. [S.1.]: Society of Naval Architects, 1988. v. 1. Citado na página 38.

LEWIS, E. V. Principles of Naval Architecture, Second Revision, Volume II: Resistance, Propulsion and Vibration. [S.l.]: Society of Naval Architects, 1988. v. 2. Citado na página $\underline{52}$.

LLOYDS, R. Rules and regulations for the classification of special service craft. Lloyd's Register: London, 2008. Citado 2 vezes nas páginas vi e 40. 
MAJOHR, J.; BUCH, T. Modelling, simulation and control of an autonomous surface marine vehicle for surveying applications measuring Dolphin MESSIN. IEE Control Engineering Series, PETER PEREGRINUS LTD, v. 69, p. 329, 2006. Citado 3 vezes nas páginas iv, $\underline{13}$ e $\underline{14}$.

MAJOHR, J.; BUCH, T.; KORTE, C. Navigation and automatic control of the measuring Dolphin (messin ${ }^{\mathrm{TM}}$ ). IFAC Proceedings Volumes, Elsevier, v. 33, n. 21, p. 399-404, 2000. Citado na página 14.

MANLEY, J. E. Development of the autonomous surface craft "ACES". In: IEEE. OCEANS'97. MTS/IEEE Conference Proceedings. [S.l.], 1997. v. 2, p. 827-832. Citado na página $\underline{8}$.

MANLEY, J. E. Unmanned surface vehicles, 15 years of development. In: IEEE. OCEANS 2008. [S.l.], 2008. p. 1-4. Citado 3 vezes nas páginas iv, $\underline{1}$ e $\underline{2}$.

MANLEY, J. E. et al. Evolution of the autonomous surface craft AutoCat. In: IEEE. Oceans 2000 MTS/IEEE Conference and Exhibition. [S.l.], 2000. v. 1, p. 403-408. Citado na página $\underline{8}$.

MARTINS, A. et al. ROAZ and ROAZ II autonomous surface vehicle design and implementation. In: International Lifesaving Congress 200\%. [S.l.: s.n.], 2007. Citado na página 13.

MAXON MOTOR. Catálogo do motor 118730. [S.1.], 2017. Disponível em: <https: //www.maxonmotor.com/medias/sys_master/root/8825408880670/17-EN-124.pdf>. Acesso em: 25 de setembro de 2017. Citado 2 vezes nas páginas vii e $\underline{61}$.

MAXON MOTOR. Catálogo do motor 148867. [S.1.], 2017. Disponível em: <https: //www.maxonmotor.com/medias/sys_master/root/8825409404958/17-EN-132.pdf>. Acesso em: 25 de setembro de 2017 . Citado 2 vezes nas páginas vii e 53.

NAVQUEST MODELS. DVL NavQuest 600 Micro. [S.1.], 2009. Disponível em: <http://www.link-quest.com/html/models_nq.htm>. Acesso em: 3 de julho de 2017. Citado 2 vezes nas páginas iv e $\underline{32}$.

NEWMAN, J. N. Marine hydrodynamics. [S.l.]: MIT press, 2018. Citado na página $\underline{46}$. NOWACKI, H. Developments in marine design methodology: roots, results and future trends. In: TAPIR ACADEMIC PRESS. IMDC 2009: 10th International Marine Design Conference, Trondheim, May 26-29, 2009. Vol. 1. [S.l.], 2009. p. 47-80. Citado na página 23.

PASCOAL, A.; SILVESTRE, C.; OLIVEIRA, P. Vehicle and mission control of single and multiple autonomous marine robots. IEE Control Engineering Series, PETER PEREGRINUS LTD, v. 69, p. 353, 2006. Citado na página $\underline{12}$.

PAULL, L. et al. AUV navigation and localization: A review. IEEE Journal of Oceanic Engineering, IEEE, v. 39, n. 1, p. 131-149, 2014. Citado 2 vezes nas páginas $2 \underline{2}$ e

PENG, Y.; HAN, J. Design and modeling of unmanned trimaran surface vehicles. In: IEEE. Information and Automation, 2009. ICIA'09. International Conference on. [S.l.], 2009. p. 751-756. Citado 3 vezes nas páginas iv, $\underline{14}$ e $\underline{15}$. 
RINA, G. Rules for the construction and classification of pleasure vessels: effective from 1 january 1994. Rina, Genova, 1994. Citado 4 vezes nas páginas vi, $\underline{40}$, $\underline{41}$ e $\underline{42}$.

SANTOS, K. S. Y. Modelo de síntese e otimização para o projeto de concepção de rebocadores portuários. Tese (Doutorado) — Universidade de São Paulo, 2016. Citado na página $\underline{22}$.

SILVA, I. S. et al. Development of a trimaran asv. IFAC-PapersOnLine, Elsevier, v. 51, n. 29 , p. 8-13, 2018. Citado 2 vezes nas páginas 느 e $\underline{68}$.

USSVTECH. 2019. Disponível em: <http://ussvtech.com/index.html>. Acesso em: 11/06/2019. Citado 2 vezes nas páginas iv e 18 .

VALAVANIS, K. P. et al. Control architectures for autonomous underwater vehicles. IEEE Control Systems Magazine, v. 17, n. 6, p. 48-64, 1997. Citado na página 65.

VILLAS BOAS, F. Desenvolvimento de uma ferramenta de CAD aplicada ao projeto de hélices para veículos aquáticos não tripulados. Dissertação (Mestrado) - Escola Politécnica, Universidade de São Paulo, 2006. Citado 3 vezes nas páginas iv, $\underline{6}$ e $\underline{12}$.

WHICKER, L. F.; FEHLNER, L. F. Free-stream characteristics of a family of low-aspect-ratio, all-movable control surfaces for application to ship design. [S.1.], 1958. Citado 2 vezes nas páginas $\underline{54}$ e $\underline{58}$.

YAAKOB, O. et al. Development of unmanned surface vehicle (USV) for sea patrol and environmental monitoring. In: Proceedings of the 8th International Conference on Marine Technology, Kuala Terengganu. [S.l.: s.n.], 2012. Citado na página 1.

YUH, J.; MARANI, G.; BLIDBERG, D. R. Applications of marine robotic vehicles. Intelligent service robotics, Springer, v. 4, n. 4, p. 221-231, 2011. Citado na página $\underline{1}$.

ZANONI, F. D. Modelagem e implementação do sistema de navegação para um AUV. Dissertação (Mestrado) — Universidade de São Paulo, 2012. Citado na página 4 .

ZHANG, F. et al. Future trends in marine robotics [tc spotlight]. IEEE Robotics \&6 Automation Magazine, IEEE, v. 22, n. 1, p. 14-122, 2015. Citado na página 1.

ZHANG, J. Design and hydrodynamic performance of trimaran displacement ships. Tese (Doutorado) - University of London, 1997. Citado 5 vezes nas páginas 므, 47, $\underline{54}, \underline{55}$ e $\underline{57}$. 


\section{A Gráficos das propriedades hidrostáti- cas da embarcação}

A seguir serão apresentadas as curvas hidrostáticas relativas ao trimarã para valores de calado variando entre 87 e $180 \mathrm{~mm}$.

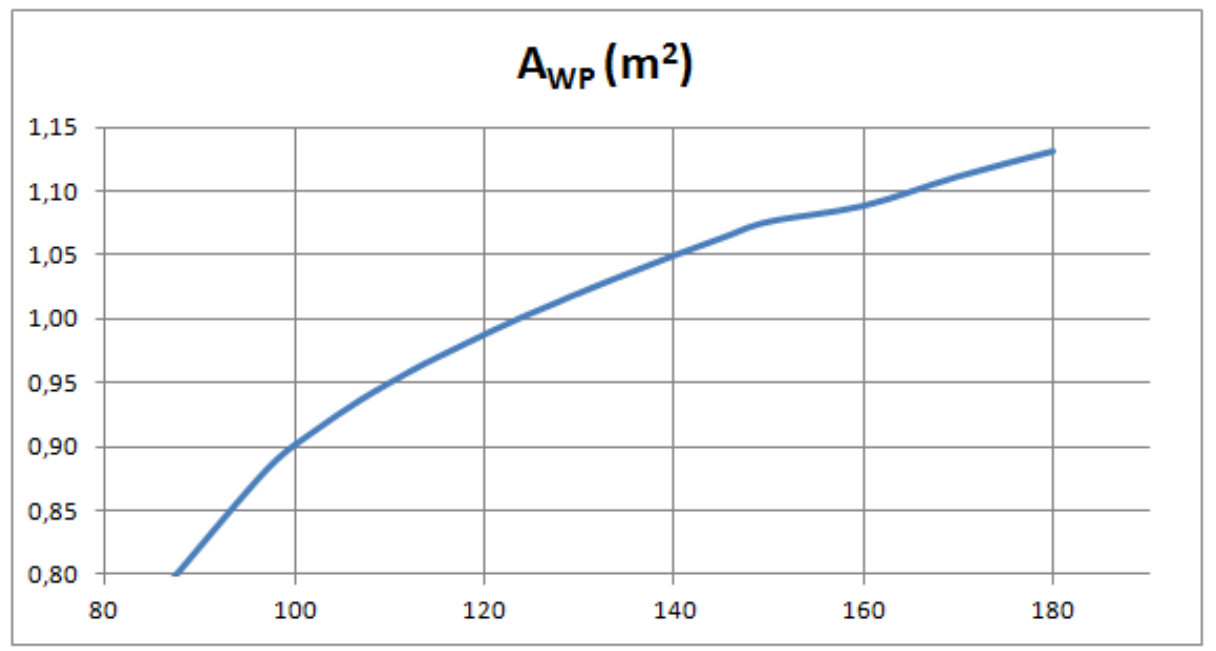

Gráfico 13 - Área do plano de linha d'água em função do calado. Fonte: autor

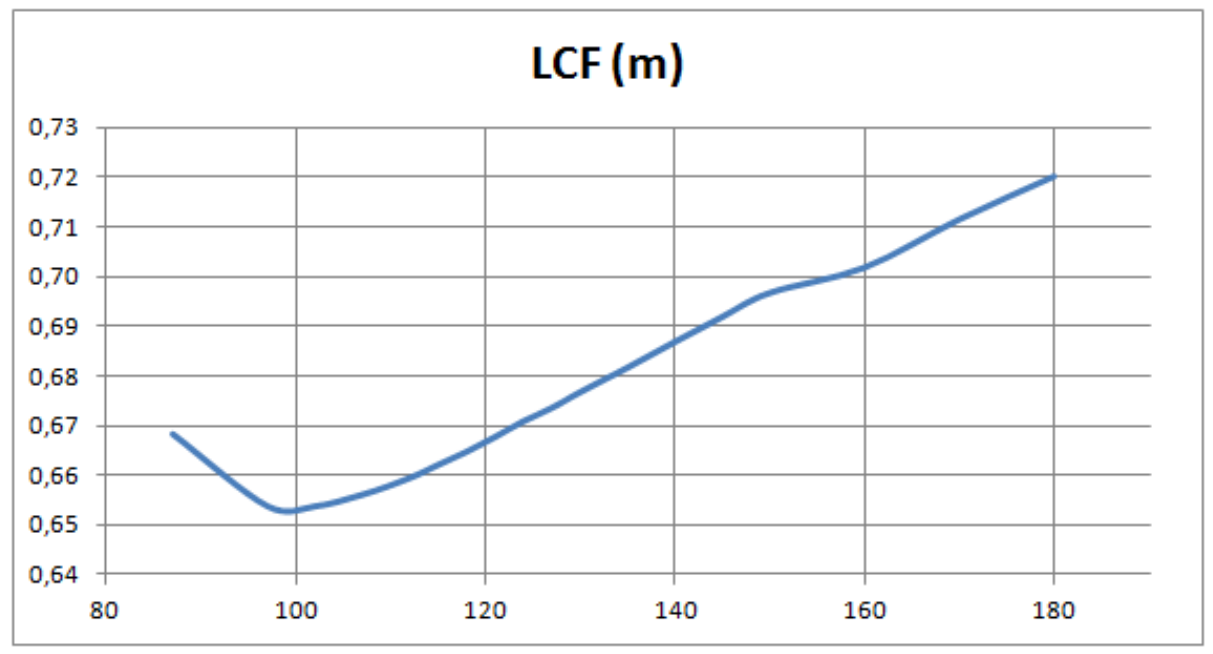

Gráfico 14 - Posição do centro de flutuação longitudinal em função do calado. Fonte: autor 


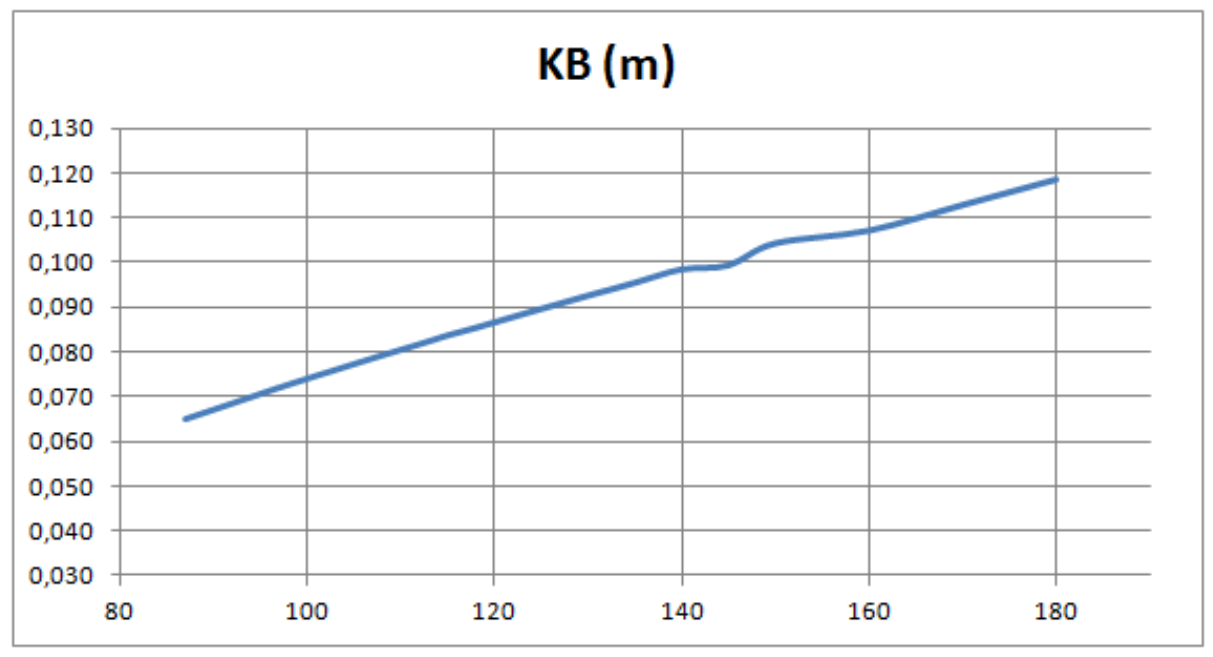

Gráfico 15 - Altura do centro de carena em função do calado. Fonte: autor

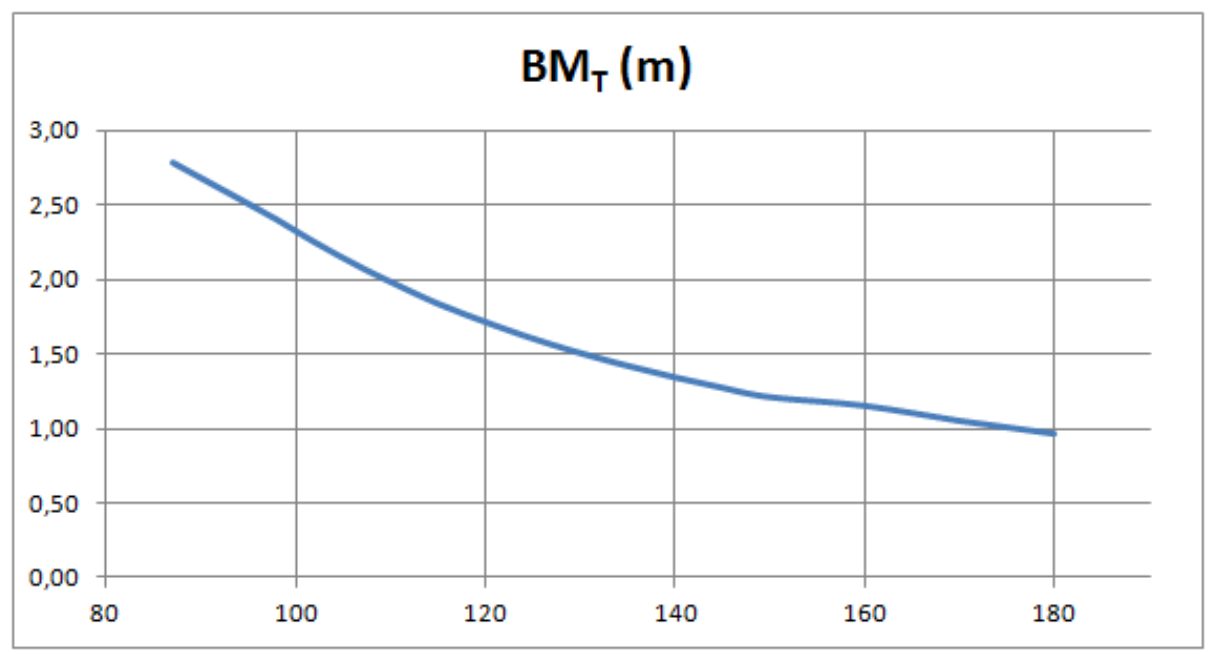

Gráfico 16 - Raio metacêntrico transversal em função do calado. Fonte: autor

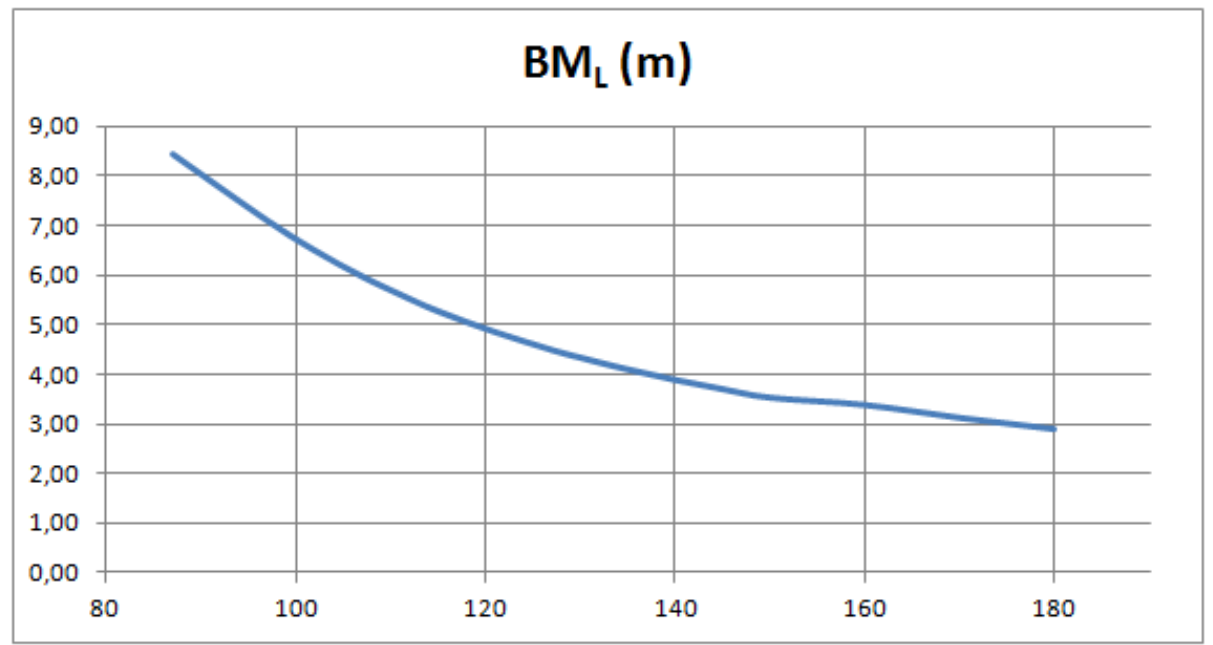

Gráfico 17 - Raio metacêntrico longitudinal em função do calado. Fonte: autor 


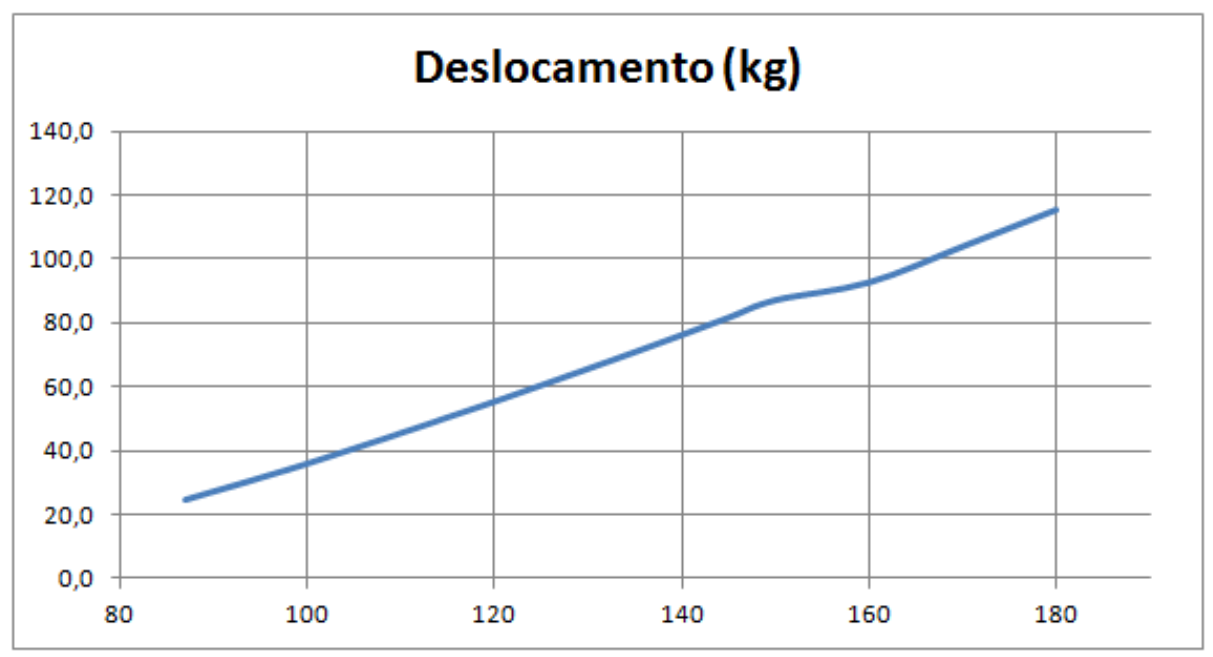

Gráfico 18 - Deslocamento em função do calado. Fonte: autor

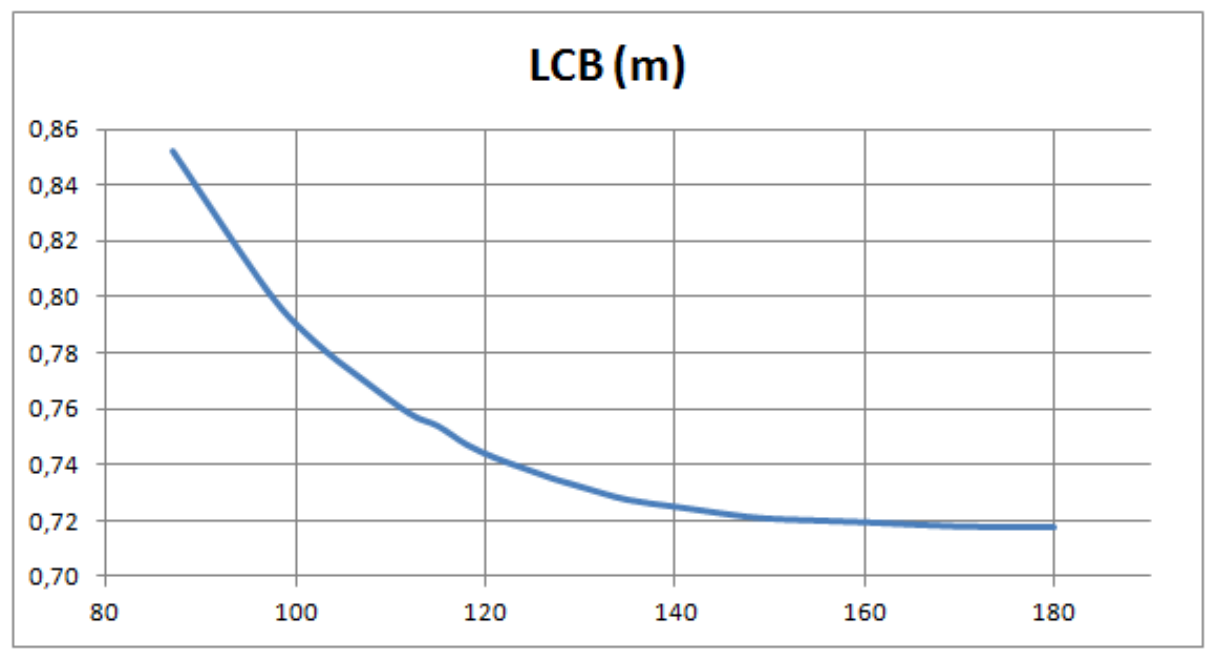

Gráfico 19 - Posição longitudinal do centro de carena. Fonte: autor

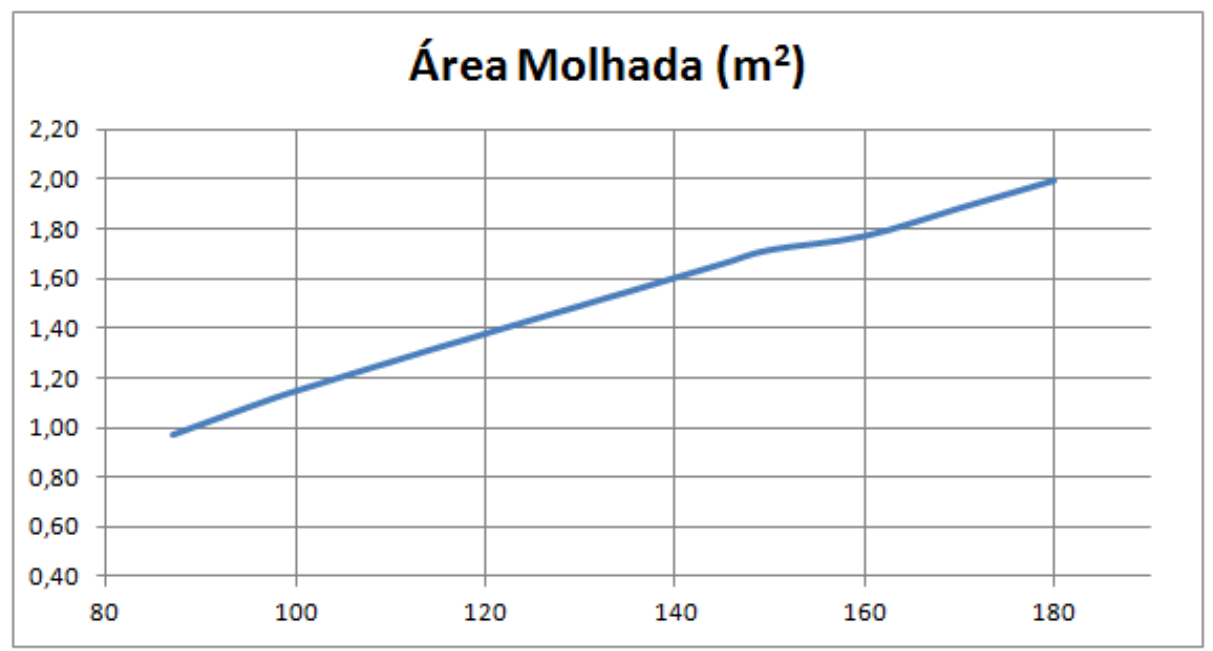

Gráfico 20 - Área molhada de toda a embarcação em função do calado. Fonte: autor 


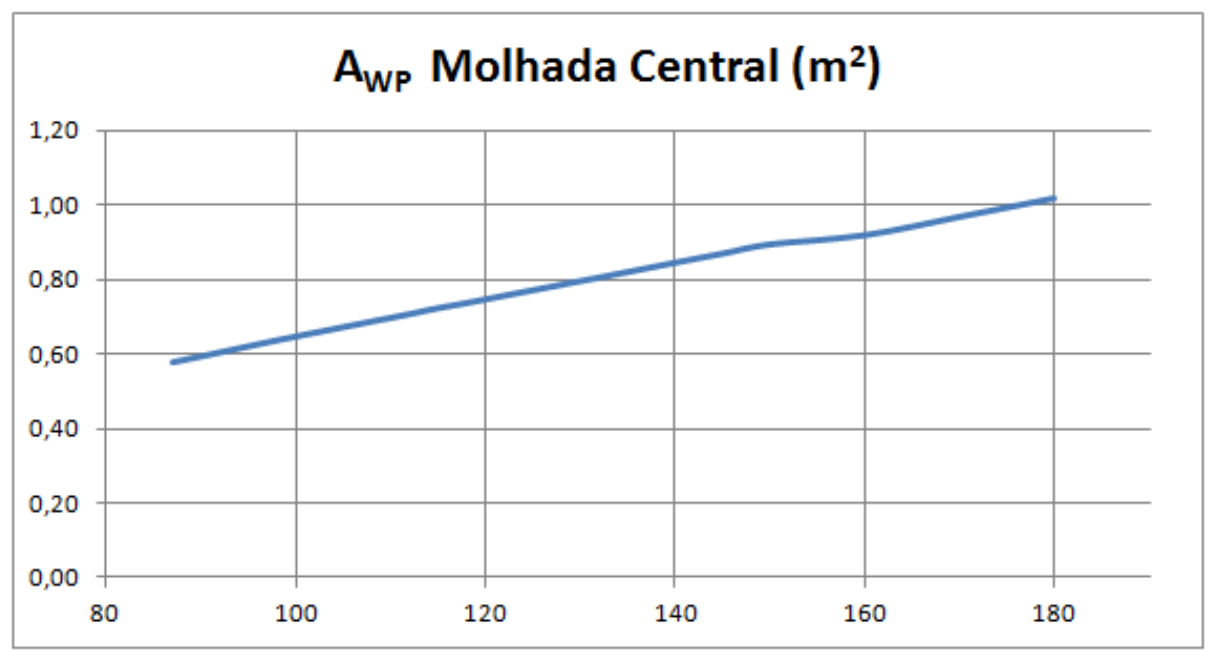

Gráfico 21 - Área molhada do casco central em função do calado. Fonte: autor

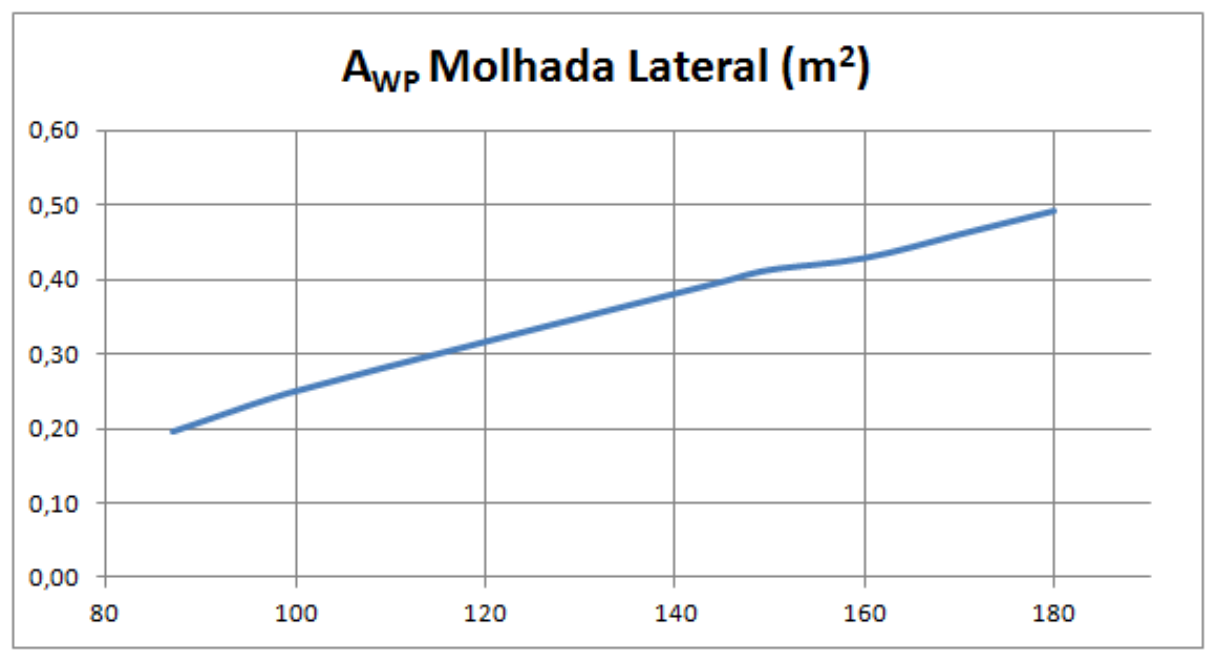

Gráfico 22 - Área molhada do casco lateral em função do calado. Fonte: autor

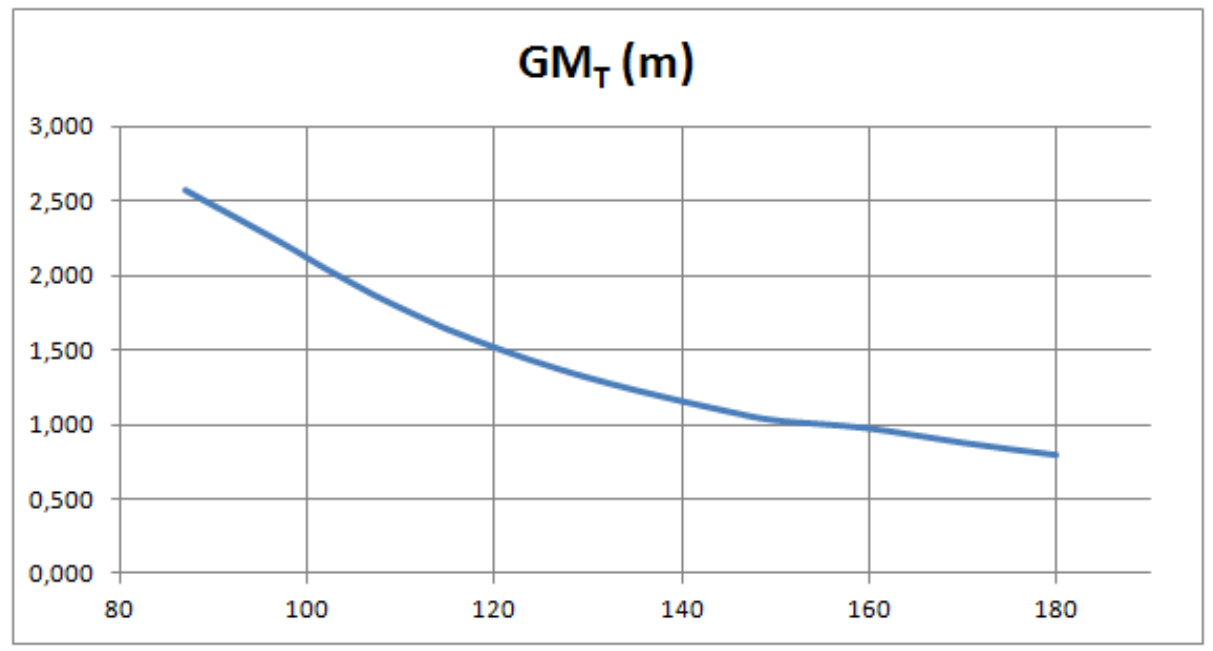

Gráfico 23 - Altura metacêntrica trasversal em função do calado. Fonte: autor 


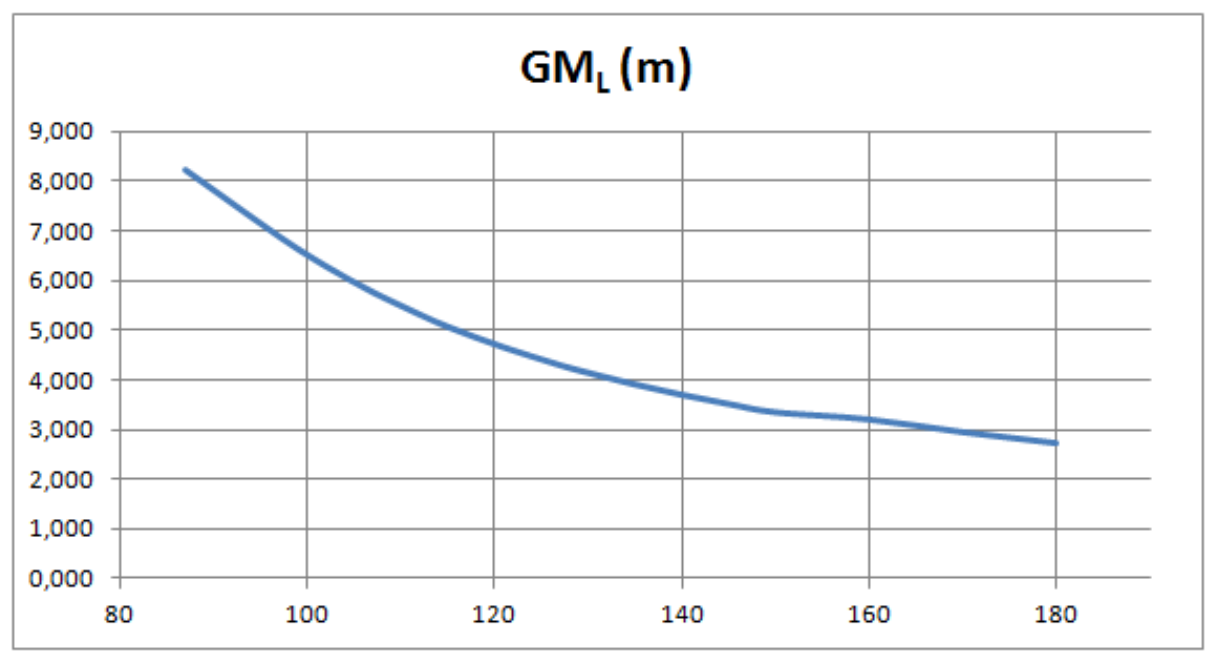

Gráfico 24 - Altura metacêntrica longitudinal em função do calado. Fonte: autor 


\section{B Carregamentos, cortante e momento fletor nos cascos}

Neste apêndice são apresentados os carregamentos e os diagramas da cortante e do momento fletor para os piores casos que o veículo poderá ser submetido.

Para facilitar a leitura, fez-se uso da seguinte nomenclatura das configurações do casco e dos casos de carregamento:

- Configuração 1: distância longitudinal dos cascos igual a $470 \mathrm{~mm}(\bar{a}=0,21)$;

- Configuração 2: distância longitudinal dos cascos igual a $880 \mathrm{~mm}(\bar{a}=0,4)$;

- Caso A: levantar o veículo pelos cascos laterais apenas;

- Caso B: levantar o veículo pelo casco central apenas.

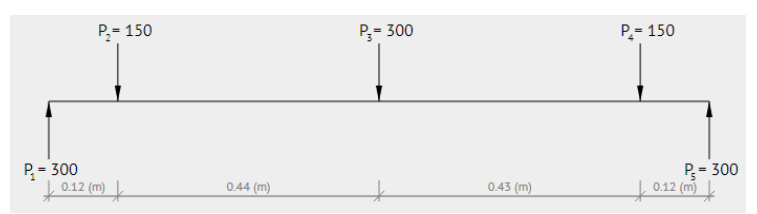

Gráfico 25 - Carregamentos das configurações 1 e 2 para o caso A. Fonte: autor

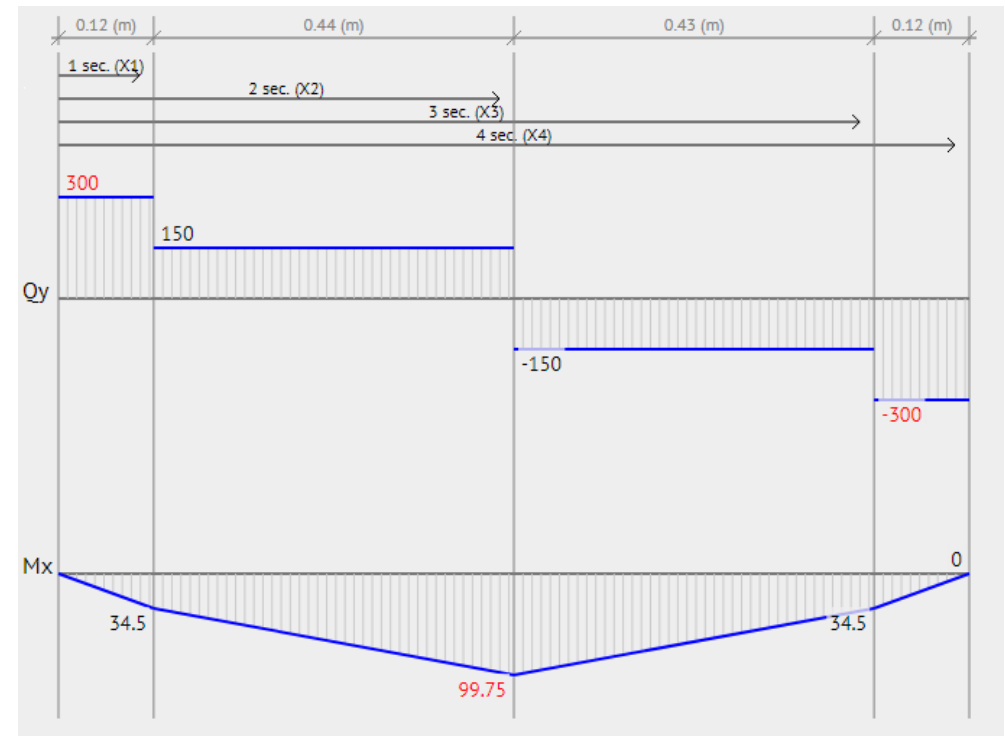

Gráfico 26 - Diagrama da cortante e do momento fletor das configurações 1 e 2 para o caso A. Fonte: autor 


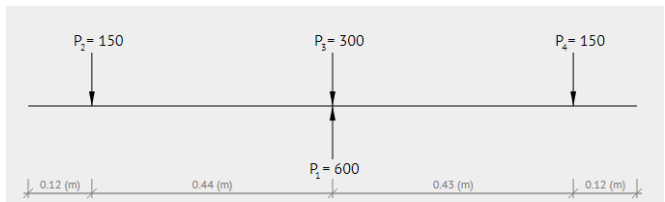

Gráfico 27 - Carregamentos das configurações 1 e 2 para o caso B. Fonte: autor

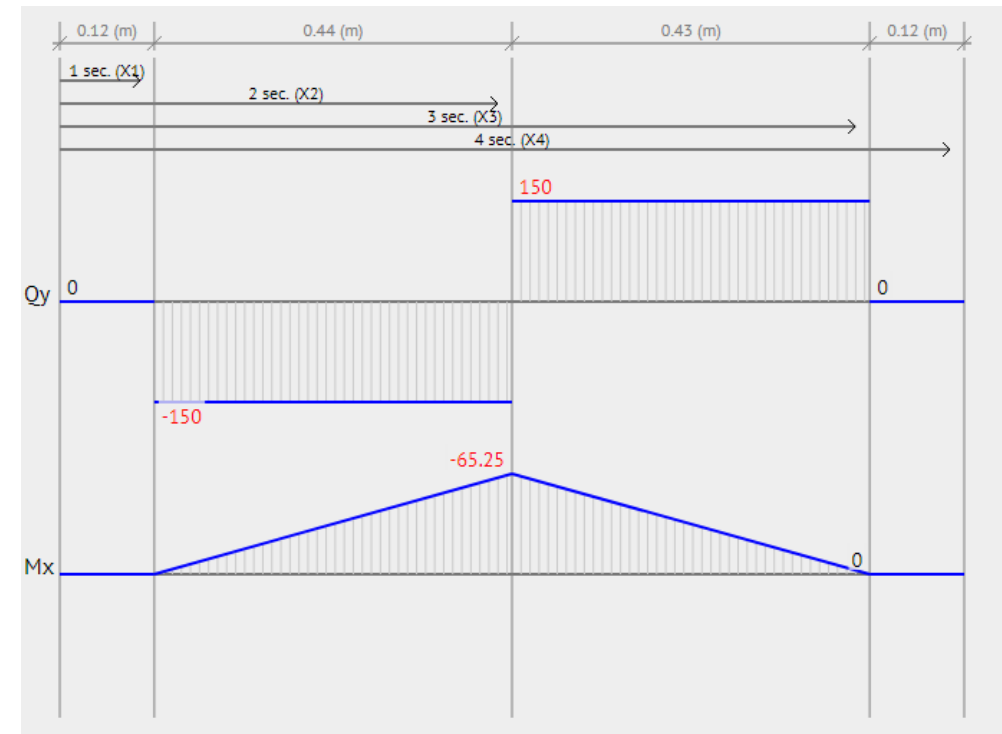

Gráfico 28 - Diagrama da cortante e do momento fletor das configurações 1 e 2 para o caso B. Fonte: autor

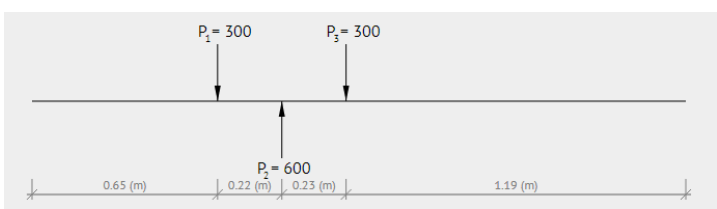

Gráfico 29 - Carregamentos das configurações 1 para o caso A. Fonte: autor

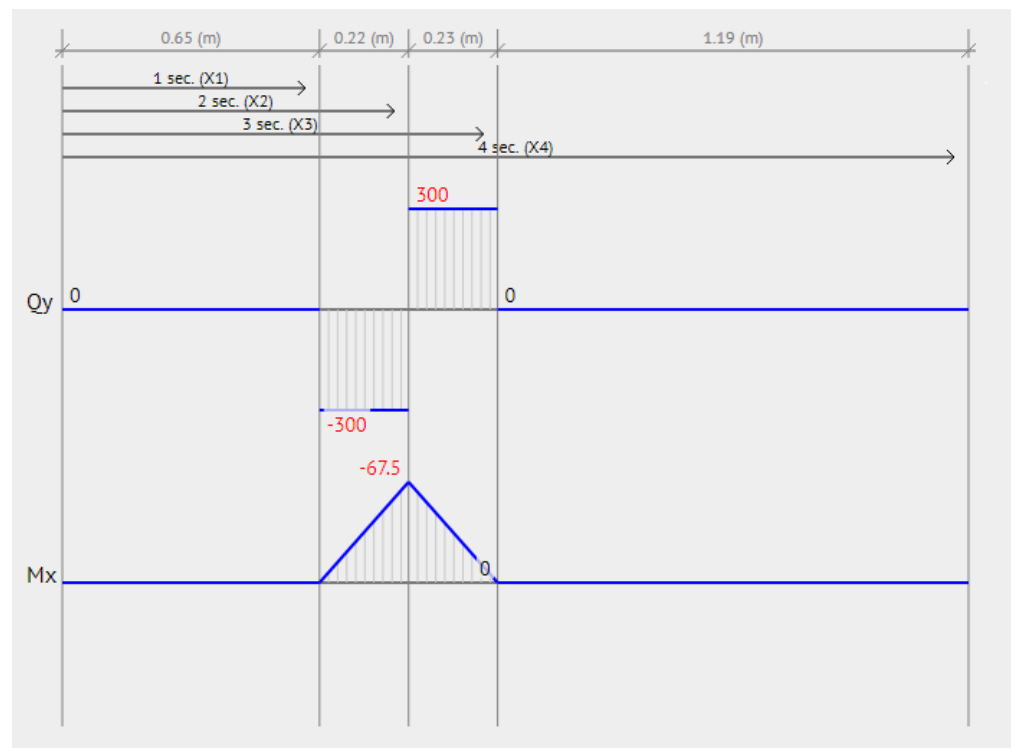

Gráfico 30 - Diagrama da cortante e do momento fletor das configurações 1 para o caso A. Fonte: autor 


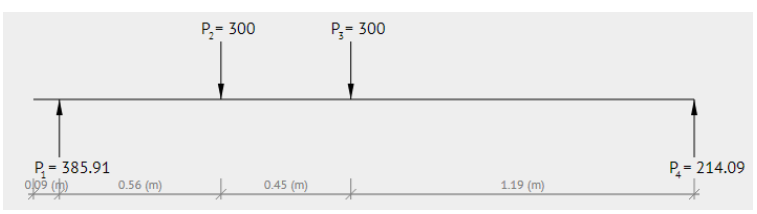

Gráfico 31 - Carregamentos das configurações 1 para o caso B. Fonte: autor

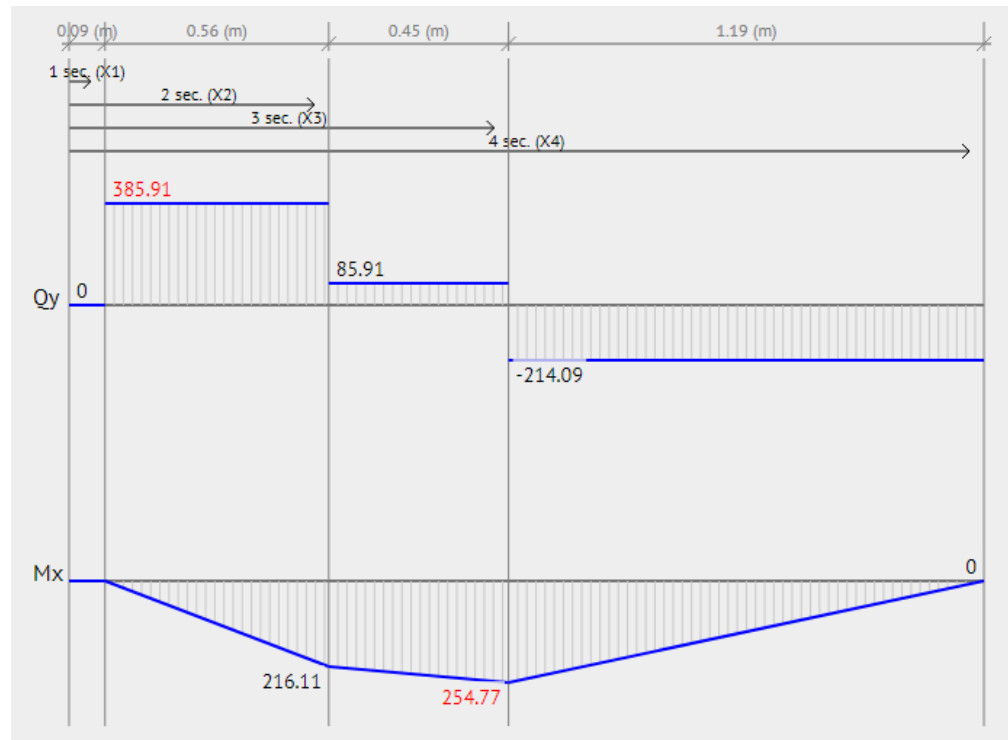

Gráfico 32 - Diagrama da cortante e do momento fletor das configurações 1 para o caso B. Fonte: autor

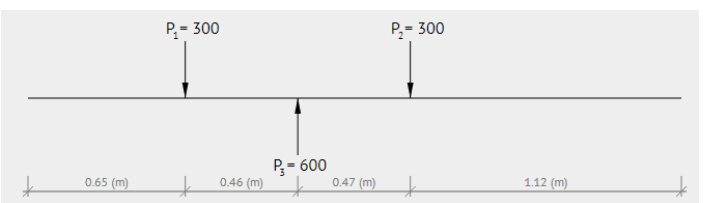

Gráfico 33 - Carregamentos das configurações 2 para o caso A. Fonte: autor

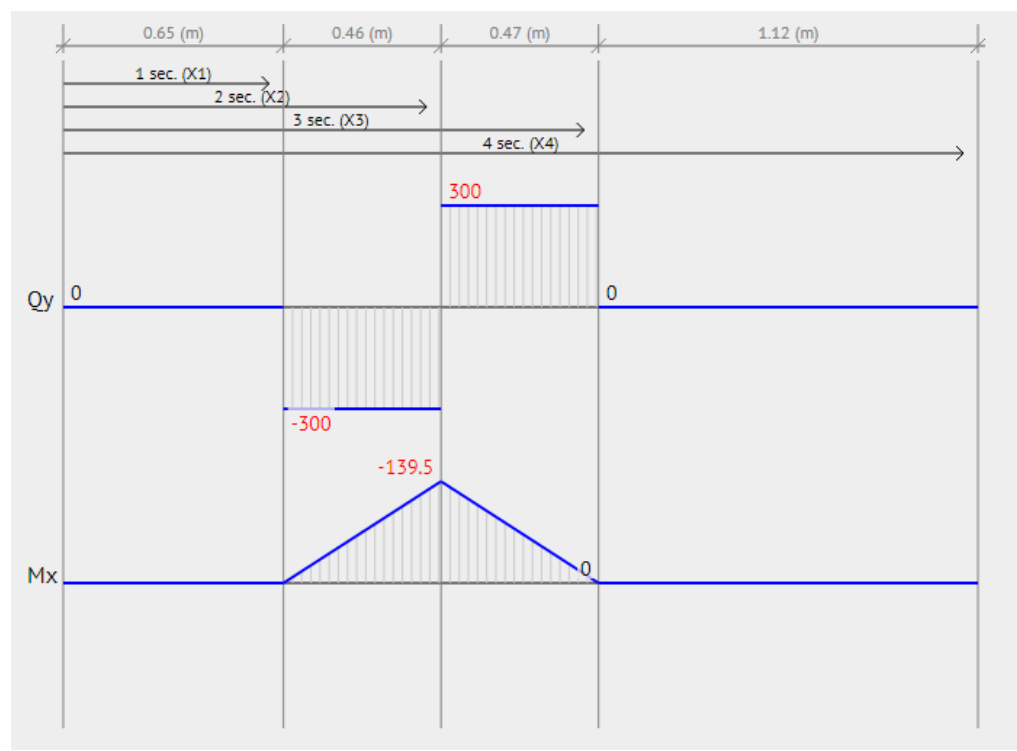

Gráfico 34 - Diagrama da cortante e do momento fletor das configurações 2 para o caso A. Fonte: autor 


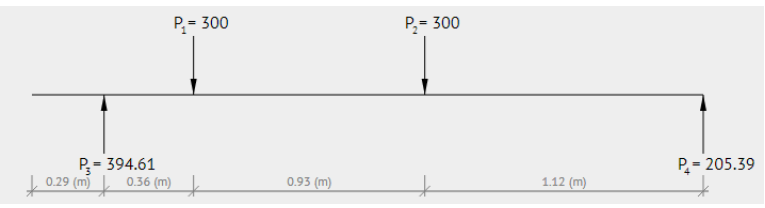

Gráfico 35 - Carregamentos das configurações 2 para o caso B. Fonte: autor

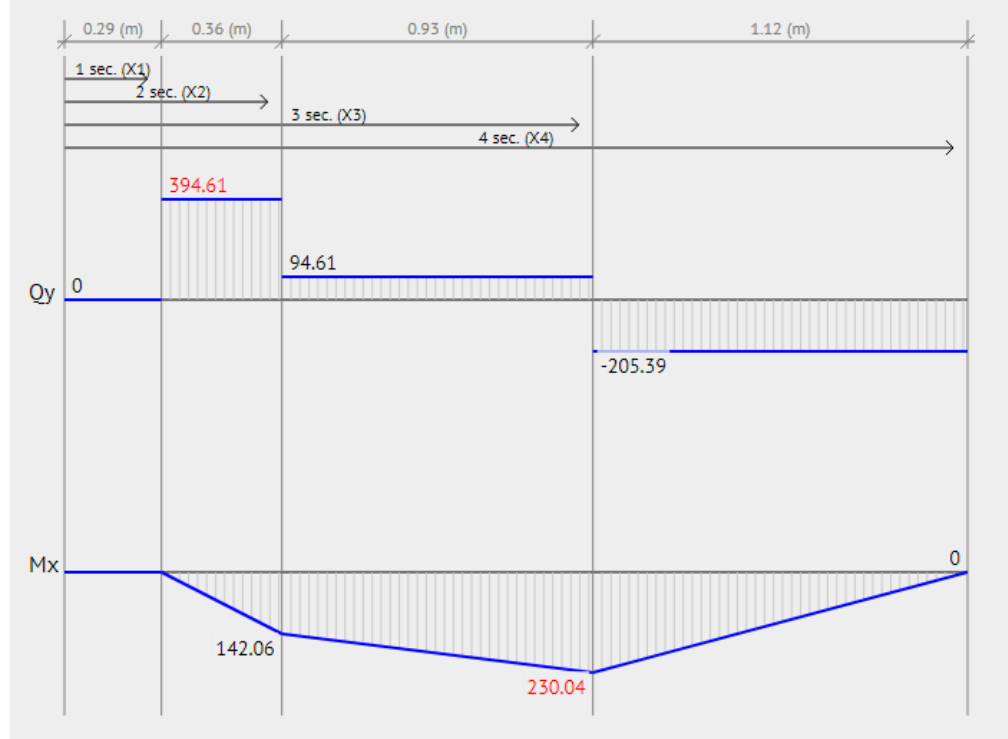

Gráfico 36 - Diagrama da cortante e do momento fletor das configurações 2 para o caso B. Fonte: autor 